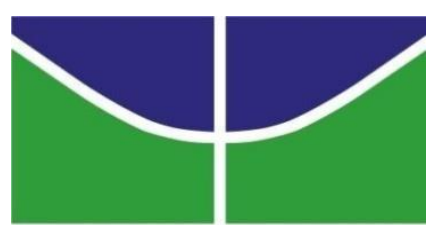

UNIVERSIDADE DE BRASÍLIA - UnB

INSTITUTO DE QUÍMICA - IQ

PROGRAMA DE PÓS-GRADUAÇÃO EM QUÍMICA - PPGQ

LABORATÓRIO DE DESENVOLVIMENTO DE PROCESSOS

QUÍMICOS - LDPQ

\title{
PRODUÇÃO DE POLI(PIVALATO DE VINILA) MAGNÉTICO VISANDO APLICAÇÕES BIOMÉDICAS
}

\section{DISSERTAÇÃO DE MESTRADO}

Robson Teixeira Araujo

Orientador: Prof. Fabricio Machado Silva, D.Sc.

BRASÍLIA, DF - BRASIL

Fevereiro de 2017 


$$
\begin{gathered}
\text { UNIVERSIDADE DE BRASÍLIA - UnB } \\
\text { INSTITUTO DE QUÍMICA - IQ } \\
\text { PROGRAMA DE PÓS-GRADUAÇÃO EM QUÍMICA - PPGQ } \\
\text { LABORATÓRIO DE DESENVOLVIMENTO DE PROCESSOS } \\
\text { QUÍMICOS - LDPQ }
\end{gathered}
$$

\title{
PRODUÇÃO DE POLI(PIVALATO DE VINILA) MAGNÉTICO VISANDO APLICAÇÕES BIOMÉDICAS
}

\begin{abstract}
Dissertação apresentada ao Programa de Pós-Graduação em Química do Instituto de Química da Universidade de Brasília como requisito parcial para a obtenção do título de Mestre em Química.
\end{abstract}

Robson Teixeira Araujo

Orientador: Prof. Fabricio Machado Silva, D.Sc.

BRASÍLIA, DF - BRASIL

Fevereiro de 2017 


\section{FOLHA DE APROVAÇÃO}

Comunicamos a aprovação da Defesa de Dissertação de Mestrado do (a) aluno (a) Robson Teixeira Araújo, matrícula no 16/0172101, intitulada "PRODUÇÃO dE POLI(PIVALATO DE VINILA) MAgNÉtICO VISANDO APLICAÇÕES BIOMÉDICAS", apresentada no (a) Auditório Azul do Instituto de Química (IQ) da Universidade de Brasília (UnB) em 10 de fevereiro de 2017.

Prof. Dr. Fabrício Machado Silva

Presidente de Banca (IQ/UnB)

Prof.a Dra. Simone Monteiro e Silva Membro Titular (IQ/UnB)

Dr. Anderson Mateus Mendonça e Silva Medeiros Membro Titular (IQ/UnB)

Dr. Rossano Gambetta

Membro Suplente (EMBRAPA Agroenergia)

Em 10 de fevereiro de 2017. 


\section{DEDICATÓRIA}

A meus pais - Gilson e Rosilda À minha esposa - Rosimeiry

À minha filha - Martina Aos meus irmãos - Gilda, Adriano e Anny 


\section{AGRADECIMENTOS}

- Ao IQ/UnB, IB/UnB e IG/UnB por terem disponibilizado equipamentos e tempo para a realização de análises dos materiais sintetizados durante minha estada no mestrado.

- À Pós-Graduação do IQ/UnB pelas oportunidades e pelo ensino de alto nível.

Meus sinceros agradecimentos a:

- A amiga e companheira de laboratório Luana Ferreira, amiga de primeira hora, pela ajuda desde o início e com quem pude trocar opiniões, comentários e receber sugestões a respeito do trabalho ao longo do curso.

- À amiga e companheira de laboratório Gabriela Ribeiro por me auxiliar no entendimento inicial das técnicas usadas no laboratório.

- À Natália Campelo e ao Marcos Calil, pelos comentários valiosos ao longo deste período no laboratório.

- Aos colegas Vianney Santos (LMC) e Luciana Machado (LAQUIMET) pela ajuda em diversos momentos ao longo do curso.

- Ao Prof. Dr. Alexandre Umpierre (LDPQ) pelas muitas sugestões ao longo do processo.

- À minha família, consanguínea e não consanguínea, especialmente meus pais e minha esposa, pela presença e apoio moral que serviram de suporte e espelho ao longo das dificuldades do percurso.

Meu agradecimento muito especial:

- Ao Prof. Dr. Fabricio Machado, meu orientador, pela paciência, orientação, dedicação, profissionalismo e acolhida na família LDPQ, e que, desde o início do mestrado, me fez ver novos horizontes através da reflexão e aprendizado. 


\section{CITAÇÃO}

"Parta do princípio de que toda crítica é construtiva. Se você pode se convencer de que a outra pessoa é bem-intencionada, você será beneficiado com as críticas dela, e não vai se aborrecer com o resto. Quando você acredita na boa intenção do crítico, você desarma um inimigo e adquire um aliado em potencial".

Carrol O'connor - ator americano (citado por Walt Andersen em Courage is a three letter word - Fawcett/Random House, 1987) 


\section{RESUMO}

Uma nova classe de materiais magnetopoliméricos foi desenvolvida visando aplicações biomédicas, como a embolização intravascular e o tratamento por hipertermia em regiões tumorais. Foram sintetizados nanocompósitos microparticulados com morfologia esférica controlada, consistindo basicamente de nanopartículas magnéticas de $\mathrm{Fe}_{3} \mathrm{O}_{4}$ nanoestruturadas com superfície modificada com ácido oleico dispersas homogeneamente em uma matriz termoplástica de poli(pivalato de vinila) - PPVi. Estas nanopartículas foram obtidas in situ via processo de polimerização em suspensão. Materiais magnetopoliméricos apresentando em sua composição nanopartículas de $\mathrm{Fe}_{3} \mathrm{O}_{4}$ na faixa de $8 \%$ p/p a $16 \%$ p/p exibem boa resposta magnética à ação de um campo externo, proporcional a fração de $\mathrm{Fe}_{3} \mathrm{O}_{4}$. Análises de difração de raios $\mathrm{X}$ revelaram que o tamanho do cristalito determinado para os nanocompósitos, entre $7 \mathrm{~nm}$ e $9 \mathrm{~nm}$, são similares aquele obtido para a magnetita pura, o que evidencia uma boa dispersão das nanopartículas de $\mathrm{Fe}_{3} \mathrm{O}_{4}$ modificadas com ácido oleico na matriz termoplástica do poli(pivalato de vinila). Um fator essencial para preservar o comportamento superparamagnético da ferrita precursora é a boa dispersão na matriz polimérica, independentemente de sua concentração nas micropartículas de PPVi. O controle de morfologia aliado a uma boa resposta superparamagnética e estabilidade térmica apropriada permite potencializar 0 emprego desta nova classe de nanocompósitos magnéticos em aplicações biomédicas diversas. Devido às propriedades apresentadas por estas nanopartículas magnéticas, há grandes possibilidades de serem usados como agentes embolizantes. 


\begin{abstract}
A new class of magnetopolymeric materials has been developed intended for medical applications such as intravascular embolization and hyperthermia therapy in tumor treatment. Microparticulate nanocomposites with controlled spherical morphology, were synthetized and consisting essentially of oleic acid surface-modified nanostructured magnetic particles of $\mathrm{Fe}_{3} \mathrm{O}_{4}$ homogeneously dispersed into a thermoplastic matrix of poly(vinyl pivalate) - PPVi. These nanoparticles have been synthesized in situ through a suspension polymerization process. Magnetopolymeric materials presenting $\mathrm{Fe}_{3} \mathrm{O}_{4}$ nanoparticles ranging from $8 \%$ wt-\% to 16 wt-\% exhibited good magnetic response relative to an external magnetic field, proportional to the fraction of $\mathrm{Fe}_{3} \mathrm{O}_{4}$. X-ray diffraction analyses showed that the crystallite size determined for the magnetic nanocomposites, in the interval between $7 \mathrm{~nm}$ and $9 \mathrm{~nm}$, are similar to the one obtained for the pure magnetite, indicating that oleic acid modified $\mathrm{Fe}_{3} \mathrm{O}_{4}$ nanoparticles were properly dispersed in the thermoplastic matrix poly(vinyl pivalate). An essential factor to preserve the superparamagnetic behavior of the precursor ferrite is a good dispersion on a polymeric matrix, independent of the $\mathrm{Fe}_{3} \mathrm{O}_{4}$ concentration into PPVi microparticles. Morphology control allied to a good superparamagnetic response and a suitable thermal stability might open opportunities for the use of this new class of magnetic nanocomposites in several biomedical applications. Based on the properties showed by these magnetic particles, there are a large possibility of use as embolic agent.
\end{abstract}




\section{SUMÁRIO}

Capítulo 1 Introdução 17

1.1

Contextualização do Problema: Nanopartículas de Magnetita, 17

Nanocompósitos Magnéticos e Suas Aplicações

1.2

1.2 .1

Objetivos da Dissertação

Objetivos Específicos $\quad 20$

Capítulo 2

2.1

2.1.1

2.1 .2

2.1 .3

2.1.3.1

2.1.3.2

2.1.3.3

2.1.3.4

2.1.3.5

2.1 .4

2.2

2.2.1

2.4

2.4 .1

2.5

2.5.1

2.5.1.1

2.5 .2

2.5 .3

2.6

2.6.1

2.6 .2

2.6 .3

Revisão bibliográfica

Propriedades Magnéticas dos Materiais 21

Propriedades Magnéticas Cooperativas $\quad 21$

Termos usados em magnetismo 21

Como o magnetismo se manifesta na matéria 22

Diamagnetismo 23

Paramagnetismo 24

Ferromagnetismo 24

Antiferromagnetismo $\quad 25$

Ferrimagnetismo 25

Histerese 25

Propriedades magnéticas de pequenas partículas 26

Materiais Superparamagnéticos 27

Materiais nanoestruturados 28

Classificação dos Materiais Nanoestruturados 29

O Ferro e Seus Óxidos $\quad 30$

A Magnetita 30

A estrutura da Magnetita 31

Estabilidade da magnetita e suas transformações 33

Química superficial da magnetita 33

Métodos Químicos de Preparação da magnetita 34

Coprecipitação $\quad 35$

Síntese Hidrotérmica 35

Síntese Sonoquímica 36

$\begin{array}{lll}2.6 .4 & \text { Processos Sol-Gel } & 36 \\ 2.6 .5 & \text { Métodos de Polióis (Solvotérmica) } & 37\end{array}$

2.6.6 Injeção de Fluxo 37

$\begin{array}{lll}2.6 .7 & \text { Eletroquímicos } & 37\end{array}$

2.6.8 Aerossol e Vapor 38

2.6.9 Sínteses em Ambientes Restritos 38

2.6.10 Microemulsão por Zona 38

$2.7 \quad$ Compósitos poliméricos 38

2.7.1 Nanopartículas de magnetita ligadas a superfície de partículas $\quad 40$ poliméricas

2.8 Caracterização de nanopartícula magnéticas 41

2.8.1 Análise de FTIR: Interação do ácido oleico com a Superfície da 41

$\begin{array}{lll}2.8 .2 & \text { Difração de raios- } X \quad 43\end{array}$

2.8.3 Microscopia de transmissão eletrônica (TEM) 44

2.8.4 Espectroscopia Raman 44

$2.9 \quad$ Aplicações de Nanopartículas de Magnetita $\left(\mathrm{Fe}_{3} \mathrm{O}_{4}\right)$

2.9.1 Biomédicas 46

2.9.2 Sensores 46

$\begin{array}{lll}2.9 .3 & \text { Carreadores de Drogas } & 47\end{array}$

2.9.4 Tratamento de Tumores por Hipertermia 47

2.9.5 Agentes de Contraste em Imagem por Ressonância Magnética 47 (MRI)

2.9.6 Agentes Ativos no Diagnóstico de Doenças 48 
2.9.7 Aplicações Tecnológicas 48

2.9.7.1 Usos Ambientais 48

$\begin{array}{lll}\text { 2.9.7.2 } & \text { Catalisadores } & 48\end{array}$

$2.10 \quad$ Emboloterapia 49

$2.11 \quad$ Toxidez da magnetita 53

$2.12 \quad$ Polímeros e Processos de Polimerização 53

$2.13 \quad$ Polimerização em Suspensão 57

2.14 Síntese de Nanocompósitos Poliméricos com Propriedades 58 Magnéticas

2.15 Encapsulação de nanopartículas magnéticas em matrizes 59 poliméricas

Capítulo 3 Procedimentos Experimentais 60

3.1 Reagentes e Materiais 60

3.1.1 Reagentes e Materiais Utilizados na Síntese e Modificação das 60

3.1.2 Reagentes e Materiais Utilizados na Síntese de Polímeros 60

3.2 Sínteses e Modificações Realizadas 61

3.2.1 Síntese de Nanopartículas Magnéticas de $\mathrm{Fe}_{3} \mathrm{O}_{4} \quad 61$

3.2.2 Modificação das Nanopartículas de $\mathrm{Fe}_{3} \mathrm{O}_{4} \quad 62$

3.3 Síntese dos Materiais Poliméricos 63

3.3.1 Reações de Polimerização em Suspensão 63

$3.4 \quad$ Procedimentos Analíticos 65

3.4.1 Espectroscopia na Região do Infravermelho com Transformada 65

3.4.2 Análise por Calorimetria Diferencial de Varredura (DSC) 66

3.4.3 Análise por Termogravimetria (TG) 66

3.4.4 Análise por Calcinação 66

3.4.5 Análise via Espectroscopia de Raios X por Energia Dispersiva 66 (EDX)

3.4.6 Análise por Difração de Raios X (DRX) 67

3.4.7 Análise por Microscopia Eletrônica de Varredura (MEV) 67

3.4.8 Análise por Microscopia Eletrônica de Transmissão (MET) 67

3.4.9 Análise por Espectroscopia Raman 68

3.4.10 Medidas de Magnetização - Força Magnética 68

3.4.11 Cromatografia por Permeação em Gel 69

Capítulo 4 Resultados e Discussões 70

4.1 Síntese de Micropartículas Poliméricas via Processo de 70

4.1.1 Modificação de Nanopartículas Magnéticas de $\mathrm{Fe}_{3} \mathrm{O}_{4}$ com Ácido 70

4.2 Nanocompósitos Poliméricos Obtidos in Situ via Polimerização 77

$\begin{array}{lll} & \text { em Suspensão } & \\ \text { Capítulo } 5 & \text { Conclusão } & 96\end{array}$

$\begin{array}{lll}5.1 & \text { Considerações Finais } & 96\end{array}$

$\begin{array}{lll}5.2 & \text { Perspectivas de Trabalhos Futuros } & 97\end{array}$

Capítulo 6 Referências Bibliográficas 99

Apêndice 1 Microscopia Eletrônica de Transmissão das Nanopartículas 110

Magnéticas de $\mathrm{Fe}_{3} \mathrm{O}_{4}$

Apêndice 2 Microscopia Eletrônica de Transmissão das Nanopartículas 111

Magnéticas de $\mathrm{Fe}_{3} \mathrm{O}_{4}$ com Superfície Modificada com Ácido Oleico

Apêndice 3 Espectros Raman dos Materiais Poliméricos com Diferentes 112 Concentrações de Nanopartículas Magnéticas de $\mathrm{Fe}_{3} \mathrm{O}_{4}$ 


\section{LISTA DE ESQUEMAS}

Esquema 2.1 Reação para produção do nylon-66 a partir da diamina de 53 hexametileno e do ácido adípico

Esquema 2.2 Representação simplificada da reação envolvendo monômeros 54 vinílicos

Esquema 2.3 Representação simplificada da reação de polimerização em 55 etapas

Esquema 3.1 $\quad$ Fluxograma de preparação das partículas de magnetita 61

$\begin{array}{lll}\text { Esquema 3.2 } & \text { Fluxograma da modificação das nanopartículas de magnetita } 62\end{array}$

Esquema 3.3 Fluxograma das reações de polimerização em suspensão 64 


\section{LISTA DE FIGURAS}

Figura 2.1

Figura 2.2

Figura 2.3

Figura 2.4

Figura 2.5

Figura 2.6

Figura 3.1

Figura 3.2

Figura 4.1

Figura 4.2

Figura 4.3

Figura 4.4

Figura 4.5

Figura 4.6

Figura 4.7

Figura 4.8

Figura 4.9

Figura 4.10

Figura 4.11

Figura 4.12

Figura 4.13

Figura 4.14

Figura 4.15

Figura 4.16

Figura 4.17

Figura 4.18

Figura 4.19

Figura 4.20

Figura 4.21

Figura 4.22
Representação de uma curva de histerese de um material magnético

Representação de uma curva de histerese de um material superparamagnético

Representação da estrutura cristalina da magnetita e maguemita 32

Representação da interação do ácido oleico com a superfície da 34 nanopartícula de magnetita

Tipos de interação entre carboxilatos e metais

41

Relação entre Tamanho Médio da Cadeia Polimérica e Conversão da 56

Reação

Representação da modificação superficial das nanopartículas 62 magnéticas

Compostos usados na polimerização do poli(pivalato de vinila)

FTIR do ácido oleico e nanopartículas magnéticas de $\mathrm{Fe}_{3} \mathrm{O}_{4}$ modificadas com ácido oleico

Representação da interação entre o ion oleato e a magnetita 72

Microscopia eletrônica de transmissão distribuição de nanopartículas 74 magnéticas de $\mathrm{Fe}_{3} \mathrm{O}_{4}$. (A) Não modificada; (B) Superfície modificada com ácido oleico

Distribuição de tamanho de partícula de nanopartículas magnéticas de $\mathrm{Fe}_{3} \mathrm{O}_{4}$. (A) Não modificada; (B) Superfície modificada com ácido oleico

Difratograma das nanopartículas magnéticas de $\mathrm{Fe}_{3} \mathrm{O}_{4}$

Perfil de perda de massa das nanopartículas magnéticas de $\mathrm{Fe}_{3} \mathrm{O}_{4} \quad 76$ modificada com ácido oleico

Distribuição de massa molar de homopolímeros de poli(pivalato de 78 vinila)

Efeito da concentração de PBO sobre a dispersão de massa molar dos homopolímeros

Estabilidade térmica dos materiais poliméricos

64

86

75

76

79

81

Difratograma dos nanocompósitos magnéticos. Concentração de 83 nanopartículas de $\mathrm{Fe}_{3} \mathrm{O}_{4}$ igual a 8,5\% p/p para amostra AOSUSP5b, $11,6 \%$ p/p para AOSUSP $10 b, 14,8 \%$ p/p para AOSUSP $15 c, 16,2 \%$ $\mathrm{p} / \mathrm{p}$ para AOSUSP20a

Espectros de energia dispersiva de raios $X$ dos nanocompósitos magnéticos. (A) AOSUSP2,5; (B) AOSUSP5a; (C) AOSUSP5b; (D) AOSUSP10a

Microscopia eletrônica de varredura dos materiais poliméricos. (A) $\mathrm{PVi}\left(\mathrm{b}_{1}\right)$; (B) PVi( $\left.\mathrm{b}_{2}\right)$; (C) PVi( $\left.\mathrm{b}_{3}\right)$; (D) PVi( $\left.\mathrm{b}_{4}\right)$.

Microscopia eletrônica de varredura dos materiais poliméricos. (A) 86 AOSUSP2,5; (B) AOSUSP2,5b

Microscopia eletrônica de varredura dos materiais poliméricos. $(A-C) \quad 88$ AOSUSP5a; (D-F) AOSUSP5b

Microscopia eletrônica de varredura dos materiais poliméricos. (A) AOSUSP10a; (B) AOSUSP10b

Microscopia eletrônica de varredura dos materiais poliméricos. (A) 90 AOSUSP15a; (B) AOSUSP15c

Força magnética relativa das nanopartículas magnéticas de $\mathrm{Fe}_{3} \mathrm{O}_{4} \quad 91$

Comportamento magnético dos materiais poliméricos 91

Força magnética relativa dos materiais poliméricos 92

Curvas de magnetização dos compósitos de magnetita e poli(pivalato 93 de vinila). (A) comportamento magnético; (B) comportamento magnético relativo

Espectroscopia Raman dos nanocompósitos poliméricos. Espectros coletados com modo de excitação em 633 nm (laser $\mathrm{He}-\mathrm{Ne}$ ).

Espectroscopia FTIR dos materiais poliméricos

6

2

(1)

(a)

(1)




\section{LISTA DE TABELAS}

Tabela 2.1 Susceptibilidade magnética para o ferro e alguns de seus óxidos

Tabela 2.2

Diâmetro crítico de condomínio $D_{\text {crit }}$ de partículas esféricas para 26

diferentes materiais

Tabela 2.3 Dimensões de diversos materiais

Tabela 2.4

Algumas propriedades físicas da magnetita e maguemita

Tabela 2.5

Vibrações de absorção na região espectral de infravermelho da magnetita

Tabela 2.6 Vibrações de absorção na região espectral de infravermelho da 42 magnetita, maguemita e hematita

Tabela 2.7 Vibrações de absorção na região espectral de infravermelho da 42 magnetita modificada (recoberta) com ácido oleico

Tabela 2.8 Vibrações de absorção na região espectral de infravermelho do 43 ácido oleico

Tabela 2.9 Picos característicos de alguns óxidos de ferro 43

Tabela 2.10 Números de onda observados para a magnetita com os fônons 45 ativos.

Tabela 2.11 Números de onda observados para a maguemita $\left(\gamma-\mathrm{Fe}_{2} \mathrm{O}_{3}\right)$ com 46 os fônons ativos.

Tabela 4.1 Principais picos e bandas de absorção observados via medidas 71 de FTIR da magnetita recoberta com ácido oleico

Tabela 4.2 Diferença entre ligantes carboxilados monodentados e 72 bidentados

$\begin{array}{lll}\text { Tabela 4.3 Condições experimentais utilizadas nas polimerizações } & 77\end{array}$

$\begin{array}{lll}\text { Tabela 4.4 } & \text { Massas molares médias de homopolímeros de PVi } & 79\end{array}$

Tabela 4.5 Temperatura de Transição Vítrea de homopolímeros de PVi $\quad 80$

Tabela 4.6 Fração mássica de NPMM e tamanho de cristalito 82 


\section{LISTA DE QUADROS}

Quadro 2.1 Representação gráfica formação espontânea de domínios em 23 diferentes materiais.

Quadro 2.2 Classificação dos materiais em relação à dimensionalidade das 28 partículas.

Quadro 2.3 Relação entre o tipo de estrutura e propriedades magnéticas dos 29 materiais.

Quadro 2.4 Compostos de ferro e suas propriedades magnéticas 30

Quadro 2.5 Outros métodos de caracterização de nanopartículas magnéticas 44

Quadro 2.6 Tipos de agentes embólicos $\quad 51$

Quadro 3.1 Compostos usados nas reações de polimerização em suspensão 65 e suas funções 


\section{NOMENCLATURA}

\section{Siglas}

A

$\mathrm{Al}(\mathrm{OH})_{3}$

AO

APS

ATC

atm

Bulk

$\mathrm{Ca}_{3}\left(\mathrm{PO}_{4}\right)_{2}$

DISP

DMF

DMM

DRX

DSC

EDX

$\mathrm{Fe}_{3} \mathrm{O}_{4}$

$\mathrm{FeCl}_{3} \cdot 6 \mathrm{H}_{2} \mathrm{O}$

$\mathrm{FeSO}_{4} \cdot 7 \mathrm{H}_{2} \mathrm{O}$

FTIR

$\mathrm{H}_{2} \mathrm{O}_{2}$

$\mathrm{HCl}$

KPS

MEHQ

MET

MEV

$\mathrm{Mg}(\mathrm{OH})_{2}$

$\mathrm{MgCO}_{3}$

MRI

$\mathrm{N}_{2}$

$\mathrm{NaOH}$

$\mathrm{nm}$

NPMM

$\mathrm{Oe}$

P.A.

PBO

$\mathrm{pH}$

pm

PMMA

ppm

PS

PVA

PVC

$\mathrm{PVi}$

$\mathrm{SA}$

SDS

$T_{c}$

TG

$\mathrm{T}_{\mathrm{n}}$

$\mu \mathrm{m}$
Ampère

Hidróxido de alumínio

Ácido oleico

Persulfato de amônio

Agente de transferência de cadeia

Atmosfera

Sólido tridimensional infinito

Fosfato de cálcio

Dispersão de massa molar

Dimetilformamida

Distribuição de massa molar

Difração de Raios X

Calorimetria Diferencial de Varredura

Espectroscopia de Raios X por Energia Dispersiva

Magnetita, tetróxido de triferro

Cloreto férrico hexahidratado

Sulfato ferroso heptahidratado

Espectroscopia na Região do Infravermelho com Transformada de

Fourier

Peróxido de hidrogênio, água oxigenada

Ácido clorídrico

Persulfato de potássio

Monometil éter de hidroquinona

Microscopia eletrônica de transmissão

Microscopia Eletrônica de Varredura

Hidróxido de magnésio

Carbonato de magnésio

Imagem por Ressonância Magnética

Gás nitrogênio

Hidróxido de sódio, soda cáustica

Nanômetro $\left(10^{-9} \mathrm{~m}\right)$

Nanopartículas magnéticas de $\mathrm{Fe}_{3} \mathrm{O}_{4}$

Oersted

Para Análise

Peróxido de benzoíla

Potencial hidrogeniônico

Picômetro $\left(10^{-12} \mathrm{~m}\right)$

Poli(metacrilato de metila)

Partes por milhão

Poliestireno

Poli(álcool vinílico)

Policloreto de vinila

Pivalato de vinila

poli(estireno-acrilonitrila)

Dodecil sulfato de sódio (ou laurilsulfato de sódio - SLS)

Temperatura Curie

Termogravimetria

Temperatura de Néel

Micrômetro $\left(10^{-6} \mathrm{~m}\right)$ 
AOSUSP2,5 Nanopartícula de magnetita a 2,5\% modificada com ácido oleico AOSUSP2,5b Nanopartícula de magnetita a 2,5\% modificada com ácido oleico amostra b

AOSUSP5a Nanopartícula de magnetita a 5,0\% modificada com ácido oleico amostra a

AOSUSP5b Nanopartícula de magnetita a 5,0\% modificada com ácido oleico amostra b

AOSUSP10a Nanopartícula de magnetita a 10,0\% modificada com ácido oleico - amostra a

AOSUSP10b Nanopartícula de magnetita a 10,0\% modificada com ácido oleico - amostra b

AOSUSP15a Nanopartícula de magnetita a 15,0 \% modificada com ácido oleico - amostra a

AOSUSP15c Nanopartícula de magnetita a 15,0 \% modificada com ácido oleico - amostra c

AOSUSP20a Nanopartícula de magnetita a 20,0\% modificada com ácido oleico

$\operatorname{PVi}\left(b_{1}\right)$

$\operatorname{PVi}\left(b_{2}\right)$

Pivalato de vinila - amostra 1

$\operatorname{PVi}\left(b_{3}\right)$

Pivalato de vinila - amostra 2

$\operatorname{PVi}\left(\mathrm{b}_{4}\right)$ Pivalato de vinila - amostra 3

Pivalato de vinila - amostra 4

\section{SÍMBOLOS GREGOS}

$v \quad$ Estiramento vibração de deformação angular em altas frequências

$\delta$ Dobramento vibração de deformação angular (dobramento) em baixas frequências

$X \quad$ Susceptibilidade magnética

$\phi \quad$ Diâmetro

\section{SUBSCRITOS}

as Assimétrico

s Simétrico 


\section{CAPÍTULO 1 - INTRODUÇÃO}

\subsection{CONTEXTUALIZAÇÃO DO PROBLEMA: NANOPARTÍCULAS DE MAGNETITA, NANOCOMPÓSITOS MAGNÉTICOS E SUAS APLICAÇÕES}

O ferro, na forma de seus diferentes óxidos, tem sido pesquisado e utilizado há anos na área biomédica. ${ }^{1}$

O uso de nanopartículas magnéticas de ferro em inúmeras aplicações biomédicas é possível pois tais materiais apresentam propriedades como a reduzida capacidade de provocar intoxicações no organismo e 0 superparamagnetismo. ${ }^{2,3}$

Observa-se que o surgimento do superparamagnetismo depende do tamanho da partícula, a rota de síntese apropriada tem de ser capaz de produzir partículas nanométricas com uma distribuição de tamanhos estreita além de baixa ou nenhuma agregação das nanopartículas. ${ }^{4}$

Como característica intrínseca ao superparamagnetismo, as nanopartículas magnéticas não se comportarem como imãs permanentes, ou seja, não retém sua magnetização após serem expostas a campos magnéticos externos. Como vantagem adicional, o comportamento superparamagnético auxilia no tratamento por hipertermia, graças ao aquecimento controlado das mesmas como resposta a ação do campo magnético externo.

Há estudos em diversas áreas como separação magnética de compostos diversos, ${ }^{5-7}$ agentes de contraste ${ }^{8,9}$ e diagnóstico, ${ }^{10}$ sensores químicos, ${ }^{11}$ tratamento por hipertermia, ${ }^{12-14}$ sistemas transportadores de fármacos, ${ }^{15}$ catálise $^{16-20}$ e emboloterapia. ${ }^{20-25}$

A estabilização das nanopartículas é feita por agentes de cobertura, que apresentam características interessantes como a ação protetora, minimização da ação agentes oxidantes, além de evitar a aglomeração de nanopartículas devido ao efeito estérico de repulsão do grupo volumoso presente na superfície das nanopartículas.

Esta estabilização é chamada de estérica, uma vez que os grupos que se ligam à superfície da partícula, Neste cenário, os agentes de cobertura, são normalmente moléculas orgânicas de cadeia longa contendo um grupo doador. ${ }^{26}$ 
A idéia fundamental é permitir uma boa compatibilidade com o(s) monômero(s) precursores. ${ }^{3}$ Compostos contendo grupos como o carboxilato e 0 fostato possuem esta propriedade e, neste trabalho, o ácido oleico foi utilizado como agente de cobertura, pois consegue se ligar de modo covalente à superfície da magnetita. ${ }^{27}$

Nanopartículas de magnetita $\left(\mathrm{Fe}_{3} \mathrm{O}_{4}\right)$ foram escolhidas para este trabalho uma vez que possuem magnetização mais elevada que outros tipos de nanopartículas, principalmente as de metais de transição ${ }^{28}$.

Nanopartículas de magnetita recobertas com ácidos carboxílicos de cadeia longa, como o ácido oleico são ideais, uma vez que a cobertura superficial reduz interações interparticulares devido a alteração entrópica causada pela compressão das cadeias poliméricas ligadas à superfície, o que melhora a estabilidade das nanopartículas em condições fisiológicas ${ }^{28}$.

Adicionalmente, a escolha pela magnetita deve-se à sua elevada de biocompatibilidade e magnetismo, mesmo em relação a outros óxidos e metais puros que preenchem requisitos importantes para aplicações biomédicas. Além disto, outros requisitos também devem ser considerados, como o a estabilidade química e baixa toxidez em condições fisiológicas, bem como rotas sintéticas simples e econômicas.

Atualmente são utilizados diversos métodos de síntese de nanopartículas, destacam-se entre eles, coprecipitação, ${ }^{29,30}$ síntese hidrotérmica, ${ }^{31,32}$ sonoquímica, ${ }^{33,34}$ processo sol-gel, ${ }^{35,36}$ polióis, ${ }^{37-39}$ injeção em fluxo, ${ }^{1}$ eletroquímicos, ${ }^{1}$ aerossol e vapor, ${ }^{1,40}$ ambientes restritos ${ }^{1}$ e microemulsão por zona. ${ }^{41}$

A despeito do elevado número de rotas sintéticas, o desafio principal inerente a obtenção de nanopartículas magnéticas é manter uma proporção adequada entre cátions $\mathrm{Fe}^{2+}$ e $\mathrm{Fe}^{3+}$, a separação das nanopartículas magnéticas do meio reacional após sua síntese, controles para evitar ou reduzir a floculação do material obtido, a remoção de surfactantes, entre outros. ${ }^{42-44}$

É importante destacar, que o tamanho de partícula do nanocompósito polimérico aliado ao comportamento superparamagnético das nanopartículas de ferro é um requisito para uso de materiais poliméricos magnéticos em aplicação aplicações médicas, como por exemplo a emboloterapia (embolização vascular), caracterizada pela introdução de material particulado finamente dividido, via 
cateter, com a finalidade obstruir mecanicamente os vasos sanguíneos que irrigam uma região tumoral.

O controle adequado do tamanho de partícula pode ser efetuado durante a síntese do material magnetopolimérico. Diversos processos de polimerização podem ser empregados com este intuito, destacando-se os processos de polimerização em suspensão, emulsão e miniemulsão. ${ }^{42}$

No que tange ao caráter superparamagnético das nanopartículas, o mesmo é preservado quando ocorre o encapsulamento (ou incorporação) por uma matriz polimérica hidrofóbica. Por isso, torna-se indispensável uma dispersão adequada, que é conseguida graças à estabilização destas nanopartículas na fase monomérica precursora do polímero de interesse. ${ }^{45,46}$

Em particular para procedimentos médicos que exigem distribuição de tamanho de partícula estreita e em dimensão micrométrica, como a embolização intravascular), o emprego da polimerização em suspensão é uma condição sine qua non, pois permite o controle fino dentro de uma ampla faixa de tamanho de partícula.

O grande desafio desta dissertação é a síntese de materiais poliméricos microparticulados, usando o processo clássico de polimerização em suspensão, dotado de boa capacidade de magnetização, morfologia esférica e baixa suscetibilidade à hidrólise, visando seu uso em procedimentos médicos de embolização intravascular. 


\subsection{OBJETIVOS DA DISSERTAÇÃO}

Neste contexto, o objetivo fundamental deste projeto de pesquisa é desenvolver novos materiais poliméricos que consistam de micropartículas esféricas de poli(pivalato de vinila) obtidos in situ em uma reação de poliadição do pivalato de vinila na presença de nanopartículas magnéticas de magnetita $\left(\mathrm{Fe}_{3} \mathrm{O}_{4}\right)$ modificadas com ácido oleico.

\subsubsection{Objetivos Específicos}

Mais especificamente para alcance dos objetivos propostos, as principais metas desta dissertação de mestrado são:

- Síntese e caracterização das nanopartículas magnéticas, visando sua utilização como carga nanoestruturada em nanocompósitos.

- Avaliar as propriedades finais dos materiais poliméricos produzidos através de reações via radicais livres do pivalato de vinila em processos de polimerização em suspensão.

- Avaliar as propriedades finais dos nanocompósitos produzidos in situ a partir da inserção de nanopartículas magnéticas à matriz polimérica de poli(pivalato de vinila) em processos de polimerização em suspensão. 


\section{CAPÍTULO 2 - REVISÃO BIBLIOGRÁFICA}

\subsection{PROPRIEDADES MAGNÉTICAS DOS MATERIAIS}

\subsubsection{Propriedades Magnéticas Cooperativas}

As propriedades magnéticas de um material devem-se ao movimento de partículas que possuem massa e carga elétrica. Podem ser elétrons, prótons, cátions, ânions ou defeitos cristalinos, uma vez que os mesmos possuem momento magnético por conta de seu movimento. Deste modo, deve-se levar em conta o tipo de momento magnético que surge a partir do tipo de interação que ocorre entre os dipolos. ${ }^{47}$

Dentro dos materiais o comportamento dos elétrons dirige as propriedades magnéticas de dois modos. $O$ primeiro tipo é o movimento rotacional dos elétrons, uma vez que o elétron pode se comportar como uma esfera carregada na qual o spin age como um pequeno imã. Spins podem ser orientados de dois modos, para cima $(\uparrow)$ ou para baixo $(\downarrow){ }^{48}$

O segundo tipo de movimento é o dos elétrons ao redor do núcleo dos átomos, gerando uma corrente circular. $O$ fluxo de carga na corrente produz linhas magnéticas conhecidas como dipolos. Em um imã, as linhas de força magnética fluem no dipolo do polo norte para o polo sul. Assim, o momento magnético é a medida deste dipolo. Elétrons em átomos tem momento magnético por conta de seus spins ou de spins e movimento orbital. ${ }^{49}$

Um elétron em órbita responde a um campo magnético segundo a configuração de spin do material. O movimento orbital destes elétrons cria correntes que geram campos magnéticos. Deste modo, todos os materiais possuem campos magnéticos gerados por movimento orbitais de seus elétrons. ${ }^{49}$

\subsubsection{Termos Usados em Magnetismo}

Algumas das medidas magnéticas são definidas a partir de conceitos fundamentais como o de dipolo magnético. Correntes geram campos definidos em temos de força de campo magnético ou intensidade $(H)$. 
Outra grandeza é a indução magnética (B) de uma função e $\mathrm{H}$ e a polarização (M).

$$
B=H+4 \pi M
$$

A magnetização pode ser entendida como a densidade do momento de dipolo magnético $(\mu)$ do material.

$$
M=\frac{\mu_{\text {total }}}{V}
$$

A susceptibilidade magnética (к) mede a eficiência do campo aplicado para induzir um momento de dipolo magnético no material. A permeabilidade magnética $(\mu)$ é a razão entre a indução magnética e o campo magnético.

$$
\mathrm{\kappa}=\frac{M}{H} \quad \text { e } \quad \mu=\frac{B}{H}
$$

Há diversas grandezas usadas no magnetismo e diversas unidades, uma das mais usadas é a unidade eletromagnética do momento de dipolo por centímetro cúbico $\left(\mathrm{emu} / \mathrm{cm}^{3}\right) .50-52$

\subsubsection{Como o Magnetismo se Manifesta na Matéria}

Para efeitos de classificação, a presença de magnetização em materiais pode ser dividida em 5 categorias básicas: materiais diamagnéticos, paramagnéticos, ferromagnéticos, antiferromagnéticos e ferrimagnéticos.

A base desta classificação é a susceptibilidade bulk (X), propriedade ligada à organização (alinhamento) dos domínios magnéticos dos materiais. Entende-se por domínio, qualquer região onde se observa um ordenamento de spins. Para alguns materiais esta formação é espontânea e, para outros, esta formação não ocorre, como mostrado no quadro 2.1 a seguir. 
Quadro 2.1. Representação gráfica formação espontânea de domínios em diferentes materiais. Adaptado das referências ${ }^{47,53,54}$.

\begin{tabular}{|c|c|c|}
\hline \multicolumn{3}{|c|}{ Formação espontânea de domínios } \\
\hline Ferrimagnéticos & Ferromagnéticos & Antiferromagnéticos \\
\hline$\uparrow \downarrow \uparrow \downarrow \uparrow \downarrow \uparrow \downarrow$ & $\downarrow \downarrow \downarrow \downarrow \downarrow \downarrow \downarrow \downarrow \downarrow \downarrow$ & $\downarrow \uparrow \downarrow \uparrow \downarrow \uparrow \downarrow \uparrow$ \\
\hline \multicolumn{3}{|c|}{ Não há formação de domínios } \\
\hline$\downarrow \uparrow \downarrow \uparrow \downarrow \uparrow \downarrow \uparrow \downarrow \uparrow$ & & $\leftarrow \uparrow \rightarrow \downarrow \nwarrow \nearrow \searrow \swarrow \leftarrow \uparrow$ \\
\hline Diamagnéticos & & Paramagnéticos \\
\hline
\end{tabular}

Os efeitos magnéticos podem ser classificados de acordo com a susceptibilidade $(X)$ e tais medidas dão informações do tamanho e forma de alguns tipos de moléculas. ${ }^{55}$

Metais e óxidos metálicos podem apresentar susceptibilidade magnética sendo que os metais apresentam os maiores valores.

Tabela 2.1. Susceptibilidade magnética para o ferro e alguns de seus óxidos. ${ }^{48}$

\begin{tabular}{|l|l|}
\hline Substância & Susceptibilidade magnética $\left(\mathbf{M}_{\mathbf{s}}\right) \mathbf{a} \mathbf{2 5} \mathbf{O}^{\mathbf{C}}\left(\mathbf{e m u} / \mathbf{c m}^{\mathbf{3}}\right)$ \\
\hline $\mathrm{Fe}($ cúbico $)$ & $1700-1714$ \\
\hline$\gamma$ - $\mathrm{Fe}_{2} \mathrm{O}_{3}$ & 394 \\
\hline $\mathrm{FeO} . \mathrm{Fe}_{2} \mathrm{O}_{3}$ & $480-500$ \\
\hline
\end{tabular}

\subsubsection{Diamagnetismo}

É uma propriedade comum a todas as substâncias, uma vez que todas possuem no mínimo um elétron em camadas completas, assim todos os momentos de spins dos elétrons são cancelados e não há magnetismo resultante. Contudo, torna-se relevante apenas quando não há paramagnetismo ou magnetismo coletivo se manifestando no sistema. ${ }^{56}$

Por ser um efeito indutivo, obedece à lei de Lenz e na presença de um campo magnético externo, as camadas sofrem um efeito de alinhamento em oposição ao campo aplicado, devido ao pequeno momento induzido, e isso gera uma repulsão fraca pelo campo magnético. Na ausência de elétrons desemparelhados na substância, essa será a única resposta ao campo.

A susceptibilidade da substância será negativa e pequena $\left(X \approx-10^{-5}\right)$. A resposta magnética é contra o campo e independe da temperatura e da força do campo magnético. Os supercondutores são um caso especial $(X \approx-1)$. Entre os 
exemplos de materiais diamagnéticos estão $\mathrm{Cu}, \mathrm{Ag}, \mathrm{Au}, \mathrm{Bi}, \mathrm{Be}$ e substâncias orgânicas, como por exemplo, $\mathrm{N}_{2} \mathrm{O}_{4} \cdot{ }^{57}$

\subsubsection{Paramagnetismo}

Nos materiais que apresentam este fenômeno, a susceptibilidade da substância será positiva e pequena ( $X \approx 10^{-3}$ a $10^{-5}$ c.g.s). Neste caso, há presença de dipolos permanentes no material. A magnetização fraca e alinhada ao campo externo, ou seja, o material é atraído pelo campo magnético moderadamente. Entre os metais que apresentam esta propriedade, podemos citar como exemplos $\mathrm{Al}, \mathrm{Pt}, \mathrm{Mn}$.

A orientação dos momentos magnéticos frente aos campos externos pode sofrer influências dos efeitos térmicos.

\subsubsection{Ferromagnetismo}

Nos materiais ferromagnéticos, há uma magnetização espontânea frente à aplicação de campos magnéticos externos. A susceptibilidade magnética $X$ é positiva e apresenta elevados valores (50 c.g.s. a 10.000 c.g.s) e entre os exemplos estão $\mathrm{Fe}, \mathrm{Co}, \mathrm{Ni}$, terras raras e suas ligas.

Os átomos ou íons das substâncias que apresentam esta propriedade possuem configuração próxima o suficiente para influenciar seus vizinhos magneticamente de modo que todos os momentos apontam em uma mesma direção.

Apresentam elevadas permeabilidades magnéticas, geram altas induções com pequenos campos, retêm a magnetização e agem como fontes de campo e podem ser usados em motores elétricos. Permanecem magnéticos mesmo quando o campo externo é removido.

Normalmente é encontrado em metais de transição e seus compostos. Neste tipo de composto, na temperatura Curie $\left(T_{c}\right)$ é observada a transição de ferromagnético para paramagnético (qualquer ferromagneto ao ser aquecido, a partir de certa temperatura se torna paramagnético). Neste ponto a permeabilidade cai bruscamente e a coercitividade/remanência se igualam a zero. 


\subsubsection{Antiferromagnetismo}

O antiferromagnetismo ocorre quando o tipo de interação favorece orientações opostas dos momentos magnéticos e, consequentemente, sua anulação parcial. Com isso apresentam susceptibilidades magnéticas menores que o esperado para rede de íons magnéticos independentes.

É comum em íons de $\mathrm{Fe}^{3+}, \mathrm{Mn}^{2+}, \mathrm{Gd}^{3+}$ que apresentam grandes momentos magnéticos e o acoplamento envolve interações através dos ânions que se localizam entre os átomos metálicos no sólido cristalino e desaparecem em soluções diluídas.

O comportamento apresentado desvia-se da lei de Curie. Apresentam atração fraca. Tem comportamento oposto ao dos materiais ferromagnéticos. Surge quando há dois tipos de íons magnéticos uma vez que os mesmos se alinham de modos diferentes em relação ao campo.

\subsubsection{Ferrimagnetismo}

Neste tipo de compostos, os íons apresentam dipolos com intensidades diferentes e sempre há um momento dipolo resultante. Exemplos destes compostos são as ferritas e óxidos metálicos em geral.

\subsubsection{Histerese}

Em um material ferro ou ferrimagnéticos não magnetizado o conjunto de spins em um domínio não estão alinhados e o resultado das interações pode ser mínimo ou zero, de acordo com a equação

$$
M_{S}=\frac{M}{\rho} \quad,(\mathrm{emu} / \mathrm{g})
$$

Se o material é submetido a um campo magnético externo, os spins de cada domínio rotacionam até que os dipolos se alinhem ao campo. O platô na curva de magnetização é chamado de magnetização de saturação $\left(\mathrm{M}_{\mathrm{s}}\right)$ e é a medida da magnetização por unidade de massa (g) e $\rho$ é a densidade do material como podem ser vistos na equação 2.4 .

Uma vez que a magnetização é proporcional ao campo aplicado, em ambientes de multidomínio, a desmagnetização ocorre por rotação de spin através dos limites do domínio. 
Se a curva de desmagnetização não segue a curva de magnetização, o material apresenta histerese, que é a diferença observada na curva da figura 2.1.

A magnetização de remanência $\left(\mathrm{Mr}_{\mathrm{r}}\right)$ é a que resta após o campo estar nulo $(H=0)$. A coercitividade, $H_{c}$, é campo externo de sinal oposto necessário para reduzir a magnetização a zero. Representa o mínimo de energia necessário para reverter a magnetização. ${ }^{3}$

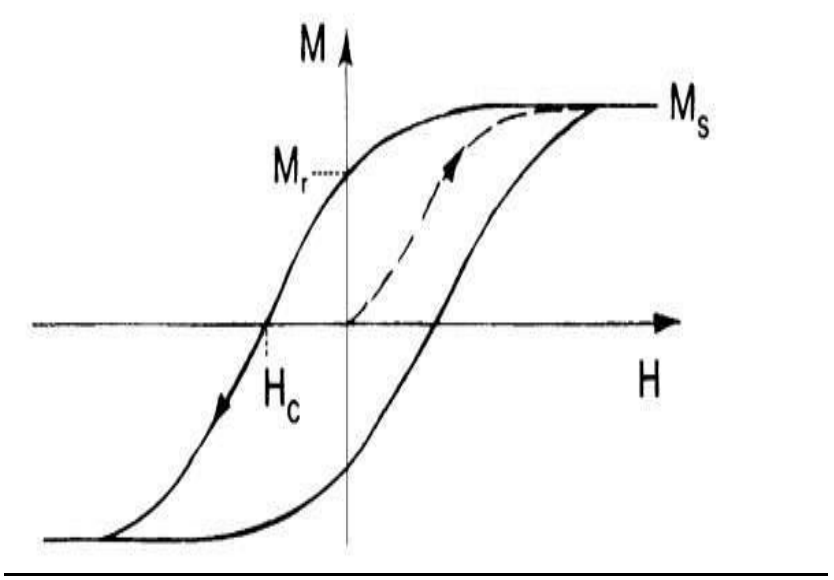

Figura 2.1. Representação de uma curva de histerese de um material magnético. ${ }^{58}$,

\subsection{PROPRIEDADES MAGNÉTICAS DE PEQUENAS PARTíCULAS}

Observa-se uma relação entre o comportamento apresentado pelas partículas, em relação às propriedades magnéticas, e o tamanho das partículas. As partículas podem apresentar características de monodomínios magnéticos (partículas menores) ou multidomínios (partículas maiores), diretamente relacionadas ao tamanho limite de partículas (tamanho ou diâmetro crítico $D_{\text {crit). }}{ }^{3}$

Tabela 2.2: Diâmetro crítico de condomínio $D_{\text {crit }}$ de partículas esféricas para diferentes materiais. ${ }^{48}$

\begin{tabular}{|l|l|}
\hline Material & $\mathbf{D}_{\text {crit }}(\mathbf{n m})$ \\
\hline $\mathrm{Co}$ & 70 \\
\hline $\mathrm{Fe}$ & 14 \\
\hline $\mathrm{Ni}$ & 55 \\
\hline $\mathrm{Fe}_{3} \mathrm{O}_{4}$ & 128 \\
\hline$\gamma-\mathrm{Fe}_{2} \mathrm{O}_{3}$ & 166 \\
\hline
\end{tabular}

A partir de um determinado valor de tamanho da partícula, chamado de raio superparamagnético, ocorre uma transição de partículas ferro e ferrimagnéticas em superparamagnéticas e grandes momentos magnéticos são 
observados sob a ação de um campo externo, o que é vantajoso no caso de aplicações in vivo, uma vez o magnetismo desaparece após a remoção do campo externo, o que evita a aglomeração de partículas no organismo. ${ }^{54}$

\subsubsection{Materiais Superparamagnéticos}

Neste tipo de material, há um tamanho crítico para que esta propriedade se manifeste, situado em torno de $30 \mathrm{~nm} .{ }^{48,59}$

Podemos observar a diferença entre um material magnético, como o mostrado na figura 2.1 e um superparamagnético, mostrado na figura 2.2 abaixo:

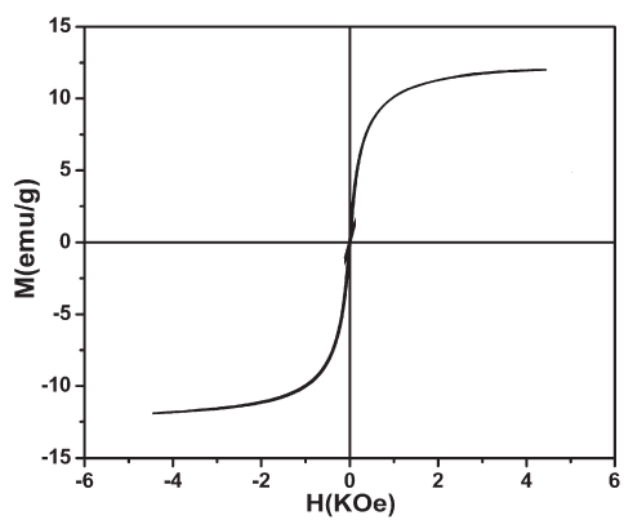

Figura 2.2. Representação de uma curva de histerese de um material superparamagnético ${ }^{60}$.

Assim, em relação ao superparamagnetismo, materiais com tal característica não apresentam magnetização remanescente na ausência de campos magnéticos externos, ou seja, não há uma memória magnética do material.

O superparamagnetismo é dependente do tipo de partícula, suas dimensões e cristalinidade, ou seja, não há um método direto de previsão do superparamagnetismo. ${ }^{52}$

A magnetização de materiais no bulk são normalmente maiores que aqueles das nanopartículas dos respectivos materiais. Valores experimentais para a magnetização de saturação da magnetita variam de 30 a $60 \mathrm{emu} / \mathrm{g}$ enquanto no sólido (bulk) podem chegar a valores iguais a $92 \mathrm{emu} / \mathrm{g} .{ }^{61}$ 


\subsection{MATERIAIS NANOESTRUTURADOS}

Atualmente muito se fala em nanotecnologia, nanocompostos, nanomundo. Quando se fala de uma nanopartícula, estamos indicando algo que apresenta um tamanho convencionado entre 1 e $100 \mathrm{~nm}$ em pelo menos uma de suas dimensões. ${ }^{62,63}$

A nanotecnologia tornou-se ao longo dos anos um campo de pesquisa importante que atrai a atenção de pesquisadores de todo o mundo. De acordo com as suas dimensões, os nanomateriais podem ser classificados da maneira mostrada no a seguir.

Quadro 2.2. Classificação dos materiais em relação à dimensionalidade das partículas. ${ }^{64}$

\begin{tabular}{|l|l|}
\hline $\begin{array}{l}\text { Tipo } \\
\text { material }\end{array}$ & \multicolumn{1}{c|}{ Características } \\
\hline Nanopartículas & $\begin{array}{l}\text { - As três dimensões tem a mesma ordem de grandeza - } \\
\text { nanométrica } \\
\text { Ex.: nanoesferas, nanocristais e grânulos nanométricos. }\end{array}$ \\
\hline Nanotubos & $\begin{array}{l}\text { - Duas das dimensões estão na mesma ordem de grandeza, mas } \\
\text { a terceira é maior, o que forma uma estrutura alongada. } \\
\text { Ex.: nanotubos de carbono (CNTs), de sílica e titânio, nanofibras. }\end{array}$ \\
\hline Nanocamadas & $\begin{array}{l}\text { - Apenas uma dimensão apresenta ordem de grandeza de } \\
\text { nanômetros. } \\
\text {-O material se apresenta na forma de folhas nanométricas. } \\
\text { Ex.: silicatos folhados, hidróxidos de camada dupla. }\end{array}$ \\
\hline
\end{tabular}

A noção do tamanho de estruturas é feita por comparação com outras estruturas conhecidas. A tabela 2.3 a seguir ilustra os diferentes tamanhos de materiais de composição orgânica e inorgânica conhecidos.

Tabela 2.3. Dimensões de diversos materiais ${ }^{52}$.

\begin{tabular}{|l|l|}
\hline \multicolumn{1}{|c|}{ Espécie } & \multicolumn{1}{c|}{ Tamanho } \\
\hline Átomo de ferro & $156 \mathrm{pm}$ \\
\hline Glucose & $900 \mathrm{pm}$ \\
\hline Fulerenos $\left(\mathrm{C}_{60}\right)$ & $<1 \mathrm{~nm}$ \\
\hline Ribossomo & $30 \mathrm{~nm}$ \\
\hline Nanopartículas & Entre 1 e $100 \mathrm{~nm}$ \\
\hline Vírus HIV & $130 \mathrm{~nm}$ \\
\hline Cromossomo X humano & $7 \mu \mathrm{m}$ \\
\hline Óvulo humano & $130 \mu \mathrm{m}$ \\
\hline Grão de sal & $0,5 \mathrm{~mm}$ \\
\hline
\end{tabular}


Tais materiais destacam-se por suas propriedades diferentes em termos elétricos, magnéticos, químicos e estruturais dos nanomateriais em relação ao bulk. ${ }^{65} \mathrm{O}$ que vai diferenciar um material na relação bulk versus nano são suas propriedades físico-químicas, tais como as quânticas e sua elevada área superficial, que se tornam mais pronunciadas à medida que o tamanho da partícula se reduz. ${ }^{66}$

A nanotecnologia aplicada ao campo dos nanocompósitos poliméricos leva em consideração o princípio básico do melhoramento das propriedades dos materiais poliméricos, conduzindo a formação de materiais mais eficientes para uso em diferentes segmentos tecnológicos como, por exemplo, biotecnologia, medicina, saúde, dispositivos eletrônicos, energia, separação, etc.

\subsubsection{Classificação dos Materiais Nanoestruturados}

Em relação à classificação dos materiais nanoestruturados, diversos métodos podem ser empregados. Um deles relaciona o tipo de estrutura e as propriedades magnéticas, como descrito no quadro 2.3 a seguir.

Quadro 2.3. Relação entre o tipo de estrutura e propriedades magnéticas dos materiais. ${ }^{65}$

\begin{tabular}{|c|c|}
\hline Tipo & Características \\
\hline A & $\begin{array}{l}\text { - Sistemas de partículas isolados; } \\
\text { - Diâmetro de partícula na faixa nanométrica. } \\
\text { - Sistemas não interativos; } \\
\text { - Propriedades magnéticas derivam do tamanho dos componentes; } \\
\text { - Não há contribuição das interações interpartículas nas propriedades } \\
\text { magnéticas. }\end{array}$ \\
\hline B & $\begin{array}{l}\text { - Partículas ultrafinas com morfologia casca-núcleo; } \\
\text { - Presença da casca reduz interações interpartículas; } \\
\text { - Há interações entre casca e núcleo; } \\
\text { - Cascas podem ser formadas por oxidação e apresentarem magnetismo; }\end{array}$ \\
\hline C & $\begin{array}{l}\text { - Nanocompósitos onde dois materiais heterogêneos são combinados; } \\
\text { - As partículas magnéticas são distribuídas em matrizes; } \\
\text { - Interações magnéticas são determinadas pela fração das partículas } \\
\text { magnéticas e o tipo de matriz empregada. }\end{array}$ \\
\hline D & $\begin{array}{l}\text { - Materiais massivos com estrutura nanométrica. } \\
\text { - Frações superiores a } 50 \% \text { da amostra são formadas por limites de grão e } \\
\text { interfaces; } \\
\text { - Propriedades dominadas por interações físicas e químicas. }\end{array}$ \\
\hline
\end{tabular}




\subsection{O FERRO E SEUS ÓXIDOS}

Há milhares de anos são conhecidos compostos de ferro, entre eles os óxidos de ferro, hidróxidos, óxido-hidróxidos, entre outros. Muitos dos compostos apresentam propriedades magnéticas diferentes e, por isto, encontram diferentes usos.

Em tempos antigos foram usados como pigmentos e em tempos mais recentes como bússolas (China antiga), que auxiliaram os primeiros navegadores a identificarem o polo norte magnético, considerado como 0 primeiro uso documentado de óxidos magnéticos de ferro. ${ }^{67}$

Quadro 2.4. Compostos de ferro e suas propriedades magnéticas. ${ }^{68}$

\begin{tabular}{|l|l|l|}
\hline \multicolumn{1}{|c|}{ Substância } & \multicolumn{1}{c|}{ Fórmula } & \multicolumn{1}{c|}{ Propriedade magnética } \\
\hline Goethita & $\alpha-F e O O H$ & Antiferromagnética \\
\hline Akaganeita & $\beta-F e O O H$ & Antiferromagnética \\
\hline Lepidocrocita & $\gamma-F e O O H$ & Antiferromagnética \\
\hline Feroxita & $\delta^{\prime}-\mathrm{FeOOH}$ & Ferrimagnética \\
\hline Ferridrita & $\mathrm{Fe}_{5} \mathrm{HO}_{8} \cdot 4 \mathrm{H}_{2} \mathrm{O}$ & Antiferromagnética \\
\hline Hematita & $\alpha-\mathrm{Fe}_{2} \mathrm{O}_{3}$ & Fracamente ferrimagnética \\
\hline Maguemita & $\mathrm{\gamma}^{-} \mathrm{Fe}_{2} \mathrm{O}_{3}$ & Ferrimagnética \\
\hline Magnetita & $\mathrm{Fe}_{3} \mathrm{O}_{4}$ & Ferrimagnética \\
\hline
\end{tabular}

A magnetita e a maguemita são os compostos mais estudados e possuem propriedades físicas semelhantes, bem como suas estruturas cristalinas. Apesar de serem ambas ferrimagnéticas, a maguemita possui uma saturação magnética menor devido ao tipo de arranjo cristalino.

Tabela 2.4. Algumas propriedades físicas da magnetita e maguemita. ${ }^{68}$

\begin{tabular}{|l|l|l|l|l|l|}
\hline & $\begin{array}{l}\text { Sistema } \\
\text { cristalino }\end{array}$ & $\begin{array}{l}\text { Célula } \\
\mathbf{( n m )}\end{array}$ & $\begin{array}{l}\text { Densidade } \\
\left(\mathbf{g} / \mathbf{c m}^{\mathbf{3}} \mathbf{)}\right.\end{array}$ & Cor & $\begin{array}{l}\text { Susceptibilidade } \\
\text { magnética } \\
(\mathbf{e m u} / \mathbf{g})\end{array}$ \\
\hline Magnetita & Cúbico & $\mathrm{a}_{\circ}=0,839$ & 5,26 & Preto & $90-98^{69}$ \\
\hline Maguemita & $\begin{array}{l}\text { Cúbico ou } \\
\text { trigonal }\end{array}$ & $\mathrm{a}_{\circ}=0,834$ & 4,87 & Marrom & $76-81$ \\
\hline
\end{tabular}

\subsubsection{A Magnetita $\left(\mathrm{Fe}_{3} \mathrm{O}_{4}\right)$}

O nome magnetita, que é um termo antigo, é provavelmente uma referência à Magnesia, cidade situada na Grécia ${ }^{28}$. No Brasil, é encontrada em depósitos minerais na região de Itabira - MG. 
Além da origem mineral, a magnetita pode ser encontrada em moluscos (rádulas), artrópodes (abelhas), pinguins, algas, fungos $\mathrm{e}$ bactérias magnetotáteis. ${ }^{70,71}$ As bactérias que produzem magnetita têm sido estudadas devido a particularidades como a distribuição estreita de tamanho de partículas.

É um composto de cor negra, ferrimagnético, contendo cátions de ferro nos estados de oxidação $+2 \mathrm{e}+3$ e possui um alto percentual de ferro. Por conta de suas propriedades magnéticas, seus depósitos minerais são de fácil localização e concentração. ${ }^{72}$

Faz parte do grupo mineral dos espinélios, pertencem ao grupo espacial Fd3m (sintético) ${ }^{28}$. Ocorre em rochas minerais ígneas e metamórficas, onde a segregação magmática ou o metamorfismo de contato pode produzir jazidas. Pode ser biogênico (detritos) e aparece em formações sedimentares.

Dentro do estudo dos materiais a magnetita tem papel especial devido a suas propriedades catalíticas e magnéticas.

\subsubsection{Estrutura da Magnetita}

As estruturas de óxidos são formadas pelo arranjo de cátions de ferro e ânions de hidroxila ou oxigênio com os cátions ocupando camadas relativas diferentes das dos ânions.

Na química, o termo ferrita é empregado a compostos que possuem o cátion férrico como maior componente. Existem 3 tipos de espinélios (compostos com estrutura do tipo $\mathrm{MgAl}_{2} \mathrm{O}_{4}$ ): ferritas espinélicas, ferritas de granada e hexaferritas.

Nas ferritas espinélicas, o arranjo é do tipo cúbico de face centrada (CFC) em relação aos ânions $\mathrm{O}^{2-}$, onde os cátions ocupam 16 sítios octaédricos (sítios B) e os ânions ocupam 8 sítios tetraédricos (sítios A). Neste tipo de empacotamento do tipo CFC existem 64 interstícios de simetria tetraédrica e 32 do tipo octaédrico.

Nas estruturas espinélicas normais $\left(\mathrm{XY}_{2} \mathrm{O}_{4}\right)$, os cátions $+3(\mathrm{Y})$ ocupam sítios octaédricos e os cátions $+2(X)$ ocupam os tetraédricos. Quando a estrutura possui parte dos íons +3 localizados em sítios tetraédricos e os restantes, juntamente com os íons +2 , em sítios octaédricos, a estrutura é denominada espinélio inverso $\left(\mathrm{B}(\mathrm{AB}) \mathrm{O}_{4}\right)$. Há ainda, uma terceira possibilidade onde os íons 
maiores estão em $1 / 8$ dos sítios tetraédricos e 1/4 dos octaédricos e os íons menores estão em $1 / 4$ dos octaédricos. ${ }^{72,73}$

No caso dos óxidos de ferro, a magnetita e a maguemita possuem estruturas cristalinas semelhantes. Em particular para maguemita, há uma deficiência de ferro em relação à magnetita e isso pode ser descrito como: ${ }^{1}$

$$
\mathrm{Fe}_{3} \mathrm{O}_{4}:\left[\mathrm{Fe}^{3+}\right] T_{d}\left[\mathrm{Fe}^{3+} \mathrm{Fe}^{2+}\right] \mathrm{O}_{h} \mathrm{O}_{4}
$$

Onde $T_{d}$ se refere a sítios tetraédricos e $O_{h}$ está relacionado aos sítios octaédricos da estrutura.

A estrutura da maghemita pode também ser descrita da seguinte forma:

$$
\left(\mathrm{Fe}^{3+}\right)\left[\mathrm{Fe}^{3+} \mathrm{Fe}^{2+}\right] \mathrm{O}_{4}^{2-}
$$

A $\quad B$

onde, A indica os sítios tetraédricos e B está relacionado aos sítios octaédricos.

Graficamente as estruturas podem ser representadas do seguinte modo: ${ }^{74}$
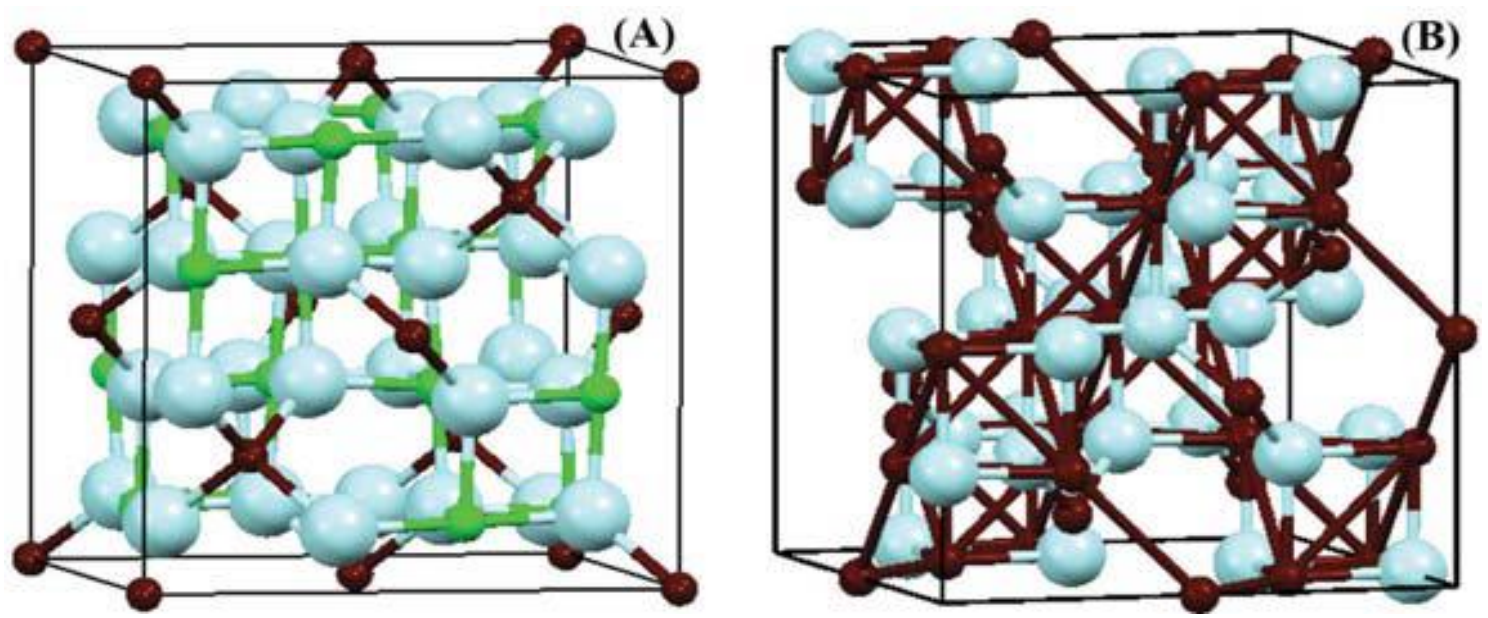

Figura 2.3: Representação da estrutura cristalina da magnetita e maguemita. Adaptado de Neto et al. ${ }^{74}$.

Uma vez que estes dois cátions coexistem na célula cristalina, há um movimento de elétrons entre os dois sítios octaédricos, o que auxilia no entendimento das propriedades magnéticas da magnetita: ${ }^{75}$ 


\subsubsection{Estabilidade da Magnetita e Suas Transformações}

A magnetita sofre facilmente oxidação à maguemita quando aquecida exposta ao ar. Quando sofre aquecimento acima de $300^{\circ} \mathrm{C}$, também sofre oxidação à hematita. ${ }^{68}$

$$
4 \mathrm{Fe}_{3} \mathrm{O}_{4}+\mathrm{O}_{2} \rightarrow 6 \mathrm{\alpha}-\mathrm{Fe}_{2} \mathrm{O}_{3} \quad \text { (formação de maguemita) }
$$

As reações possíveis no sistema são as seguintes

$$
\mathrm{Fe}_{3} \mathrm{O}_{4} \stackrel{300^{\circ} \mathrm{C}}{\longrightarrow} \gamma-\mathrm{Fe}_{2} \mathrm{O}_{3} \stackrel{400^{\circ} \mathrm{C}}{\longrightarrow} \mathrm{\alpha}-\mathrm{Fe}_{2} \mathrm{O}_{3}
$$

Sinteticamente a magnetita pode ser preparada por diversas técnicas, como a precipitação de misturas de íons férricos e ferrosos em meio alcalino, por oxidação de íons ferrosos de soluções de hidróxidos ferrosos, pela interação de íons ferrosos com ferridratos ou decomposição de precursores orgânicos.

\subsubsection{Química superficial da magnetita}

As propriedades físicas e químicas superficiais de nanopartículas magnéticas são importantes no entendimento das propriedades e uso de partículas magnéticas.

No caso da magnetita, os átomos de ferro agem como ácidos de Lewis e se coordenam com espécies que agem como bases de Lewis ao doarem pares de elétrons. Em sistemas aquosos, os átomos de ferro se coordenam com a água, que sofre dissociação para que a superfície do óxido de ferro seja funcionalizada com grupos hidroxila.

Por conta das forças atrativas associadas a nanopartículas de magnetita, a proteção contra agregação é feita por diversos métodos, entre eles a criação de uma camada eletrostática dupla, o uso de surfactantes como estabilizantes estéricos ou por modificação do ponto isoelétrico com coberturas. ${ }^{76,77}$

A estabilidade pode ser estérica, quando depende do tipo de eletrólito ou eletrostática, que depende do tipo de solvente e da massa molar da camada de polímero adsorvido na superfície e normalmente a estabilidade é melhorada quando ocorre a ação destes dois mecanismos juntos. ${ }^{78}$

A estabilização de superfícies de magnetita pode ser feita em meio aquoso pelo uso de surfactantes anfotéricos. A cabeça polar pode ser um grupo 
fosfato, sulfato ou carboxilato. Grupos carboxilato são muitos usados por conta da capacidade de interagir de modo covalente com a superfície da nanopartícula.

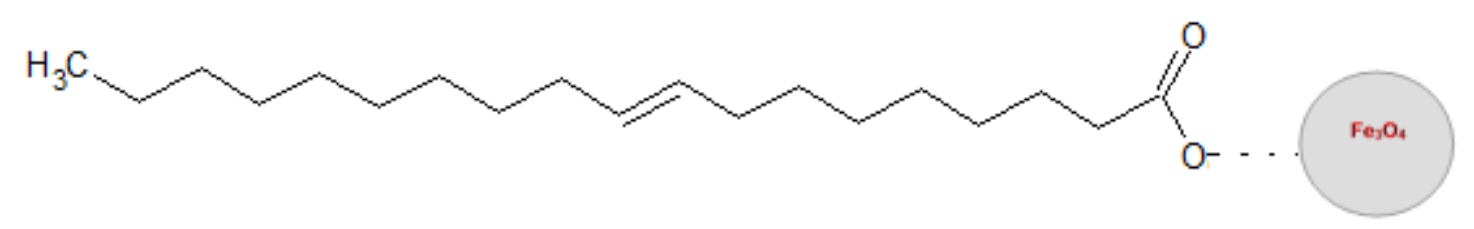

Figura 2.4. Representação da interação do ácido oleico com a superfície da nanopartícula de magnetita

Podem ser usados como estabilizantes estéricos para nanopartículas, compostos com cadeias variando entre 10 e 15 carbonos formam soluções dispersíveis em água. 27, 79, 80 .

Neste trabalho, foi utilizado o ácido oleico e a partir de dados da literatura sabe-se que o processo de adição de ácido oleico aos precursores da reação pode afetar a estrutura e o tamanho da ferrita espinélica e mudar as propriedades magnéticas das nanopartículas. ${ }^{81,82}$

Uma vez que a ligação de surfactantes à superfície da nanopartícula afetas as propriedades magnéticas, há evidências de que a presença de carboxilatos durante a formação da nanopartícula provoca interferência durante o crescimento do cristal, interferindo no desenvolvimento de forma e tamanho uniformes e com poucos defeitos. ${ }^{83}$

O efeito da adsorção superficial geralmente é investigado por conta de sua presença durante a formação da nanopartícula e do resultado de propriedades magnéticas apresentadas pelo sistema. Estes efeitos são aumentados devido a partícula ter grande área superficial e raio superfície/volume elevado.

\subsection{MÉTODOS QUÍMICOS DE PREPARAÇÃO DA MAGNETITA}

Uma vez que a magnetita encontrada na natureza é de baixa cristalinidade, com cristais nanométricos que não exibem uma morfologia de materiais bem cristalizados, com muitas impurezas e defeitos associados que são resultado das condições de formação encontradas na natureza, como temperatura e $\mathrm{pH}^{84}$ 
De modo a contornar todas estas particularidades, faz-se uso de rotas sintéticas de modo a obter materiais que atinjam padrões adequados à destinação tecnológica a qual se destina.

Dados da literatura mostram uma relação entre o tempo de formação da magnetita e a temperatura. Há um limite de temperatura para a formação de partículas magnéticas, a partir do qual há uma alteração qualitativa na formação da magnetita. ${ }^{76}$

\subsubsection{Coprecipitação}

É uma das técnicas mais usadas na síntese de nanopartículas pela facilidade do procedimento experimental. No caso de materiais de ferro, é feita a partir de misturas de sais de ferro em estados de oxidação diferentes (ferroso e férrico) em soluções alcalinas. ${ }^{85}$ Há diversas variantes da técnica, dependendo do objetivo desejado. ${ }^{29,30}$

Algumas das sínteses também trabalham com modificações de temperatura e modificação superficial para originarem produtos com morfologias diferenciadas. ${ }^{86}$

Nas condições reacionais, observa-se um aumento do tamanho da partícula à medida que aumenta a temperatura ${ }^{69} \mathrm{O}$ limite de temperatura é o da ebulição da água, quando há formação de partículas com baixa cristalinidade e grande polidispersividade. ${ }^{3}$

A distribuição de tamanhos pode ser controlada pelas condições reacionais como a concentração de reagentes, o tipo de base usada, o pH e a força iônica do meio. ${ }^{87-89}$

Uma outra vantagem do método é a pureza do material, uma vez que a quantidade de impurezas é mínima em relação a outros métodos sintéticos. Entre as desvantagens do método, estão a oxidação quando deixados ao ar e a aglomeração das nanopartículas. ${ }^{1}$

\subsubsection{Síntese Hidrotérmica}

Neste tipo de processo, a síntese ocorre em altas temperaturas (em torno de $200^{\circ} \mathrm{C}$ ) em reatores ou autoclaves a elevadas pressões (> $100 \mathrm{~atm}$ ). São conhecidas algumas rotas sintéticas para a formação de ferritas por esse 
processo, entre elas a hidrólise e oxidação de ou neutralização de hidróxidos metálicos mistos.

Uma característica deste método em relação ao tamanho da partícula diz respeito ao controle efetivo pelas velocidades de crescimento e nucleação dos cristais, determinado por fatores como temperatura. ${ }^{31}$

Outra característica deste método é a obtenção de partículas monodispersas e altamente cristalinas. Alguns trabalhos trazem modificações para melhoria das propriedades tais como as magnéticas e hidrofílicas. ${ }^{3,32}$

\subsubsection{Síntese Sonoquímica}

Este tipo de síntese é caracterizado pelo uso de ondas de alta frequência, variando de quilo a mega-hertz, o que provoca formação de bolhas em líquidos, com nucleação, crescimento e coalescência rápida, que permite a conversão de sais de $\mathrm{Fe}^{2+}$ em partículas com magnetismo.

Neste tipo de síntese, o uso de elevadas energias para excitação, pode conduzir a temperaturas muito elevadas em algumas áreas $\left(>5000^{\circ} \mathrm{C}\right) \mathrm{e}$ pressões $\left(>100 \mathrm{~atm}\right.$ ) em períodos curtos de tempo. ${ }^{90}$ Isto pode produzir fases metaestáveis de compostos como o ferro puro em estado amorfo.

As partículas produzidas por esta técnica possuem superfícies muito reativas. A técnica pode ser usada na produção de quantidades grandes de material, o que é de interesse de segmentos industriais. A produção é feita a partir de compostos organometálicos ${ }^{34}$ e alguns tipos de compostos são limitantes ao crescimento das nanopartículas. Entre eles, podem ser citados polímeros, agentes de cobertura orgânicos, agentes estruturais.

\subsubsection{Processos Sol-Gel}

O fundamento da técnica é a hidroxilação e condensação de precursores moleculares em solução, o que origina um sol de partículas de tamanho nanométrico. Ao longo do processo ocorrem condensações e polimerizações que formam óxidos metálicos tridimensionais - gel. Esses processos podem ser feitos a temperaturas ordinárias, mas são necessários aquecimentos posteriores para que o produto adquira o estado cristalino. ${ }^{35}$ 
Há fatores que influenciam alguns parâmetros do material obtido (cinética, crescimento, hidrólise, condensação). Fatores como tipo de solvente, temperatura, concentrações dos precursores, $\mathrm{pH}$ e tipo de sal afetam as propriedades do material. Entre as vantagens da técnica estão a homogeneidade, pureza do material, baixo custo dos materiais usados. ${ }^{36}$

\subsubsection{Métodos de Polióis (Solvotérmica)}

A vantagem deste método é que o material obtido tem formas bem definidas e tamanhos controlados. ${ }^{37,38}$ É semelhante ao processo sol-gel.

Os compostos dessa classe possuem elevadas constantes dielétricas e podem agir como solventes de compostos inorgânicos. Como possuem pontos de ebulição elevados, podem ser usados como materiais no preparo de compostos inorgânicos. Além disso, podem servir como agentes de redução e estabilizantes no controle de crescimento e agregação.

O princípio desta técnica é a suspensão de um precursor em um poliol seguida de agitação e aquecimento em temperatura que seja igual à de ebulição do poliol. Ao longo do processo o precursor sofre solubilização no diol formando intermediários que são reduzidos a núcleo metálicos que formam as partículas metálicas. ${ }^{39}$

\subsubsection{Injeção de Fluxo}

Matrizes como emulsões são usadas na síntese de partículas com distribuição estreita de tamanhos e morfologias. O tipo e geometria do reator podem agir como uma zona de reação diferente.

O princípio da técnica consiste na mistura de reagentes em fluxo laminar em reatores tubulares de dimensão capilar. Entre as vantagens do método, estão a reprodutibilidade e controle externo do processo. ${ }^{1}$

\subsubsection{Eletroquímicos}

O princípio da técnica é a deposição de ferro sob condições oxidantes para preparar óxidos de ferro (maghemita e magnetita). Normalmente, o eletrodo de ferro é colocado em solução aquosa de DMF juntamente com surfactantes catiônicos. ${ }^{1}$ 


\subsubsection{Aerossol e Vapor}

A técnica pode ser usada quando se deseja produção contínua e elevada de material. Pode ser uma pirólise de spray, onde soluções de sais férricos e agentes redutores em solventes orgânicos são colocados em diversos reatores e o aerossol sofre condensação enquanto o solvente sofre evaporação.

No caso de serem usados lasers (pirólise a laser), o volume reacional é menor, pois o laser aquece a mistura gasosa produzindo partículas de tamanho reduzido e sem agregação..$^{1,40}$

\subsubsection{Sínteses em Ambientes Restritos}

Quando se faz uso deste tipo de técnica, os ambientes usados são surfactantes anfotéricos que criam micelas reversas em solventes apolares. Moléculas que formam vesículas podem servir de suporte para a reação. Tal técnica encontra usos em aplicações biológicas que empreguem o uso de nanorreatores sintéticos e biológicos. ${ }^{1}$

\subsubsection{Microemulsão por Zona}

Neste tipo de processo, ocorre o encapsulamento de materiais em microesferas poliméricas. A partir da dissolução de um polímero em pequenas quantidades de solvente com a adição subsequente a um sistema não solvente micelar provoca a precipitação do polímero na forma de micropartículas estáveis. ${ }^{41}$

\subsection{COMPÓSITOS POLIMÉRICOS}

Materiais compósitos, conjugados ou compostos são materiais projetados de modo a conjugar características desejáveis de dois ou mais materiais. ${ }^{91}$ Possuem pelo menos dois componentes ou duas fases, com propriedades físicas e químicas nitidamente distintas, em sua composição.

Observa-se que quando os constituintes do compósito se misturam, formam um composto com propriedades diferentes dos materiais originais e, em alguns casos, o material final apresenta propriedades não existentes nos materiais originais. ${ }^{92}$ 
Entre os exemplos de combinações possíveis, podemos citar metais e polímeros, metais e cerâmicas e polímeros e cerâmicas que encontram uso em diversos campos.

No caso da síntese dos compósitos, os materiais que os compõem são de dois tipos basicamente:

a) Matrizes: podem ser poliméricas, metálicas ou cerâmicas e conferem estrutura ao material compósito através do preenchimento dos espaços vazios que ficam entre os materiais de modo a mantê-los em suas posições relativas.

b) Reforços: podem ser fibras orgânicas, cerâmicas, metálicas, vidro ou madeira, entre tantos outros tipos. Tem a função de realçar propriedades mecânicas, eletromagnéticas ou químicas do material compósito como um todo.

Alguns materiais podem ser coloidais e feitos a partir da incorporação de materiais orgânicos ou inorgânicos que ajudam no melhoramento das propriedades. ${ }^{93}$ Neste cenário, os óxidos de ferro, como a magnetita, encontram aplicações em diversas áreas como sensores, refrigeração magnética, armazenamento de dados, materiais adsorventes, catalisadores, uma vez que podem ser magnéticos.

Quando são adicionados materiais de dimensões abaixo de $100 \mathrm{~nm}$, costuma-se denominá-los nanocompósitos. Em relação à síntese de nanocompósitos à base de magnetita, existem processos diversos como sol-gel, eletroquímicos, deposição química de vapor e pirólise.

Quando as nanopartículas são incorporadas em polímeros sintetizados in situ, os compostos são denominados compósitos magnéticos. Quanto aos compostos poliméricos com propriedades magnéticas, são importantes devido à grande gama de aplicações nas mais diversas áreas como saúde, industrial, catálise, entre outras.

À medida que o comportamento dos materiais nanoparticulados é entendido, novas técnicas de síntese surgem e procuram contornar os problemas inerentes à síntese de tais materiais tais como a degradação do mesmo devido à elevada área, que pode ser feita através de coberturas poliméricas, por exemplo. 
Na literatura, compostos do tipo casca-núcleo (core/shell) são feitos de um núcleo metálico/óxido coberto com uma casca de outro material. A vantagem do uso de sistemas deste tipo são: ${ }^{3}$

1. Proteção ao núcleo de compostos de ferro por uma camada polimérica de modo a evitar a oxidação;

2. A proteção pode ser usada para ajustar a reatividade do núcleo interno.

$\mathrm{Na}$ síntese de nanocompósitos os mesmos podem ser de diferentes formatos, embora os esféricos sejam os preferenciais pela razão área/volume.

$\mathrm{Na}$ literatura são reportados diversos tipos de síntese, que podem envolver precursores orgânicos. ${ }^{94}$ Como exemplo, podemos citar o procedimento de obtenção de compósitos magnéticos híbridos de alumínio e óxido de ferro, cuja síntese consiste da mistura de sais de alumínio e ferro em meio alcalino em contato com quitosana, sob agitação, forma um material híbrido, após a eliminação da matriz orgânica por calcinação com diferentes estequiometrias dependendo das quantidades iniciais de sais.

Neste tipo de material observa-se, ainda, a existência de superparamagnetismo, uma vez que as partículas obtidas têm tamanhos que propiciam o surgimento da propriedade.

Outra aplicação de compósitos magnéticos é na indústria petrolífera, como absorventes em vazamentos de óleo em corpos aquáticos. ${ }^{95}$ Por exemplo, materiais poliméricos a base de lignina, óleo da casca do caju e resinas de formaldeído são empregados para a síntese do compósito com maghemita incorporada ao longo da síntese de modo a dotá-lo de propriedades magnéticas. Aqui o compósito de óxido de ferro magnético é produzido por coprecipitação e adicionado às resinas produzidas por catálise ácida de modo a produzir um material sólido que apresenta bons resultados quanto à capacidade de remoção de petróleo em águas.

\subsubsection{Nanopartículas de Magnetita Ligadas a Superfície de Partículas Poliméricas}

Uma outra abordagem para os compostos magnéticos é a adsorção de nanopartículas na superfície de polímeros. O método de síntese inclui a preparação de nanopartículas aniônicas de óxido de ferro juntamente com catiônicas do polímero; a adsorção das partículas aniônicas do óxido à superfície 
do polímero e a encapsulação das partículas magnéticas cobertas no polímero. ${ }^{96-98}$

\subsection{CARACTERIZAÇÃO DE NANOPARTÍCULAS MAGNÉTICAS}

\subsubsection{Análise de FTIR: Interação do ácido oleico com a Superfície da Magnetita}

A análise via infravermelho pode ser usada no entendimento do tipo de interação que ocorre entre o ácido oleico e a superfície da nanopartícula de magnetita, uma vez que durante a estabilização surge uma interação covalente observável espectroscopicamente.

O grupo carboxilato ( $\mathrm{COO}^{-}$) do ácido oleico apresenta uma banda característica de estiramento em $1710 \mathrm{~cm}^{-1}$, e ao se ligar à magnetita, ocorre uma mudança na absorção do grupo, com uma redução de frequência de absorção com um alargamento da banda e isto pode ser visto em $1600 \mathrm{~cm}^{-1}$ por conta do estiramento antissimétrico do grupo COO- ${ }^{-79}$

Em relação à adsorção de água e hidroxilas na superfície de nanopartículas, a absorção ocorre em $3440 \mathrm{~cm}^{-1}$ e $3380 \mathrm{~cm}^{-1}$, respectivamente. Há estudos na literatura sobre o modo de adsorção do grupo carboxilato à superfície da magnetita por uma configuração quelante bidentada, uma vez que o $\mathrm{Fe}^{3+}$ é um ácido de Lewis. Neste caso há uma banda que aparece em 1520 $\mathrm{cm}^{-1}$ (assimétrico) e $1425 \mathrm{~cm}^{-1}$ (simétrico). Uma banda fraca é observada entre 1560-1580 $\mathrm{cm}^{-1}$ por conta do oleato ligando-se de modo bidentado.

A interação dos carboxilatos-metais pode ser caracterizada por quatro tipos diferentes: monodentado, bidentado (ponte ou quelante) e interação iônica.
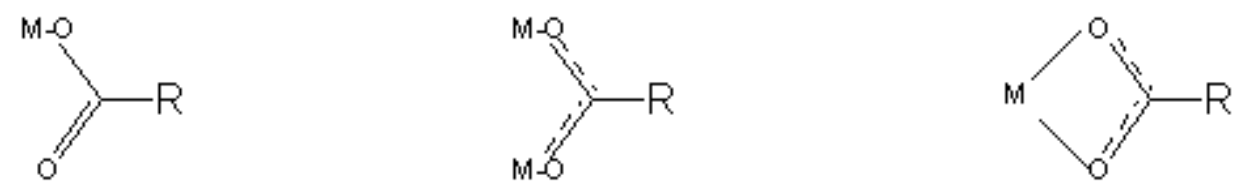
a) monodentado
b) bidentado
c) ponte

Figura 2.5. Tipos de interação entre carboxilatos e metais. ${ }^{99}$ 
As Tabelas 2.5 a 2.8 ilustram típicas absorções e seus comprimentos de ondas característicos, observados para a magnetita pura e modificada, e para os materiais poliméricos obtidos via reações de polimerização em suspensão.

Tabela 2.5. Vibrações de absorção na região espectral de infravermelho da magnetita. ${ }^{100,101}$

\begin{tabular}{|l|l|l|}
\hline $\begin{array}{c}\text { Tipo de } \\
\text { deformação }\end{array}$ & $\begin{array}{c}\text { Absorção } \\
\left(\mathbf{c m}^{-1}\right)\end{array}$ & \multicolumn{1}{c|}{ Tipo de ligação avaliada } \\
\hline Estiramento & $3200-3600$ & $\begin{array}{l}\text { v(O-H) da água ou do H ligado de grupos } \mathrm{OH} \text { (do ácido } \\
\text { oleico) }\end{array}$ \\
\hline Estiramento & 580 & $\begin{array}{l}\text { Pico característico, estiramento da ligação Fe-O do sitio } \\
\text { tetraédrico }\end{array}$ \\
\hline Estiramento & 400 & $\begin{array}{l}\text { Pico característico, estiramento da ligação Fe-O do sitio } \\
\text { octaédrico }\end{array}$ \\
\hline
\end{tabular}

Tabela 2.6: Vibrações de absorção na região espectral de infravermelho da magnetita, maguemita e hematita ${ }^{100,101}$

\begin{tabular}{|l|l|}
\hline Composto & \multicolumn{1}{|c|}{ Absorção $\mathbf{( c m}^{-1}$ ) } \\
\hline Magnetita & $\begin{array}{l}566(500-700) \text { (Banda, fraca) } \\
404 \text { (300-500) (Banda larga, fraca) }\end{array}$ \\
\hline Maguemita & $\begin{array}{l}1790 \text { (banda muito fraca, 690 (forte), 628 (forte), 550 (muito forte), 475 } \\
\text { (fraca). 437 (fraca), 418 (muito fraca), 386 (forte), 3611 (muito fraca) }\end{array}$ \\
\hline Hematita & 535 (forte), 464 (Média), 308 (fraca) \\
\hline
\end{tabular}

Tabela 2.7 Vibrações de absorção na região espectral de infravermelho da magnetita modificada (recoberta) com ácido oleico.

\begin{tabular}{|c|c|c|}
\hline $\begin{array}{c}\text { Tipo de } \\
\text { deformação } \\
\text { (axial simétrica } \\
\text { ou assimétrica) }\end{array}$ & $\begin{array}{l}\text { Absorção } \\
\left(\mathrm{cm}^{-1}\right)\end{array}$ & Tipo de ligação avaliada \\
\hline Estiramento & 457,626 e 695 & $\mathrm{Fe}-\mathrm{O}$ \\
\hline Estiramento & 3391 & $\mathrm{Fe}-\mathrm{OH}$ \\
\hline Dobramento & 1406 & C-H do ácido oleico \\
\hline Dobramento & 1466 & $\mathrm{C}=\mathrm{C}$ do ácido oleico \\
\hline Estiramentos & $\begin{array}{l}3005, \quad 2852 \\
2923 \text { e } 2954\end{array}$ & $\begin{array}{l}\text { Vibração do } \mathrm{CH}=\text { cis, que é assimétrico em } \\
\text { relação a } \mathrm{CH}_{3} \text { e } \mathrm{CH}_{2} \text { e simétrico em relação a } \\
\mathrm{CH}_{2} \text { respectivamente }\end{array}$ \\
\hline Estiramentos & 1530 & $\begin{array}{l}\text { Grupo carboxilato do } A O \text { na superfície da } \\
\text { magnetita }\end{array}$ \\
\hline Estiramentos & 2922 ( banda) & $\begin{array}{l}\text { Deslocamento do estiramento assimétrico de } \\
\mathrm{CH}_{2}\end{array}$ \\
\hline Estiramentos & 2852( banda) & Deslocamento do estiramento simétrico de $\mathrm{CH}_{2}$ \\
\hline Estiramentos & 1050 (forte) & $\begin{array}{l}\text { Estiramento da ligação } \mathrm{C}-\mathrm{O} \text {, o que mostra que } \\
\mathrm{AO} \text { é quimissorvido nas partículas de } \mathrm{Fe}_{3} \mathrm{O}_{4} \\
\text { como carboxilato. }\end{array}$ \\
\hline
\end{tabular}


Tabela 2.8 Vibrações de absorção na região espectral de infravermelho do ácido oleico. ${ }^{102}$

\begin{tabular}{|l|l|l|}
\hline $\begin{array}{c}\text { Tipo de } \\
\text { deformação }\end{array}$ & \multicolumn{1}{|c|}{$\begin{array}{c}\text { Absorção } \\
\left(\mathbf{c m}^{-1}\right)\end{array}$} & \multicolumn{1}{c|}{ Tipo de ligação avaliada } \\
\hline Estiramentos & 3710 e 2700 & Estiramento O-H \\
\hline Estiramentos & 2924 e 2854 & Estiramentos $\mathrm{CH}_{2}$ assimétrico e simétrico \\
\hline Estiramento & 1710 (Pico intenso) & Derivado do estiramento $\mathrm{C}=\mathrm{O}$ \\
\hline Estiramento & 1285 (banda) & Presença de estiramento C-O \\
\hline Bending & 1462 e 937 (bandas) & $\begin{array}{l}\text { O-H no plano } \\
\text { O-H fora do plano }\end{array}$ \\
\hline
\end{tabular}

\subsubsection{Difração de raios $X$}

A determinação de estruturas cristalinas é feita a partir da difração de raios $X$ para obter o espaçamento da rede cristalina da amostra. A estrutura apresenta elementos de simetria em relação aos planos, eixos e centros. São descritos em função dos índices hkl de Miller.

A fonte de radiação pode ser CoKa ou FeKa. CuKa pode ser usada embora o ferro absorva a radiação e leve a redução na intensidade da radiação ${ }^{84}$.

A intensidade dos picos pode ser usada na quantificação dos tipos de óxido de ferro presentes na amostra por comparação com os padrões de referência.

Tabela 2.9. Picos característicos de alguns óxidos de ferro. ${ }^{103}$

\begin{tabular}{|l|l|l|l|l|l|l|l|l|}
\hline Composto & \multicolumn{10}{|c|}{ Valores dos picos } \\
\hline $\begin{array}{l}\mathrm{Hematita} \\
\left(\alpha-\mathrm{Fe}_{2} \mathrm{O}_{3}\right)\end{array}$ & 28 & 39 & 42 & 48 & 58 & 64 & 74 & 76 \\
\hline $\begin{array}{l}\text { Magnetita } \\
\left(\mathrm{Fe}_{3} \mathrm{O}_{4}\right)\end{array}$ & 21 & 35,6 & 43,3 & 53,4 & 57,3 & 62,8 & 74,3 & \\
\hline $\begin{array}{l}\text { Maguemita } \\
\left(\gamma-\mathrm{Fe}_{2} \mathrm{O}_{3}\right)\end{array}$ & 27 & 35 & 38 & 41 & 47 & 50 & 58 & 63 \\
\hline
\end{tabular}

O tamanho do cristal pode ser calculado a partir dos padrões de raios $X$ usando a fórmula de Debye-Scherer, onde DoRx representa o tamanho médio do cristalito, $\mathrm{k}$ é uma constante associada ao formato da partícula e tem valor normalmente igual a 0,9. $\lambda$ é o comprimento de onda da radiação CuKa (igual a $0,1542 \mathrm{~nm}), \beta$ é a largura a meia altura do pico de maior intensidade [correspondente à reflexão (311)] e $\theta$ é relacionado ao ângulo de difração de Bragg ${ }^{68}$.

$$
D_{h k l}=\frac{K \lambda}{b \cos \theta}
$$




\subsubsection{Microscopia de transmissão eletrônica (MET/TEM)}

Uma outra técnica que possibilita o tamanho de partículas a partir das micrografias e permite determinar a distribuição de tamanhos de partículas. A distribuição de tamanho pode ser calculada a partir da equação a seguir.

$$
p_{d}=\frac{1}{D p_{d} \sqrt{2 \pi}} \exp \left(\ln \frac{D}{D_{o}}\right)^{2}
$$

Onde: $\rho_{d}=$ desvio padrão do diâmetro; $D$ = Diâmetro, $D_{o}=$ diâmetro médio.

Quadro 2.5. Outros métodos de caracterização de nanopartículas magnéticas.

\begin{tabular}{|l|l|l|}
\hline \multicolumn{1}{|c|}{ Método } & \multicolumn{1}{|c|}{ Sigla } & \multicolumn{1}{c|}{ O que determina } \\
\hline $\begin{array}{l}\text { Espectroscopia de energia } \\
\text { dispersiva }\end{array}$ & EDS & $\begin{array}{l}\text { Espaçamento de rede, tamanho de } \\
\text { partícula, estrutura do composto e } \\
\text { cristalinidade }\end{array}$ \\
\hline Análise termogravimétrica & TGA & \% de magnetita na amostra \\
\hline
\end{tabular}

\subsubsection{Espectroscopia Raman}

Este tipo de espectroscopia usa o espalhamento da luz e as vibrações moleculares que são geradas para entender o tipo de estrutura, a simetria, o ambiente eletrônico e os tipos de ligações presentes na estrutura, permitindo uma análise qualitativa dos compostos. ${ }^{104}$

O efeito Raman traz informações complementares ao infravermelho e são as duas técnicas mais importantes na observação vibracional do espectro. ${ }^{105} \mathrm{O}$ fundamento da técnica é o espalhamento inelástico da radiação por amostras sólidas, liquidas ou gasosas, onde os fótons sofrem excitação ou desativação.

Nesta técnica, as regras de seleção são diferentes das do infravermelho uma vez que os sinais associados às vibrações de moléculas provocam alterações na polarizabilidade de moléculas. Grupos como -C-X $(X=\mathrm{F}, \mathrm{Cl}, \mathrm{Br}$, I), $-\mathrm{C}-\mathrm{NO}_{2},-\mathrm{C}-\mathrm{S}-,-\mathrm{S}-\mathrm{S}-,-\mathrm{C}=\mathrm{C}-,-\mathrm{C}=\mathrm{S}-,-\mathrm{N}=\mathrm{N}-,-\mathrm{S}-\mathrm{H}-,-\mathrm{CN}$, entre outros dão sinais intensos.

A emissão é fraca mas variações da técnica podem amplificá-la em diversas ordens de magnitude quando o comprimento de onda da fonte usada, normalmente um laser, é semelhante ao da banda de absorção eletrônica, num efeito de ressonância. ${ }^{106}$ 
Entre as vantagens da técnica, estão a possibilidade de realização de amostras in situ, com resultados imediatos e não destrutivos e a não interferência da agua no sistema. ${ }^{107}$

A estrutura da magnetita, que pertence ao grupo espacial Fd3m $\left(\mathrm{O}^{7} \mathrm{~h}\right)$, com uma célula cristalina de 56 átomos, o que possibilita 42 modos vibracionais diferentes. A partir da análise de teoria de grupos, podemos ter os seguintes modos:

$$
\mathrm{A}_{1 g}+\mathrm{E}_{g}+\mathrm{T}_{1 \mathrm{~g}}+3 \mathrm{~T}_{2 \mathrm{~g}}+2 \mathrm{~A}_{2 \mathrm{u}}+2 \mathrm{E}_{\mathrm{u}}+5 \mathrm{~T}_{1 \mathrm{u}}+2 \mathrm{~T}_{2 \mathrm{u}}
$$

Destes modos, $T_{1 g}, A_{2 u}, E_{u}, T_{2 u}$ são inativos, restando 5 modos vibracionais no espectro Raman $\left(A_{1 g}+E_{g}+T_{2 g}\right)$ e mais 5 no infravermelho(5T $\left.T_{1 u}\right) .{ }^{108}$ Os valores vibracionais para a magnetita, maguemita e hematita são os seguintes:

Tabela 2.10: Números de onda observados para a magnetita com os fônons ativos. ${ }^{100,103,109-111}$

\begin{tabular}{|c|c|c|c|}
\hline Observado $\left(\mathrm{cm}^{-1}\right)$ & Espécie de simetria & Atividade & Íon responsável \\
\hline 210 & $\mathrm{~T}_{1 \mathrm{u}}(1)$ & $\mathrm{IR}$ & $A, B, O$ \\
\hline 193 (fraca) & $T_{2 g}(1)$ & Raman & $\mathrm{A}, \mathrm{O}$ \\
\hline 308 (fraca) & $\mathrm{T}_{2 g}(2)$ & Raman & 0 \\
\hline 270 & $\mathrm{~T}_{1 \mathrm{u}}(2)$ & IR & $A, B, O$ \\
\hline 350 & $\mathrm{~T}_{1 \mathrm{u}}(3)$ & IR & $\mathrm{A}, \mathrm{B}, \mathrm{O}$ \\
\hline 540 (fraca) & $T_{2 g}(3)$ & Raman & $\mathrm{A}, \mathrm{O}$ \\
\hline 560 & $T_{1 u}(4)$ & $\mathrm{IR}$ & $A, B, O$ \\
\hline 670 (forte) & $A_{1 g}$ & Raman & \\
\hline
\end{tabular}

Há dificuldades na correta atribuição dos fônons para a magnetita, uma vez que a intensidade do laser usado interfere na análise de dados devido ao aquecimento que provoca a transformação da magnetita em hematita e maguemita. ${ }^{109}$

Alguns dos fônons aparecem em amostras especificas, uma vez que podem resultar de modos de ativação não previstos na teoria de grupos, como compostos nãos estequiométricos, presença de defeitos, vacâncias de rede e cátions intersticiais. ${ }^{110}$ 
Tabela 2.11. Números de onda observados para a maguemita $\left(\gamma-\mathrm{Fe}_{2} \mathrm{O}_{3}\right)$ com os fônons ativos. ${ }^{103,109}$

\begin{tabular}{|l|l|l|l|}
\hline Observado $\mathbf{( c m}^{-1}$ ) & Espécie de simetria & Atividade & ĺon responsável \\
\hline & $\mathrm{T}_{2}(1)$ & $\mathrm{IR}$ & $\mathrm{Fe}+\mathrm{O}$ (estrutura larga) \\
\hline 350 (forte) & $\mathrm{T}_{1}(1)$ & Raman & $\mathrm{Fe}+\mathrm{O}$ (estrutura larga) \\
\hline 319 & $\mathrm{~T}_{2}(2)$ & $\mathrm{IR}$ & $\mathrm{Fe}+\mathrm{O}$ \\
\hline 440 & $\mathrm{~T}_{2}(3)$ & $\mathrm{IR}$ & $\mathrm{Fe}+\mathrm{O}$ \\
\hline 500 (forte) & $\mathrm{E}(3)$ & Raman & $\mathrm{Fe}+\mathrm{O}$ (estrutura larga) \\
\hline 553 & $\mathrm{~T}_{2}(4)$ & $\mathrm{IR}$ & $\mathrm{Fe}+\mathrm{O}$ \\
\hline 700 (forte) & $\mathrm{A}_{1}$ & Raman & $\mathrm{Fe}+\mathrm{O}$ (estrutura larga) \\
\hline
\end{tabular}

Há uma redução na simetria que segue a sequência

$$
\mathrm{Fe}_{3} \mathrm{O}_{4}>\gamma-\mathrm{Fe}_{2} \mathrm{O}_{3}>\alpha-\mathrm{Fe}_{2} \mathrm{O}_{3},
$$

o que gera um aumento no número de fônons ativos no Raman, que podem ser explicados devido ao aquecimento, que provoca transições de fase.

\subsection{APLICAÇÕES DE NANOPARTÍCULAS DE MAGNETITA $\left(\mathrm{FE}_{3} \mathrm{O}_{4}\right)$}

As aplicações de nanopartículas magnéticas de $\mathrm{Fe}_{3} \mathrm{O}_{4}$ podem ser encontradas nas seguintes áreas:

\subsubsection{Biomédicas}

Neste caso são necessárias partículas que possuam altos valores de magnetização, tamanhos menores que $100 \mathrm{~nm}$ e distribuições de tamanho de partículas estreitas. Além disso, deve-se fabricar uma estrutura que não seja agressiva ao corpo humano e para isso as partículas devem ser atóxicas e biocompatíveis de modo que as coberturas de partículas são necessárias para este tipo de aplicação. ${ }^{1}$

\subsubsection{Sensores}

Nanopartículas podem ser usadas na melhoria de limites de detecção em diversos métodos como métodos fluorimétricos, de detecção elétrica e magnética e gravimétrica, entre outros. ${ }^{11}$ 


\subsubsection{Carreadores de Drogas}

A aplicação de drogas ao longo de tratamentos médicos traz muitos inconvenientes devido a problemas com solubilidade dos materiais no organismo, os danos colaterais a tecidos e órgãos sãos, perda rápida de atividade dos compostos, problemas farmacocinéticos com a droga e a falta de seletividade dos compostos, entre outros.

Sistemas de transporte de drogas (DDS - drug delivery systems) baseados em nanopartículas associadas a biomoléculas ou polímeros surgiram como uma tentativa de se resolver várias das dificuldades citadas anteriormente no tratamento de diversas moléstias.

Com o uso deste tipo de sistemas, há uma melhora nas propriedades farmacocinéticas e na biodistribuição, uma vez que a dose da droga pode ser controlada para liberação lenta ao invés de entrar no sistema corporal rapidamente e ser excretada em pouco tempo. ${ }^{15}$

\subsubsection{Tratamento de Tumores por Hipertermia}

As primeiras referências ao uso de tratamentos por hipertermia reportados na literatura datam da década de 1960 no tratamento de câncer. ${ }^{13}$ Neste tipo de abordagem, o princípio da técnica é a diferença de comportamento entre células sadias e as doentes em relação aos efeitos térmicos. ${ }^{12}$

São usadas nanopartículas "tunadas", isto é, preparadas para que tenham um efeito térmico controlável de modo que não formem pontos muito quentes dentro do organismo e que possam prejudicá-lo ao longo do tratamento. ${ }^{14}$

Contudo, há diversas questões sendo estudadas ainda a respeito do uso de nanopartículas tais como: biocompatibilidade e resistência tissular a nanopartículas, facilidade de carreadores nanométricos, entre outros.

\subsubsection{Agentes de Contraste em Imagem por Ressonância Magnética (MRI)}

Um dos grandes problemas na área de diagnósticos médicos diz respeito à necessidade de procedimentos invasivos. Neste ponto, os métodos que usam agentes de contraste se tornam interessantes, uma vez que são métodos não invasivos, trazem informações em tempos muito pequenos e dão informações detalhadas sobre tecidos moles em organismos. ${ }^{9}$ 
Para uso neste tipo de aplicação, as partículas dependem das características das partículas utilizadas, notadamente partículas de tamanho nanométrico $(<20 \mathrm{~nm})$ e grandes momentos magnéticos. ${ }^{8}$

\subsubsection{Agentes Ativos no Diagnóstico de Doenças}

Quando se faz uso de agente de diagnóstico para doenças, durante o processo de aplicações biológicas são levados em conta cuidados como a dispersibilidade em água no $\mathrm{pH}$ semelhante ao do organismo humano e a proteção das moléculas com materiais atóxicos de modo a evitar efeitos colaterais aos usuários do produto.

No caso do organismo humano, é interessante que no tratamento da hipertermia as partículas sejam transportadas até o local e lá ativadas com campos externos, neste caso, há o problema de tamanho da partícula versus magnetização, uma vez que moléculas maiores tem maiores valores de magnetização porém têm mais dificuldade de transporte ao longo do percurso e tendem a se aglomerar. ${ }^{10}$

\subsubsection{Aplicações Tecnológicas}

\subsubsection{Meio Ambiente}

Em termos de aplicações ambientais, podemos citar o uso de nanopartículas como materiais absorventes de cátions metálicos no meio ambiente. Devido às propriedades absorventes e magnéticas, nanopartículas de $\mathrm{Fe}_{3} \mathrm{O}_{4}$ mostram-se materiais com boa capacidade de adsorção de cátions metálicos e, por isso, podem ser usadas em remediação ambiental na captura de efluentes na forma gasosa ou em solução. ${ }^{5}$

Nanopartículas podem ser usadas também na recuperação de metais pesados do ambiente por adsorção, uma vez que se mostram economicamente viáveis no tratamento de efluentes. ${ }^{6,7}$

\subsubsection{Catalisadores}

$\mathrm{Na}$ literatura há diversas aplicações de nanopartículas como catalisadores, uma vez que podem ser recobertas e dispersas em solventes 
orgânicos. A vantagem de seu uso vem de suas propriedades como a elevada área superficial e a facilidade de remoção ao final da reação, o que reduz custos. Podem ser usados em sínteses assimétricas enancioseletivas, ${ }^{16}$ catalisadores de $\mathrm{H}_{2} \mathrm{O}_{2}$ por reação de Fenton, ${ }^{18,17}$ produção de estireno por desidrogenação de etilbenzeno, processo de Fischer-Tropsch. ${ }^{20,19}$

\subsection{EMBOLOTERAPIA}

O termo significa a oclusão intencional de um vaso por entrada de material estranho com intenção de reduzir o calibre do vaso e reduzir ou interromper o fluxo através do mesmo. A técnica se apoia em elementos como a seleção do agente adequado, a aplicação clínica e a perícia. ${ }^{20,21}$

A técnica tem quase 100 anos e ressurgiu como um tratamento durável para lesões vasculares de diversos tipos. Entre suas vantagens estão 0 acesso seguro e fácil em locais de lesões de difícil acesso. É um tratamento pouco invasivo e usado em situações onde a cirurgia não é aconselhável. ${ }^{22}$

$O$ procedimento pode ser usado em terapia anticâncer por isquemia, 0 que resulta em uma necrose do tumor. $O$ efeito é potencializado pelo tratamento conjunto com quimioterápicos (quimioembolização). Outra possibilidade de uso é no controle de hemorragias severas devido a tumores que possam afetar 0 funcionamento do organismo. ${ }^{21}$

Alguns biomateriais usados na embolização líquida possuem o cuidado de serem usados com a mínima invasividade em tratamentos por imageamento de lesões vasculares. Quando são injetados, ocorrem modificações que podem levar a formação de materiais sólidos e estes processos incluem polimerizações, precipitações, formação de ligações cruzadas por processos térmicos ou iônicos.

Quando estes materiais chegam ao sítio de atuação, provocam tromboses ou bloqueios na lesão à medida que a cimentação do material ocorre. Para evitar efeitos colaterais, devem ser levadas em conta a biocompatibilidade, a biodegradabilidade e as propriedades biomecânicas dos materiais usados.

Como o diâmetro de pequenos capilares se situa em torno de 5-8 $\mu \mathrm{m}$, é interessante que o embolizante tenha partículas de tamanho superior a $10 \mu \mathrm{m}$ para que o tratamento seja eficiente. ${ }^{23} \mathrm{Em}$ relação ao tamanho e forma, 
embolizantes irregulares podem aglomerar-se em veias de maior calibre. Se forem elásticas possuem um alcance maior no interior dos vasos.

A vantagem do uso de líquidos embólicos em relação a outras técnicas usadas (serpentinas, balões e partículas) reside no fato de formarem géis que enchem o espaço totalmente no interior da lesão. São usados diversos materiais que possuam biocompatibilidade como o poli(álcool vinílico) (PVA), gelatinas esponjosas, microesferas de amido ou colágeno. ${ }^{23}$

Alguns polímeros possuem efeitos indesejáveis como a agregação e formação de massas irregulares que podem levar ao entupimento dos cateteres utilizados. Assim, há uma limitação na capacidade de penetração do material na lesão. Este é um dos desafios a serem resolvidos neste tipo de terapia. ${ }^{23,24}$

Partículas de óxido de ferro superparamagnéticas sofrem degradação rápida em ambientes oxidantes ou em sistemas biológicos, sofrendo aglomeração e alterações nas propriedades magnéticas. Para aplicações em sistemas biológicos, é necessário que apresentem propriedades compatíveis e que sejam funcionalizadas de modo a serem protegidas do meio.

Devido a esta necessidade, normalmente são recobertas com moléculas hidrofílicas como dextranas, quitosanas e outras. ${ }^{25} \mathrm{Em}$ relação aos efeitos dos embolizantes, podemos classificá-los diversos modos, de acordo com o nível de oclusão e mecanismo, como exemplifica o quadro 2.6. 
Quadro 2.6. Tipos de agentes embólicos. ${ }^{74}$

\begin{tabular}{|c|c|c|c|c|c|}
\hline $\begin{array}{l}\text { Tipo de } \\
\text { agente }\end{array}$ & Material & $\begin{array}{l}\text { Tamanho de } \\
\text { partícula }\end{array}$ & Aplicação & Vantagens e Desvantagens & Ref. \\
\hline \multirow[b]{2}{*}{ Temporário } & $\begin{array}{l}\text { Agente de } \\
\text { autotransplante }\end{array}$ & $2-30 \mathrm{~mm}$ & $\begin{array}{l}\text { Interromper } \\
\text { sanguíneo. }\end{array}$ & $\begin{array}{l}\begin{array}{l}\text { Barato, oferece } \\
\text { decomposição. }\end{array} \\
\text { deco }\end{array}$ & 112,113 \\
\hline & $\begin{array}{l}\text { Esponjas de } \\
\text { gelatina } \\
\text { reabsorvível } \\
(\text { gelfoam } ®)\end{array}$ & $\begin{array}{l}\text { Compressa } \\
\text { ou pó. } 0,5 \text { a } 2 \\
\mathrm{~mm}\end{array}$ & $\begin{array}{l}\text { Controle temporário de } \\
\text { vasos, usado em } \\
\text { traumas. }\end{array}$ & $\begin{array}{l}\text { Administrável como pó ou pasta. Pode ocorrer } \\
\text { embolização distal (longe do sitio) com isquemia } \\
\text { (supressão de circulação sanguínea). Recanalização } \\
\text { em tempo curto (4-6 semanas) }\end{array}$ & 112,113 \\
\hline \multicolumn{6}{|l|}{ Permanentes } \\
\hline \multirow{3}{*}{ Sólidos } & Serpentinas & & $\begin{array}{l}\text { Aneurisma, } \\
\text { completa de grandes } \\
\text { vasos. }\end{array}$ & $\begin{array}{l}\text { Há diversos tipos, deve-se escolher o mais adequado, } \\
\text { barato e de fácil uso. Formação de vasos colaterais }\end{array}$ & $\begin{array}{l}21,112 \\
113,114\end{array}$ \\
\hline & Plugues & & $\begin{array}{l}\text { Oclusão completa do } \\
\text { vaso com pouco produto. }\end{array}$ & $\begin{array}{l}\text { Normalmente usados com serpentina e partículas } \\
\text { para gerar trombose. Deve-se saber o tamanho } \\
\text { adequado. }\end{array}$ & 112,113 \\
\hline & Balões & & $\begin{array}{l}\text { Oclusão permanente de } \\
\text { vasos grandes. }\end{array}$ & $\begin{array}{l}\text { Pouco usado por conta da disponibilidade de } \\
\text { serpentinas e plugues. }\end{array}$ & 112,113 \\
\hline \multirow[b]{2}{*}{ Particulados } & $\begin{array}{l}\text { poli(álcool } \\
\text { vinílico) (PVA) }\end{array}$ & $\begin{array}{l}150-1000 \\
\mu \mathrm{m}\end{array}$ & $\begin{array}{llr}\text { Oclusão } & \text { simples ou } \\
\text { múltipla de pequenos } \\
\text { vasos, } \\
\text { tumores. }\end{array}$ & $\begin{array}{l}\text { Variedade de tamanhos: deve-se evitar a oclusão de } \\
\text { cateter ou embolização de outros locais. Ocorrem } \\
\text { modificações na morfologia por conta da calcificação } \\
\text { no organismo. }\end{array}$ & $\begin{array}{l}112,113 \\
115,116 \\
117\end{array}$ \\
\hline & $\begin{array}{l}\text { Microesferas } \\
\text { compressíveis }\end{array}$ & & $\begin{array}{l}\text { Usada em embolização } \\
\text { uterina, } \\
\text { quimioembolização } \\
\text { transarterial para } \\
\text { oclusão de vasos } \\
\text { pequenos. }\end{array}$ & $\begin{array}{l}\text { Mais caro que PVA, verificação de tamanho é } \\
\text { importante. Tem uma penetração melhor que o PVA } \\
\text { por conta da não agregação e superfície hidrofílica e } \\
\text { elasticidade. }\end{array}$ & $\begin{array}{l}24,118 \\
119,120\end{array}$ \\
\hline Líquidos & Trombina & & $\begin{array}{l}\text { Para pseudoaneurismas, } \\
\text { serpentinas saturadas } \\
\text { antes de coagulação. }\end{array}$ & $\begin{array}{l}\text { Deve-se evitar refluxo ao injetar e provocar } \\
\text { embolização distal. }\end{array}$ & 112,113 \\
\hline
\end{tabular}




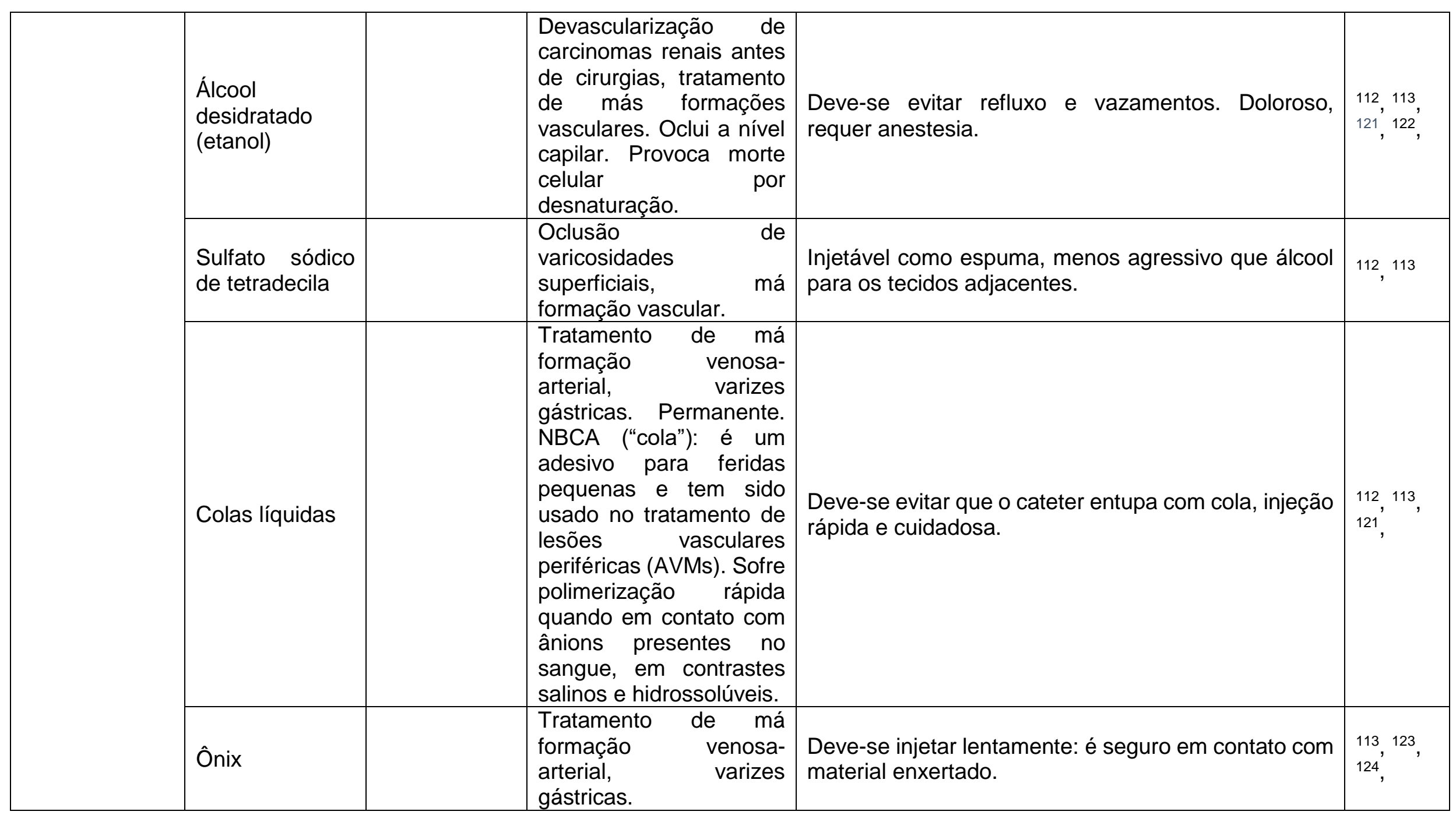




\subsection{TOXIDEZ DA MAGNETITA}

Em sistemas biológicos a magnetita normalmente é encapsulada em proteínas de modo a torna-la atóxica. ${ }^{125}$ Há estudos sobre a toxidez de nanopartículas ligadas a citrato. Em relação à $L D_{50}$, o valor encontrado é de 400 $\mathrm{mg} / \mathrm{kg}$.

\subsection{POLÍMEROS E PROCESSOS DE POLIMERIZAÇÃO}

Polímeros são macromoléculas, de elevada massa molar, formadas pela repetição de unidades estruturais menores (meros), cujo tamanho de cadeia pode facilmente alcançar centenas ou milhares de unidades méricas, dependendo do tipo de sistema de polimerização empregado. Uma gama enorme de polímeros sintéticos pode ser obtida via polimerização de um número enorme de monômeros caracterizados por apresentar grupos funcionais reativos ou duplas ligações susceptíveis a reação química.

Historicamente os diversos tipos de polímeros (ou reações envolvidas durante a síntese) podem ser classificados de duas formas, levando em consideração: i) estrutura (arquitetura) molecular, e ii) mecanismo de polimerização. ${ }^{126}$

A classificação com base na arquitetura macromolecular tem como base fundamental as diferenças composicionais observadas entre o polímero e os monômeros precursores. Neste sentido, são considerados polímeros de condensação, macromoléculas provenientes da reação entre monômeros multifuncionais (dois ou mais grupos), cuja reação de condensação ocorre com

a eliminação de pequenas moléculas, como por exemplo, a água. Um exemplo desse tipo de reação á a condensação de diaminas e diácidos com eliminação de água, que segue o seguinte esquema abaixo:

$$
\mathrm{H}_{2} \mathrm{~N}-\mathrm{R}_{1}-\mathrm{NH}_{2}+\mathrm{NHO}_{2} \mathrm{C}-\mathrm{R}_{2}-\mathrm{CO}_{2} \mathrm{H} \quad \rightarrow \quad \mathrm{H}_{2} \mathrm{~N}-\mathrm{R}_{1}-\mathrm{NH}_{2}+\mathrm{NHO}_{2} \mathrm{C}-\mathrm{R}_{2}-\mathrm{CO}_{2} \mathrm{H}+\mathrm{H}_{2} \mathrm{O}
$$

Esquema 2.1. Reação para produção do nylon-66 a partir da diamina de hexametileno e do ácido adípico. 
Ainda com base na distinção quanto à arquitetura macromolecular, são considerados polímeros de adição, macromoléculas formadas através de reações poliméricas de monômeros vinílicos nas quais não ocorre a eliminação de pequenas moléculas.

No caso particular dos polímeros de adição, as unidades de repetição (mero) apresentam composição similar à do monômero de origem. Tais polímeros derivam de monômeros contendo duplas ligações $C=C$, que são conhecidos como monômeros vinílicos (vinil significa $\mathrm{CH}_{2}=\mathrm{CH}$ - ligado a outro substituinte, como por exemplo, $\mathrm{H}$, alquila, arila, nitrila, éster, ácido, cetona, éter e halogênio).

Polímeros de adição são formados por reações de monômero(s) com eliminação da dupla e formação de ligações simples, podendo ser representado de forma simplificada como:

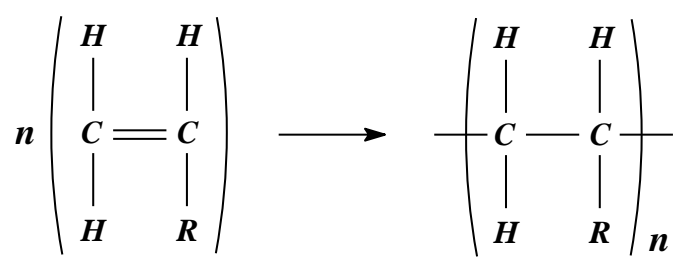

Esquema 2.2. Representação simplificada da reação envolvendo monômeros vinílicos.

De acordo com o mecanismo de polimerização, as reações de polimerização são comumente classificadas em i) polimerização em etapas, e ii) polimerização em cadeia (crescimento de cadeia). A despeito das diferenças significativas observadas entre as polimerizações em etapa e crescimento de cadeia, a forma como as moléculas de monômero(s) se combinam (e consequentemente são incorporadas a cadeia polimérica) consiste na diferença fundamental entre estes dois mecanismos.

No caso particular das reações em etapa, espécies oligoméricas (dímeros, trímeros, tetrâmeros, etc.) ao se combinarem dão origem a cadeias poliméricas de maior tamanho. A reação ocorre entre as espécies presentes no sistema reacional independentemente do tamanho que estejam, como ilustra o esquema 2.3. 


$$
\begin{aligned}
& \text { Monômero }+ \text { Monômero } \longrightarrow \text { Dímero } \\
& \text { Dímero }+ \text { Monômero } \longrightarrow \text { Trímero } \\
& \text { Dímero }+ \text { Dímero } \longrightarrow \text { Tetrâmero } \\
& \text { Trímero }+ \text { Monômero } \longrightarrow \text { Tetrâmero } \\
& \text { Trímero }+ \text { Dímero } \longrightarrow \text { Pentâmero } \\
& \text { Tetrâmero }+ \text { Dímero } \longrightarrow \text { Hexâmero } \\
& \text {..... etc }
\end{aligned}
$$

Esquema 2.3. Representação simplificada da reação de polimerização em etapas.

A reação entre grupos funcionais é característica das reações de polimerização em cadeia. Vale salientar que a funcionalização das cadeias poliméricas formadas favorece sobremaneira a reação entre espécies reativas de diferentes tamanhos, com características de reação do tipo cadeia-cadeia (polímero-polímero).

Embora por razões práticas tais polimerizações sejam conduzidas na presença de catalisadores, reações de policondensação ${ }^{1}$ autocatalíticas (na ausência de catalisadores) também ocorrem.

Reações de polimerização em cadeia são caracterizadas pela adição (incorporação) sucessiva de moléculas de monômero às cadeias poliméricas. $\mathrm{A}$ formação das cadeias poliméricas, através de reações de propagação (crescimento de cadeia polimérica), depende exclusivamente da presença de espécies ativas (sítios ou centros ativos), como por exemplo, um radical, um cátion, um ânion ou um metal de transição.

De acordo com o tipo de espécie ativa, as reações de polimerização por adição podem ser classificadas como: reações via radicais livres, reações aniônicas, reações catiônicas, reações de coordenação, polimerização estereoespecífica, reações por transferência de grupos, entre outras.

Nas polimerizações em cadeia não existe reação entre espécies reativas de diferentes tamanhos. Deste modo, os dímeros, trímeros, etc., não reagem uns com os outros, apresentando características de reação cadeia-monômero

\footnotetext{
${ }^{1}$ Tanto os termos Condensação e Etapas, bem como Adição e Cadeia são usualmente empregados como sinônimos.
} 
(polímero-monômero). Estas reações são tipicamente muito mais rápidas do que as reações em etapas, cujo crescimento de cadeia polimérica se dá por adições sucessivas de monômeros na ordem de milhares.

Diferenças importantes determinadas pela relação entre o tamanho da cadeia polimérica e a conversão da reação são observadas entres as polimerizações em etapas e crescimento de cadeia.

Tipicamente, o peso molecular médio (massa molar média) de polímeros de adição não está relacionado ao percentual de conversão durante a polimerização. Já polímeros de condensação tem seu peso molecular dependente da conversão do sistema, como ilustra a Figura 2.4.

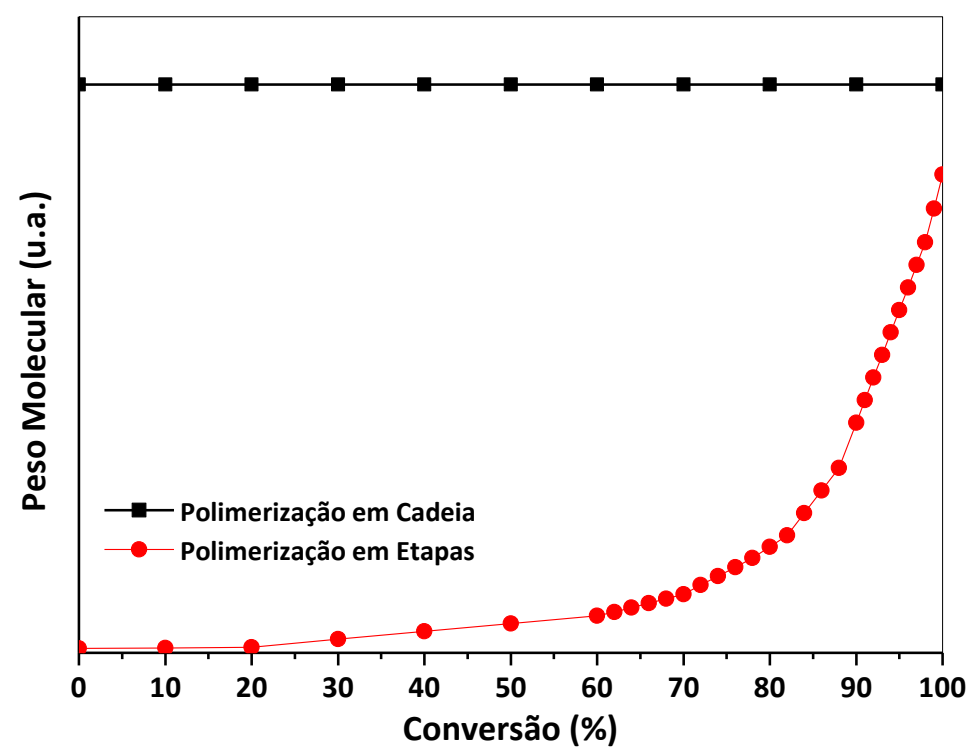

Figura 2.6. Relação entre Tamanho Médio da Cadeia Polimérica e Conversão da Reação. (Adaptado de Odian ${ }^{126}$ )

Inúmeros polímeros (ou famílias de polímeros) podem ser sintetizados em sistemas de polimerização que diferem entre si quanto à homogeneidade, genericamente classificados em sistemas homogêneos e heterogêneos, dependendo fundamentalmente da solubilidade do(s) monômero(s) e/ou cadeias poliméricas no meio reacional.

Os processos de polimerização, em fase homogênea ou heterogênea, são dotados de características que Ihe são peculiares, permitindo, desta forma, a obtenção de materiais poliméricos dos mais variados tipos e propriedades (tamanho médio de cadeia, morfologia de partícula, composição química, etc.). 
Neste cenário, destacam-se os processos de polimerização em fase homogênea: massa e solução; e processos em fase heterogênea: suspensão, emulsão, miniemulsão, microemulsão, dispersão, massa-suspensão, suspensão-emulsão, microssuspensão, entre outros. ${ }^{127}$

\subsection{POLIMERIZAÇÃO EM SUSPENSÃO}

Processos de polimerização em suspensão são amplamente empregados para produção de partículas poliméricas em escala micrométrica (com diâmetro médio de partícula na faixa de $50 \mu \mathrm{m}<\phi<500 \mu \mathrm{m}$ ). Estes sistemas de polimerização são caracterizados por conter espécies reativas insolúveis em uma fase aquosa, onde são dispersas à custa de agitação (cisalhamento) vigorosa e da ação estabilizante de protetores coloidais não iônicos, normalmente polímeros hidrossolúveis também conhecidos como agentes de suspensão (graças à ação protetiva minimiza o fenômeno indesejável de coalescência das gotas monoméricas). ${ }^{127-129}$

Em alguns processos de polimerização em suspensão compostos inorgânicos finamente divididos e insolúveis em água como o talco, a hidroxiapatita, o caulim, $\circ \mathrm{MgCO}_{3}, \circ \mathrm{Mg}(\mathrm{OH})_{2}, \circ \mathrm{Ca}_{3}\left(\mathrm{PO}_{4}\right)_{2}$ e $\circ \mathrm{Al}(\mathrm{OH})_{3}$ são também utilizados ${ }^{126}$.

Nestes processos gotas de monômero(s), apropriadamente dispersas na fase aquosa contínua, contendo iniciadores (peróxidos orgânicos ou azocompostos) organossolúveis comportam-se como microrreatores de polimerização em massa (exibindo cinética de reação similar a observada em polimerizações em massa).

Processos heterogêneos, como a polimerização em suspensão, são usados principalmente para contornar problemas relacionados ao descontrole térmico associado ao aumento de viscosidade do sistema à medida que a fase orgânica rica em monômero(s) é convertida em polímero.

Estes processos reúnem como vantagens adicionais a facilidade de separação dos produtos ao final da reação e incidência de pequenas quantidades de contaminantes nos produtos de reação, além do fácil controle de 
temperatura e troca de calor. Devido a estas características, podem ser usado em diversas aplicações biomédicas e tecnológicas. ${ }^{44}$

Inúmeros polímeros de elevado interesse industrial são produzidos via polimerização em suspensão, como por exemplo, o poli(cloreto de vinila) (PVC), o poliestireno (PS), o poli(metacrilato de metila) (PMMA), a poliacrilonitrila (PAN), poli(estireno-acrilonitrila) (SAN), entre outros.

Alguns autores tratam de forma mais detalhada processos de polimerização em suspensão no que diz respeito à influência das principais variáveis de processos sobre a qualidade dos materiais poliméricos obtidos em suspensão. ${ }^{127}$.

\subsection{SÍNTESE DE NANOCOMPÓSITOS POLIMÉRICOS COM PROPRIEDADES MAGNÉTICAS}

Polímeros podem ser desenhados para apresentar resposta a uma série de efeitos de externos, como variações de temperatura, $\mathrm{pH}$, campo magnético, meio solvente, entre outros. ${ }^{130}$

Por apresentarem comportamento magnéticos, materiais magnetopoliméricos são normalmente de fácil manuseio e, por isso, podem ser aplicados na manipulação e automação de equipamentos analíticos que permitem a separação rápida e a estabilização das nanopartículas, além da elasticidade e possibilidade de funcionalização superficial que possibilite o uso como ligantes específicos para imunoensaios, sequenciamento de ácidos nucléicos, células, microrganismos entre outros. ${ }^{131}$

$\mathrm{Na}$ área biomédica, a síntese de nanomateriais com propriedades bifuncionais é crescente, uma vez que este tipo de material tem aplicações como separação de células, DDS (drug delivery systems), suporte de enzimas e proteínas, imunologia, purificação de ácidos nucléicos. ${ }^{132}$

Uma vez que óxidos metálicos são mais resistentes à degradação que os metais puros, eles são os primeiros candidatos nas rotas sintéticas de nanomateriais. Propriedades de interesse, como a magnetização, dependem de fatores como composição química, morfologia, tamanho, estrutura cristalina, cristalinidade, entre outros. 
No contexto de emboloterapia, é preferível nanomateriais cujo tamanho de monodomínios conduza a um comportamento superparamagnético. Outro aspecto importante, diz respeito funcionalização das nanopartículas com o intuito de aumentar sua estabilidade na forma coloidal.

Adicionalmente, agentes embolizantes à base de PPVi são pouco suscetíveis a reações de hidrólise indesejáveis, o que inibe uma possível recanalização dos vasos sanguíneos.

Através de processos de polimerização em suspensão podem ser obtidos materiais do tipo casca polimérica-núcleo magnético usando-se compostos como PPVi e magnetita, que ajuda na estabilização do material obtido.

Nesta rota sintética, a morfologia é controlável por este tipo de processo e o mesmo pode ser usado na área de separação magnética na área biomédica. ${ }^{131}$

\subsection{ENCAPSULAÇÃO DE NANOPARTÍCULAS MAGNÉTICAS EM MATRIZES POLIMÉRICAS}

A encapsulação de partículas em matrizes poliméricas traz novas propriedades que as partículas não recobertas não apresentam. No caso de carreadores de droga, é interessante que o organismo não reconheça as nanopartículas como organismos estranhos e, deste modo, não seja eliminada rapidamente pela corrente sanguínea. ${ }^{133}$

Deste modo, polímeros hidrofílicos, flexíveis, aniônicos podem conferir propriedades que evitem interações com proteínas do sangue. Um obstáculo para isto é a obtenção de partículas estáveis, com cobertura biocompatível para partículas que são rapidamente biodegradáveis. Além disto, a degradação da camada de cobertura permite que as proteínas do sangue se liguem às nanopartículas e façam a fagocitose rapidamente.

Uma outra vantagem do encapsulamento é a proteção superficial conta a oxidação, o que melhora a dispersividade, estabilidade estérica ou eletrostática e redução na toxidez. Há diversos meios de realizar a proteção, como dispersão em albumina, quitosana, polímeros de PVA. 


\section{CAPÍTULO 3 - PROCEDIMENTOS EXPERIMENTAIS}

\subsection{REAGENTES E MATERIAIS}

\subsubsection{Reagentes e Materiais Utilizados na Síntese e Modificação das Nanopartículas de $\mathrm{Fe}_{3} \mathrm{O}_{4}$}

Nitrogênio, usado nas reações para manter a atmosfera inerte, fornecido pela White Martins Ltda com $99.5 \%$ de pureza. Água destilada foi usada como meio reacional. Os reagentes hidróxido de sódio $(\mathrm{NaOH})$ com pureza de $99 \%$, cloreto férrico hexahidratado $\left(\mathrm{FeCl}_{3} \cdot 6 \mathrm{H}_{2} \mathrm{O}\right)$ com pureza de $97 \%$, sulfato ferroso heptahidratado $\left(\mathrm{FeSO}_{4} \cdot 7 \mathrm{H}_{2} \mathrm{O}\right)$ com $99 \%$ de pureza, ácido clorídrico $(\mathrm{HCl}) \mathrm{com}$ $37 \%$ de pureza, álcool etílico (99\%), acetona com pureza de 99,5\%, sulfato de alumínio hidratado com $98 \%$ de pureza, ácido acrílico e ácido metacrílico, ambos com pureza de $99 \%$ foram fornecidos pela VETEC Química Fina Ltda. O ácido oleico foi fornecido pela Synth com pureza de $99 \%$. Os solventes e reagentes não sofreram nenhum tratamento prévio, como purificação ou secagem, antes do uso, e foram utilizados como recebidos dos fornecedores.

\subsubsection{Reagentes e Materiais Utilizados na Síntese dos Polímeros}

O pivalato de vinila (PVi), estabilizado com 6-15 ppm de monometil éter de hidroquinona (MEHQ), usado como monômero nas polimerizações, foi adquirido da Aldrich apresentando pureza de 99\%. A fase contínua usada como meio de suspensão foi água destilada. A hidroquinona, com pureza de $99 \%$, foi fornecida pela Merck.

Nas reações de polimerização em suspensão os seguintes reagentes foram utilizados: i) como iniciador de reação foi usado o peróxido de benzoíla (BPO), com pureza de $75 \% \mathrm{~m} / \mathrm{m}$, (contendo $25 \% \mathrm{~m} / \mathrm{m}$ de água estabilizante, com oxigênio ativo equivalente a $5 \% \mathrm{~m} / \mathrm{m}$ ), gentilmente doado pela Arkema;

ii) o poli(álcool vinílico) (PVA) POVAL B24, usado como agente de suspensão, foi gentilmente doado pela Denka com grau de hidrólise na faixa de $86-89 \%$ ) e pureza de $99 \%$.

Todos os reagentes usados não foram purificados para uso nas reações, tendo sido utilizados como foram recebidos. 


\subsection{SÍNTESES E MODIFICAÇÕES REALIZADAS}

\subsubsection{Síntese de Nanopartículas Magnéticas de $\mathrm{Fe}_{3} \mathrm{O}_{4}$}

Nanopartículas de $\mathrm{Fe}_{3} \mathrm{O}_{4}$ são obtidas pelo método da coprecipitação, baseado no método descrito por Pu et al. ${ }^{134}$ (ver Esquema 3.1). Inicialmente, prepara-se uma solução com $5 \mathrm{~mL}$ de $\mathrm{HCl}$ em $125 \mathrm{~mL}$ de $\mathrm{H}_{2} \mathrm{O}$ destilada. São adicionados $3,1 \mathrm{~g}$ de $\mathrm{FeSO}_{4} \cdot 7 \mathrm{H}_{2} \mathrm{O}$ e $6,1 \mathrm{~g}$ de $\mathrm{FeCl}_{3} \cdot 6 \mathrm{H}_{2} \mathrm{O}$. A mistura é aquecida até $60^{\circ} \mathrm{C}$ sob agitação e em atmosfera de $\mathrm{N}_{2}$ por 30 minutos. A solução contendo a mistura de sais é adicionada a um béquer contendo $620 \mathrm{~mL}$ de $\mathrm{H}_{2} \mathrm{O}$ e $37,5 \mathrm{~g}$ de $\mathrm{NaOH}$, previamente aquecida a $60^{\circ} \mathrm{C}$ e com borbulhamento de $\mathrm{N}_{2}$. O sistema é mantido por 30 minutos a $60^{\circ} \mathrm{C}$ sob agitação e com borbulhamento de $\mathrm{N}_{2}$. As nanopartículas formadas são lavadas com água destilada até $\mathrm{pH}$ neutro e mantidas em etanol P.A.

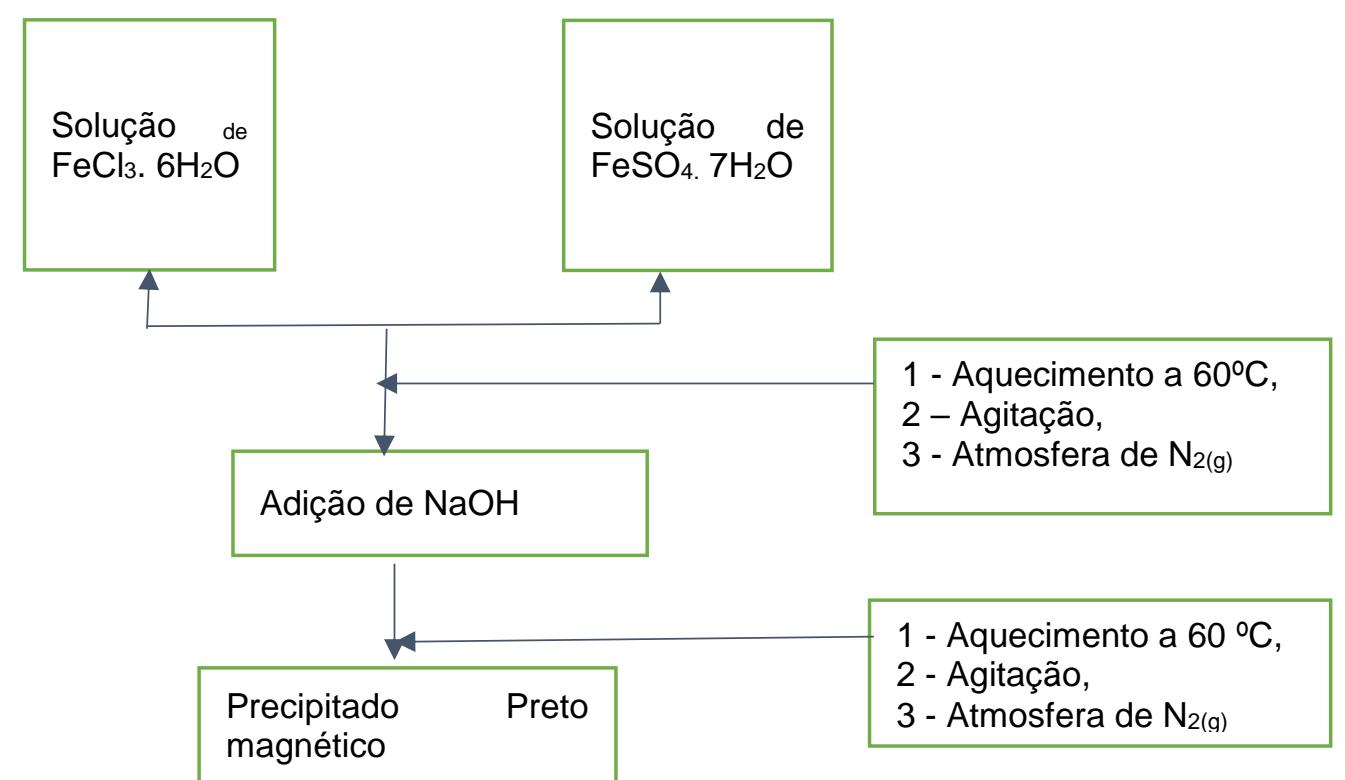

Esquema 3.1. Fluxograma de preparação das partículas de magnetita.

O processo de síntese das nanopartículas de magnetita pode ser representado pela equação a seguir:

$\mathrm{FeSO}_{4} \cdot 7 \mathrm{H}_{2} \mathrm{O}+\mathrm{FeCl}_{3} \cdot 6 \mathrm{H}_{2} \mathrm{O} \stackrel{\text { Método de coprecipitação }}{\longrightarrow} \underset{\mathrm{Fe}_{3} \mathrm{O}_{4}}{1 \mathrm{mmol}} \stackrel{ }{2 \mathrm{mmol}}$
$\longrightarrow \mathrm{Fe}_{3} \mathrm{O}_{4}$




\subsubsection{Modificação das Nanopartículas de $\mathrm{Fe}_{3} \mathrm{O}_{4}$}

O procedimento experimental adotado para modificação da superfície das nanopartículas é similar aquele proposto por Pich et al. ${ }^{135} \mathrm{e}$ Huang et al. ${ }^{136}$ (ver Esquema 3.2). A partir da produção de uma batelada de magnetita, aproximadamente $5 \mathrm{~g}$ de nanopartículas de $\mathrm{Fe}_{3} \mathrm{O}_{4}$ são dispersas em $170 \mathrm{~mL}$ de água. A mistura é então aquecida, sob agitação, a $85^{\circ} \mathrm{C}$ com borbulhamento de $\mathrm{N}_{2}$. Em seguida, 5,6 mL de ácido oleico (AO) são adicionados, por gotejamento, a uma taxa máxima de $0,5 \mathrm{~mL} / \mathrm{min}$ sob agitação. Ao final da adição de $A O, 0$ sistema foi mantido em agitação por mais 30 minutos, seguido de resfriamento até a temperatura ambiente.

Um excesso de $A O$ foi utilizado para inibir a coagulação das nanopartículas de magnetita durante a etapa de adição de $A O$, e consequentemente garantir a dispersão e a modificação apropriada das mesmas. ${ }^{42-44}$ As nanopartículas com superfícies modificadas por AO apresentam-se como uma dispersão coloidal bastante estável, cuja separação de fases, necessária para recuperação das mesmas, é realizada pela adição de sulfato de alumínio.

Após segregação de fases, as nanopartículas são lavadas com água destilada até $\mathrm{pH}$ neutro. Em seguida o material é lavado três vezes com acetona. Após remoção do excesso de acetona, as nanopartículas são dispersas em monômero pivalato de vinila, seguido de borbulhamento com nitrogênio e posterior armazenamento em atmosfera inerte em geladeira.

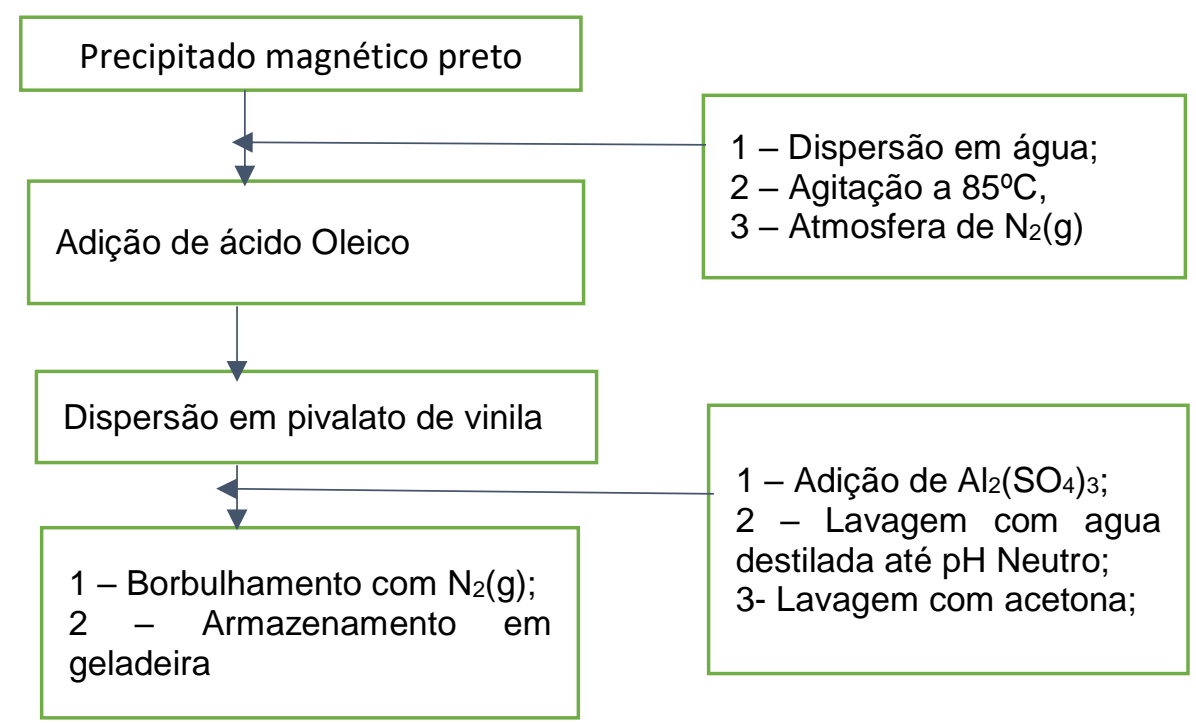

Esquema 3.2. Fluxograma da modificação das nanopartículas de magnetita. 
A modificação superficial das nanopartículas de magnetita pode ser representada, de modo simplificado, na figura 3.1 abaixo.

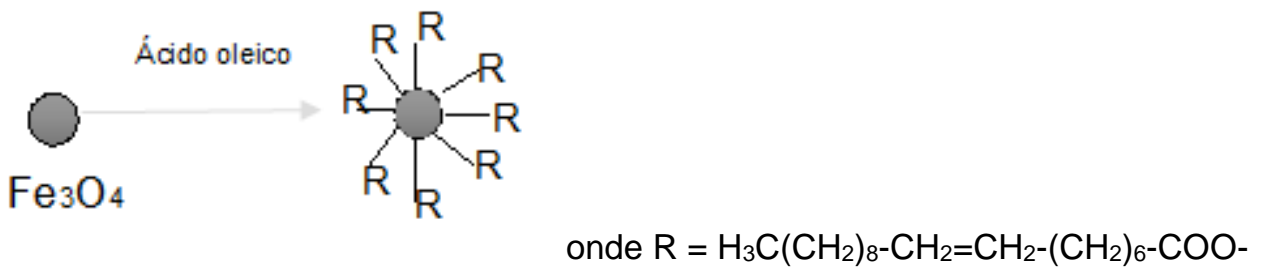

Figura 3.1: Representação da modificação superficial das nanopartículas magnéticas

\subsection{Síntese dos Materiais Poliméricos}

\subsubsection{Reações de Polimerização em Suspensão}

As reações de polimerização em suspensão foram conduzidas em um reator de vidro borossilicato encamisado de $200 \mathrm{~mL}$, acoplado a um banho térmico de água e condensador (ver Esquema 3.3). Inicialmente, é adicionada uma solução de PVA, de concentração variável entre 0,2 g/L e 1,0 g/L, dependendo da concentração de magnetita usada.

A solução de PVA é aquecida até $75^{\circ} \mathrm{C}$ sob atmosfera de $\mathrm{N}_{2}$ com agitação entre 450 e 650 rpm. Após estabelecimento da temperatura inicial de reação, a mistura contendo quantidades variando de 0,2 g a 2,0 g de peróxido de benzoíla, $20 \mathrm{~g}$ de pivalato de vinila (PVi) e nanopartículas de $\mathrm{Fe}_{3} \mathrm{O}_{4} \mathrm{com}$ fração mássica (em relação ao PVi) na faixa de 0 a 20 \% é adicionada ao reator.

A reação de polimerização é mantida a $75^{\circ} \mathrm{C}$ durante as quatro primeiras horas, e então, elevada até $85^{\circ} \mathrm{C}$ por mais duas horas, uma vez que o tempo de meia vida para o iniciador é de cerca de 80 minutos, o que garante o consumo do iniciador ${ }^{126}$.

Ao final da reação, o polímero microparticulado é filtrado a vácuo e lavado com uma solução de dodecilsulfato de sódio para eliminação de quaisquer quantidades de monômero residual.

Uma segunda lavagem é feita com uma solução de hidroquinona 200 ppm, recém-preparada, para inibir uma eventual polimerização posterior. Após lavagem, o material polimérico é mantido em estufa a $60{ }^{\circ} \mathrm{C}$ por 72 horas para eliminação de eventuais espécies voláteis presentes em sua fase amorfa. 


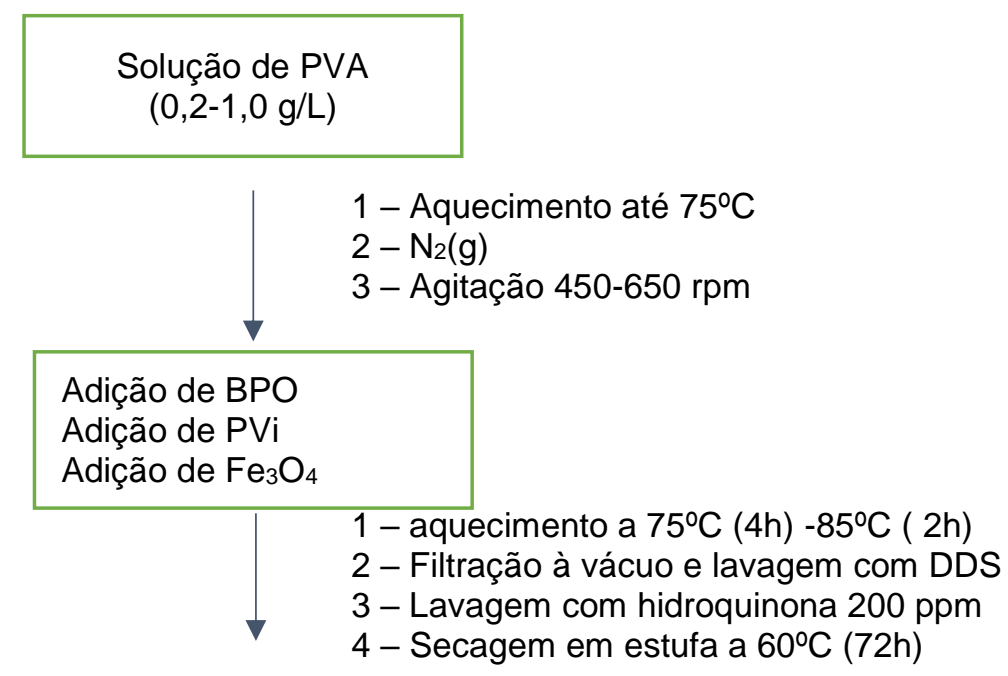

Esquema 3.3. Fluxograma das reações de polimerização em suspensão.

As reações que ocorrem na polimerização seguem os princípios mostrados no esquema 2.2 e 2.3 e podem ser representadas do seguinte modo:

Etapa 1: iniciação (passo 1)

$40-90^{\circ} \mathrm{C}$

R-COO:OOC-R $2 \mathrm{CO}_{2}+2 \mathrm{R}^{*}$ (BPO)

(passo 2)

$\mathrm{R}^{*}+-\mathrm{H}_{2} \mathrm{C}=\mathrm{CH}_{2}$ $\mathrm{R}: \mathrm{CH}_{2}-\mathrm{CH}_{2}^{*}$

(PVi)

Onde:<smiles>O=C(OOC(=O)c1ccccc1)c1ccccc1</smiles>

BPO (Peroxido de benzoila)<smiles>C=COC(=O)C(C)(C)C</smiles>

PVi

(Pivalato de vinila)

Figura 3.2: Compostos usados na polimerização do poli(pivalato de vinila)

Etapa 2: propagação (passo 3)

$\mathrm{R}: \mathrm{CH}_{2}-\mathrm{CH}_{2}{ }^{*}+\mathrm{n}-\left[-\mathrm{H}_{2} \mathrm{C}=\mathrm{CH}_{2}-\right] \rightarrow \mathrm{R}-\left[\mathrm{CH}_{2}-\mathrm{CH}_{2}-\mathrm{nn}_{n}-\mathrm{CH}_{2}-\mathrm{CH}_{2}{ }^{*}\right.$ 
A reação continua até o término do crescimento por combinação ou desproporcionamento:

Etapa 3: terminação

(Passo 4)

$2 \mathrm{R}-\left[\mathrm{CH}_{2}-\mathrm{CH}_{2}-\right]_{\mathrm{n}}-\mathrm{CH}_{2}-\mathrm{CH}_{2}$.

Combinação

$\left[\mathrm{R}-\left(\mathrm{CH}_{2}-\mathrm{CH}_{2}-\right)_{n} \mathrm{CH}_{2}-\mathrm{CH}_{2}\right]_{2}$

Desproporcionamento

$2 \mathrm{R}-\left[\mathrm{CH}_{2}-\mathrm{CH}_{2}-\right]_{n}-\mathrm{CH}_{2}-\mathrm{CH}_{2} \cdot \longrightarrow\left[\mathrm{R}-\left(\mathrm{CH}_{2}-\mathrm{CH}_{2}-{ }_{n} \mathrm{CH}_{=} \mathrm{CH}_{2}\right]_{2}+\left[\mathrm{R}-\left(\mathrm{CH}_{2}-\mathrm{CH}_{2}-{ }_{n} \mathrm{CH}_{2}-\mathrm{CH}_{3}\right.\right.\right.$

O quadro 3.1 a seguir mostra a função de cada um dos compostos usados no esquema 3.6.

Quadro 3.1. Compostos usados nas reações de polimerização em suspensão e suas funções

\begin{tabular}{|l|l|}
\hline Composto & Função \\
\hline $\mathrm{N}_{2}$ & Garante atmosfera inerte \\
\hline $\mathrm{BPO}$ & Iniciador da reação radicalar \\
\hline $\mathrm{PVi}$ & Monômero usado para polimerização \\
\hline $\mathrm{Fe}_{3} \mathrm{O}_{4}$ & Nanopartícula magnética \\
\hline $\mathrm{DDS}$ & Elimina monômeros residuais \\
\hline Hidroquinona & Inibidor de polimerização \\
\hline
\end{tabular}

\subsection{PROCEDIMENTOS ANALÍTICOS}

Nesta seção são apresentados os principais procedimentos analíticos utilizados para caracterização dos materiais obtidos nas reações de coprecipitação, modificação da superfície das nanopartículas magnéticas e reações de polimerização em suspensão e emulsão.

\subsubsection{Espectroscopia na Região do Infravermelho com Transformada de Fourier (FTIR)}

As análises foram realizadas em um espectrômetro de infravermelho da marca JASCO, modelo FT/IR-4100, em célula de refletância total atenuada (ATR), com varredura de espectro na faixa de $4000 \mathrm{~cm}^{-1}$ a $500 \mathrm{~cm}^{-1}$ e média de 64 scans. 


\subsubsection{Análise por Calorimetria Diferencial de Varredura (DSC)}

As transições térmicas dos materiais poliméricos foram avaliadas por meio de calorimetria diferencial de varredura (DSC) com o auxílio de um calorímetro Shimadzu, modelo DSC-60 (Shimadzu Scientific Instruments, EUA), operado com a taxa de aquecimento de $10^{\circ} \mathrm{C} \cdot \mathrm{min}^{-1} \mathrm{em}$ atmosfera de nitrogênio e fluxo igual a $30 \mathrm{~mL} \cdot \mathrm{min}^{-1}$. As análises foram realizadas em panelas de alumínio com uma massa de amostra de aproximadamente $10 \mathrm{mg}$.

\subsubsection{Análise por Termogravimetria (TG)}

A estabilidade térmica dos materiais foi avaliada através de análises termogravimétricas (TG/DTA) com o auxílio de uma termobalança Shimadzu modelo TA-60WS (Tóquio, Japão), operada a uma taxa de aquecimento de $10^{\circ} \mathrm{C} \cdot \mathrm{min}^{-1}$, sob atmosfera de nitrogênio com vazão de $30 \mathrm{~mL} \cdot \mathrm{min}^{-1}$. As análises foram realizadas em panela de platina com uma massa de amostra de aproximadamente $10 \mathrm{mg}$.

\subsubsection{Análise por Calcinação}

A fração nanopartículas presentes nos nanocompósitos poliméricos foi quantificada via procedimento de calcinação. Os materiais foram calcinados em forno de quartzo em atmosfera de nitrogênio, cujo procedimento foi realizado em triplicatas. A rampa de aquecimento variando $10^{\circ} \mathrm{C} \cdot \mathrm{min}^{-1}$ até $700^{\circ} \mathrm{C}$ com uma isoterma de $1 \mathrm{~h}$ e resfriamento até a temperatura ambiente.

\subsubsection{Espectroscopia de Raios X por Energia Dispersiva (EDX)}

Espectrometria de energia dispersiva de raios $X$ foi utilizada para avaliação das nanopartículas magnéticas e dos nanocompósitos de poli(pivalato de vinila) e $\mathrm{Fe}_{3} \mathrm{O}_{4}$. As análises foram realizadas em um espectrômetro de fluorescência de raios X Shimadzu, modelo EDX720 (Shimadzu Europa GmbH, Duisburg, Alemanha) à vácuo com colimador de $5 \mathrm{~mm}$, com feixe variando de 50 $\mathrm{keV}$ (canal Sc-Ti, passo de 0,02) e $15 \mathrm{keV}$ (canal Na-Sc, passo de 0,01) com 2048 pontos. 


\subsubsection{Difração de Raios X (DRX)}

Os materiais foram caracterizados por difração de Raios $X$ utilizando-se um difratômetro Bruker D8 FOCUS (Bruker AXS, Inc., Wisconsin, EUA), com radiação $\mathrm{CuK}_{\alpha}=1,5418$, voltagem de $40 \mathrm{kV}$ e amperagem de $30 \mathrm{~mA}$. A faixa de

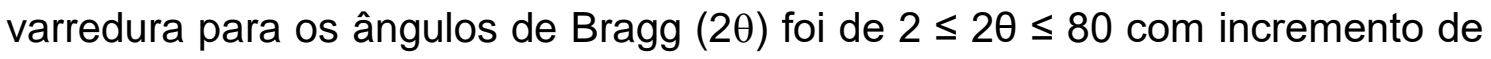
$0,05^{\circ}$ e velocidade angular de $0,25^{\circ} \cdot \mathrm{min}^{-1}$.

Padrões de difração das amostras fornecem informações importantes sobre o tamanho médio dos cristalitos do material inorgânico, que pode ser determinado pela equação de Debye-Scherrer, descrita como ${ }^{137}$ :

$$
D_{\mathrm{DRX}}=\mathrm{k} \cdot \lambda /[\beta \cdot \cos (\theta)]
$$

onde, DDRx representa o tamanho médio do cristalito, $\mathrm{k}$ é uma constante associada ao formato da partícula e tem valor normalmente igual a 0,9. $\lambda$ é o comprimento de onda da radiação CuKa (igual a 0,1542 nm), $\beta$ é a largura a meia altura do pico de maior intensidade [correspondente a reflexão (311)] e $\theta$ é relacionado ao ângulo de difração de Bragg.

\subsubsection{Microscopia Eletrônica de Varredura (MEV)}

A morfologia das partículas poliméricas foi determinada através de microscopia eletrônica de varredura em um equipamento Jeol, modelo JSM$7001 \mathrm{~F}$ (Tóquio, Japão), operando com um feixe de elétrons de $15 \mathrm{keV}$. Os materiais poliméricos foram previamente recobertos com uma fina camada de ouro, depositados pelo processo de sputtering.

\subsubsection{Microscopia Eletrônica de Transmissão (MET)}

A morfologia das nanopartículas de $\mathrm{Fe}_{3} \mathrm{O}_{4}$ foi avaliada por microscopia eletrônica de transmissão em um equipamento Jeol, modelo JEM-1011 (Tóquio, Japão), operando com um feixe de elétrons de $80 \mathrm{keV}$. Para o caso particular das nanopartículas magnéticas, informações fornecidas pela MET são fundamentais para determinação da distribuição do tamanho de partícula (DTP) e do valor médio do diâmetro das partículas. 


\subsubsection{Espectroscopia Raman}

O equipamento utilizado foi um espectrômetro Raman modelo InVia da Renishaw, com microscópio óptico confocal e modo de excitação em $633 \mathrm{~nm}$ (laser $\mathrm{He}-\mathrm{Ne}$ ) e $785 \mathrm{~nm}$ (diodo), e redes de $1200 \mathrm{~L} / \mathrm{mm}$ e $1800 \mathrm{~L} / \mathrm{mm}$. Os espectros das amostras foram obtidos com aumento de 50x e rede de 1200 $\mathrm{L} / \mathrm{mm}$, em modo de varredura, com tempo de exposição de 10 segundos e potência de $50 \mathrm{~mW}(633 \mathrm{~nm})$ e $500 \mathrm{~mW}(785 \mathrm{~nm})$, respectivamente.

\subsubsection{Medidas de Magnetização - Força Magnética}

Medições de força magnética dos materiais foram realizadas em uma aparato experimental similar ao descrito por Grance et al. ${ }^{95}$, e que consiste da combinação de uma balança analítica Shimadzu AY220 (Shimadzu do Brasil, São Paulo, Brasil), uma fonte de tensão ICEL PS-4100 (Icel, Manaus, Brasil), um multímetro digital ICEL MD-6450 (Icel, Manaus, Brasil), um medidor de campo magnético Globalmag TLMP-Hall-02 (Globalmag, São Paulo, Brasil), um porta amostra e um eletroímã.

A força magnética é determinada com base na variação da massa das amostras na presença de campos magnéticos diferentes, produzidos pelo eletroímã. De acordo com este procedimento experimental, a variação aparente de massa da amostra em presença do campo magnético foi calculada subtraindo a massa da amostra em presença de um campo magnético a partir da massa da amostra.

A força magnética (FM) oposta a força gravitacional é dada por:

$$
\mathrm{F}_{\mathrm{M}}=\Delta \mathrm{m} \cdot \mathrm{g}
$$

onde FM é a força magnética, $\Delta \mathrm{m}$ é a variação da massa aparente na presença do campo magnético e g é a aceleração da gravidade.

A calibração do sistema foi realizada na ausência de material magnético, tomando como material de referência o cloreto de cobalto (II) hexahidratado $\left(\mathrm{CoCl}_{2} \cdot 6 \mathrm{H}_{2} \mathrm{O}\right)$. Os ensaios de magnetização com $\mathrm{CoCl}_{2} \cdot 6 \mathrm{H}_{2} \mathrm{O}$ conduziram a uma força magnética igual a $(0.18 \pm 0.02) \mathrm{mN}$ em $(838 \pm 1)$ Gauss. 


\subsubsection{Cromatografia por Permeação em Gel}

Os pesos moleculares médios em número e massa e as distribuições de peso molecular (DPMs) foram determinados por cromatografia de permeação em gel (GPC) em um Viscotek GPCmax ${ }^{\mathrm{TM}}$ (Malvern Instruments Ltd, Worcestershire, UK), equipado colunas lineares com géis de porosidade na faixa de $10^{3} \AA$ a $10^{6} \AA$, amostrador automático, com detector refratométrico (Viscotek 3580) e bomba com sistema de degasagem.

A curva de calibração foi construída usando amostras de poliestireno com peso molecular na faixa de $3 \times 10^{3} \mathrm{~g} \cdot \mathrm{mol}^{-1}$ a $1.85 \times 10^{6} \mathrm{~g} \cdot \mathrm{mol}^{-1} \mathrm{e}$ dispersão de peso molecular menor que 1.05. As análises foram realizadas usando tetrahidrofurano (THF) como fase móvel a $40^{\circ} \mathrm{C}$ e vazão de $1 \mathrm{~mL} \cdot \mathrm{min}^{-1}$.

As amostras de polímero, isentas de umidade (ou solventes / monômero), na concentração de aproximadamente $1,5 \mathrm{~g} / \mathrm{L}$ a 2,0 $\mathrm{g} / \mathrm{L}$, solubilizadas em THF, foram filtradas em filtros de membrana microporosa (diâmetro médio de poros igual a $0,45 \mu \mathrm{m}$ ) para posterior injeção automática em loop com um volume de $200 \mu \mathrm{L}$. 


\section{CAPÍTULO 4 - RESULTADOS E DISCUSSÕES}

\subsection{SÍNTESE DE MICROPARTÍCULAS POLIMÉRICAS VIA PROCESSO DE POLIMERIZAÇÃO EM SUSPENSÃO}

\subsubsection{Modificação de Nanopartículas Magnéticas de $\mathrm{Fe}_{3} \mathrm{O}_{4}$ com Ácido Oleico}

A modificação superficial das nanopartículas magnéticas de $\mathrm{Fe}_{3} \mathrm{O}_{4}$ (NPMM) representa uma etapa essencial à preparação dos materiais poliméricos magnéticos via polimerização em suspensão in situ, pois garante boa compatibilidade entre as NPMM e monômero pivalato de vinila.

É fundamental que no princípio da reação as NPMM mantenham-se homogeneamente distribuídas nas gotas de pivalato de vinila (PVi) dispersas na fase aquosa contínua, onde a dispersão NPMM / PVi será gradualmente convertida em partículas poliméricas magnéticas micrométricas.

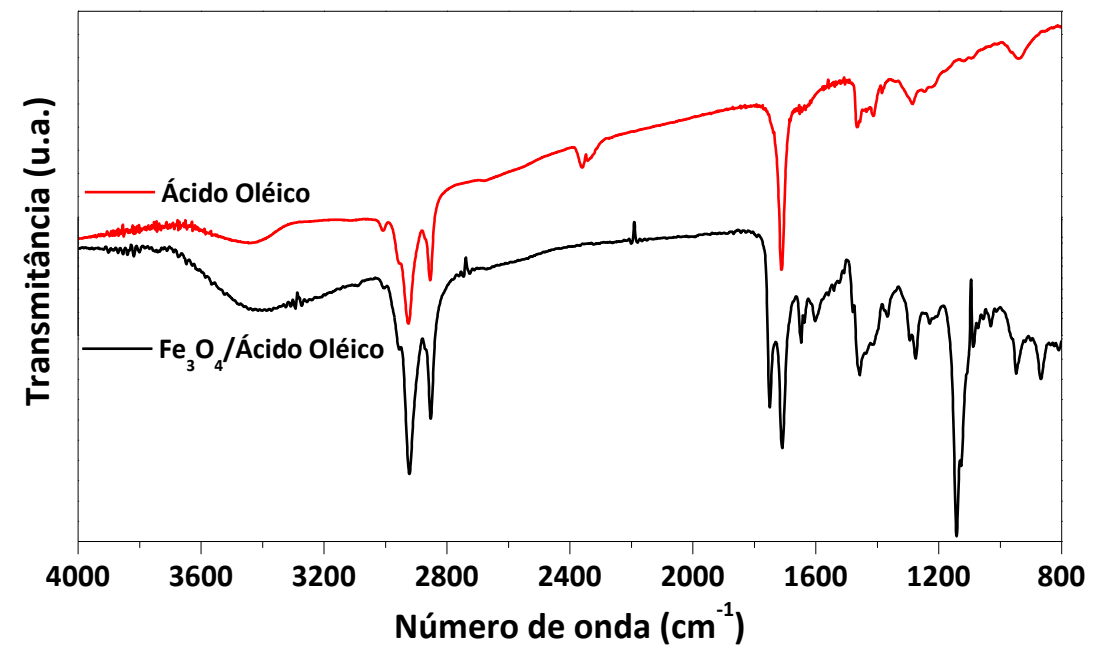

Figura 4.1. FTIR do ácido oleico e nanopartículas magnéticas de $\mathrm{Fe}_{3} \mathrm{O}_{4}$ modificadas com ácido oleico.

A Figura 4.1 apresenta espectros de infravermelho (IR) do ácido oleico (AO) e das nanopartículas de magnetita com superfície modificada com AO. De acordo com a figura, os espectros do AO e das NPMM são caracterizadores por apresentarem uma banda larga entre $3710 \mathrm{~cm}^{-1}$ e $3030 \mathrm{~cm}^{-1}$, devida ao estiramento $\mathrm{O}-\mathrm{H}$ da cadeia do ácido graxo livre ou agua adsorvida, uma banda de estiramento carbonila intensa em $1710 \mathrm{~cm}^{-1}$, modos vibracionais do 
estiramento $\mathrm{C}-\mathrm{H}$ representados por picos de absorção observados em $3008 \mathrm{~cm}$ ${ }^{1}\left(v_{\text {as }} \mathrm{CH}_{3}\right), 2955 \mathrm{~cm}^{-1}\left(v_{\text {as }} \mathrm{CH}_{2}\right), 2925 \mathrm{~cm}^{-1}\left(v_{\mathrm{s}} \mathrm{CH}_{3}\right)$ e $2854 \mathrm{~cm}^{-1}\left(v_{\mathrm{s}} \mathrm{CH}_{2}\right) \cdot{ }^{138-140}$

A modificação superficial das nanopartículas é evidenciada pelo aparecimento de picos intensos em $1750 \mathrm{~cm}^{-1}$ devido ao estiramento $\mathrm{C}=\mathrm{O}$ da carbonila e em torno de $1142 \mathrm{~cm}^{-1}$ devido ao estiramento $\mathrm{C}-\mathrm{O}$ da carboxila.

Além disso, duas novas bandas surgem em $1646 \mathrm{~cm}^{-1}$ (estiramento assimétrico de COO-, vs) e $1366 \mathrm{~cm}^{-1}$ (estiramento simétrico de COO-, vas), que são explicadas pelo padrão de ligação entre ácidos carboxílicos na superfície da nanopartícula que são combinações de moléculas ligadas simetricamente e aquelas ligadas formando ângulos com a superfície. ${ }^{140-142} \mathrm{~A}$ Tabela 4.1 sumariza os principais picos e bancas observados via medidas de FTIR.

Tabela 4.1. Principais picos e bandas de absorção observados via medidas de FTIR da magnetita recoberta com ácido oleico.

\begin{tabular}{|c|c|c|}
\hline $\begin{array}{l}\text { Pico e } \\
\text { bandas }\end{array}$ & Explicação & Ref. \\
\hline $\begin{array}{l}3700- \\
3030\end{array}$ & Estiramento de hidroxila $v(\mathrm{O}-\mathrm{H})$ do $\mathrm{H}$ do ácido oleico & $\begin{array}{l}85,140, \\
141,143\end{array}$ \\
\hline $\begin{array}{l}2922 \\
\text { forte }\end{array}$ & Estiramento assimétrico de grupos metileno vas $(\mathrm{C}-\mathrm{H})$ do ácido oleico & $85,141-146$ \\
\hline $\begin{array}{l}2853 \\
\text { forte }\end{array}$ & Estiramento simétrico de grupos metileno $v_{s}(\mathrm{C}-\mathrm{H})$ do ácido oleico & $\begin{array}{l}140,141, \\
143-145, \\
147\end{array}$ \\
\hline 1749 & $v(\mathrm{C}=\mathrm{O})$ no $\mathrm{COOH}$ da cobertura monomérica. & 142 \\
\hline 1708 & $v(\mathrm{C}=\mathrm{O})$ no $\mathrm{COOH}$ da cobertura dimérica & $85,141-145$ \\
\hline 1646 & $\begin{array}{l}\text { Estiramento assimétrico } v_{\mathrm{s}}(\mathrm{COO}-) \text { do carboxilato do ácido oleico em } \\
\text { combinação com o } \mathrm{Fe} \text { da superfície da magnetita que formam uma } \\
\text { ligação parcial que enfraquece a ligação } \mathrm{C}=\mathrm{O} \text { e reduz a frequência de } \\
\text { estiramento. }\end{array}$ & 140,141 \\
\hline 1601 & vas (COO-) do COOH quimicamente adsorvido & 142 \\
\hline 1457 & $\begin{array}{l}\text { Dobramento } \delta_{a s}(\mathrm{C}-\mathrm{H}) \text { do } \mathrm{CH}_{3} \text { do ácido oleico. Normalmente se } \\
\text { sobrepõem às vibrações assimétricas dos grupos metileno, junto com } \\
\text { o estiramento simétrico indica que o ácido está ligado à superfície da } \\
\text { magnetita de modo covalente. }\end{array}$ & $\begin{array}{l}85,140 \\
144-147\end{array}$ \\
\hline 1367 & Estiramento simétrico vas (COO-) do carboxilato & 140 \\
\hline 1142 & Estiramento v(C-O) & 146 \\
\hline 948 & Dobramento de $\mathrm{OH}$ fora do plano $\delta_{\text {oop }}(\mathrm{O}-\mathrm{H})$ & 145,146 \\
\hline 577 & $\begin{array}{l}\text { Pico característico da magnetita, estiramento da ligação Fe-O do sítio } \\
\text { tetraédrico }\end{array}$ & $\begin{array}{l}85,143, \\
148\end{array}$ \\
\hline
\end{tabular}

A diferença de números de onda $\Delta$, entre o estiramento assimétrico $v_{\text {as }}\left(\mathrm{COO}^{-}\right)$e o simétrico $v_{\mathrm{s}}\left(\mathrm{COO}^{-}\right)$das bandas de infravermelho (IR) auxiliam na identificação do tipo de interacao. 
Por exemplo, a ausência de um pico de COO- e o aparecimento um de modo de vibração $\mathrm{C}=\mathrm{O}$ pode ser um indicativo de que a carboxila se ligue de modo monodentado à superfície da nanopartícula. ${ }^{144}$

Deve-se levar em conta, também, que as moléculas do AO no estado adsorvido são sujeitas a fenômenos de superfície que podem gerar bandas características deslocadas para regiões de frequências mais baixas indicando, deste modo, que as cadeias do ácido carboxílico na monocamada ao redor da nanopartícula estão empacotadas..$^{99}$

Os dados registrados na literatura indicam que a maior diferença $\left(\Delta=200 \sim 320 \mathrm{~cm}^{-1}\right)$ é a interação monodentada e a menor $\left(\Delta<110 \mathrm{~cm}^{-1}\right)$ é a bidentada quelante. Na faixa intermediária $\left(\Delta=140 \sim 190 \mathrm{~cm}^{-1}\right)$ é do bidentado em ponte.

Em particular para as nanopartículas magnéticas modificadas com $A O, 0$ valor observado para $\Delta\left[\Delta=v_{\text {as }}(\mathrm{COO}-)-v_{\mathrm{s}}(\mathrm{COO}-)\right]$ equivale a $279 \mathrm{~cm}^{-1}$, o que sugere uma interação monodentada entre o carboxilato e o átomo de ferro, como representado na figura 4.2 abaixo. ${ }^{141,147}$

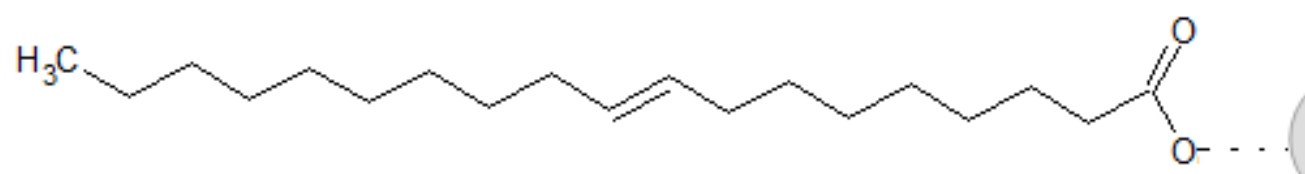

Figura 4.2: Representação da interação entre o ion oleato e a magnetita

A distinção entre interações monodentada e bidentada é observada através de frequências específicas do carboxilato que auxiliam a interpretação do infravermelho e do modo de coordenação, como ilustra a Tabela 4.2 a seguir.

Tabela 4.2. Diferença entre ligantes carboxilados monodentados e bidentados ${ }^{99}$.

\begin{tabular}{|l|l|l|l|}
\hline \multirow{2}{*}{ Interação } & \multicolumn{2}{|c|}{ Estiramento } & \\
\cline { 2 - 4 } & $\begin{array}{c}\text { Simétrico }- \\
v_{\mathrm{s}}(\mathrm{COO}-), \mathrm{cm}^{-1}\end{array}$ & $\begin{array}{c}\text { Assimétrico }-v_{\mathrm{as}}(\mathrm{COO}-), \\
\mathrm{cm}^{-1}\end{array}$ & $\Delta\left(v_{\mathrm{as}}-\mathrm{v}_{\mathrm{s}}\right), \mathrm{cm}^{-1}$ \\
\hline Monodentado & 1370 & 1650 & 280 \\
\hline Bidentado & 1450 & 1580 & 130 \\
\hline
\end{tabular}

A Figura 4.3 apresenta a morfologia das partículas de magnetita e das NPMM modificadas com AO, observada por microscopia eletrônica de 
transmissão (MET). Como pode ser observado, em ambos os casos NPMM apresentam estreita distribuição de tamanho partícula e bastantes similares (imagens adicionais nos Apêndices 1 e 2).

O tamanho médio (DMET) determinadas com base na Figura 4.4 equivale a 7,71 $\pm 1,61 \mathrm{~nm}$ para NPMM puras e 7,68 $\pm 1,65 \mathrm{~nm}$ para as NPMM modificadas com ácido oleico, o que indica que o procedimento experimental adotado para modificação superficial das NPMM não altera o tamanho e a morfologia das magnetitas precursoras.

A Figura 4.5 mostra o difratograma típico observado para as nanopartículas magnéticas sintetizadas neste trabalho. São observados picos característicos da magnetita em $2 \theta=30,2,35,6,43,3,53,4,57.3,62.8$ e 74,3, correspondentes às reflexões (220), (311), (400), (422), (511), (440) e (533), evidenciam que a magnetita sintetizada apresenta estrutura cristalina do tipo espinelio.

O tamanho médio dos cristalitos, determinado a partir da equação de Debye-Scherrer (ver Equação 1), ${ }^{137}$ assumiu valor igual a $8 \mathrm{~nm}$, característico de nanopartículas magnéticas que apresentam comportamento superparamagnético, normalmente atribuído a materiais que apresentam monodomínios magnéticos, cujo tamanho do cristalito é inferior ao valor crítico equivalente a $25 \mathrm{~nm} .{ }^{149,} 150$

É importante ressaltar que o tamanho médio de nanodomínios obtidos via difração de raios $X$ é bastante próximo aquele obtido via medidas de MET, cujo resultado corrobora a hipótese de superparamagnetismo das nanopartículas de $\mathrm{Fe}_{3} \mathrm{O}_{4}$ adotada neste trabalho.

Se consideramos que a distância das ligações carbonila é de 0,122 nm e que as mesmas encontram-se alinhadas devido à interações eletrostáticas, para o valor médio de $8 \mathrm{~nm}$, equivalente à uma área superficial $\left(\mathrm{S}_{\mathrm{NP}}=4 \cdot \pi \cdot \mathrm{r}^{2}\right)$ de 804 $\mathrm{nm}^{2}$, a superfície de cada partícula magnética é recoberta por aproximadamente 6590 moléculas de ácido oleico. ${ }^{44}$ 

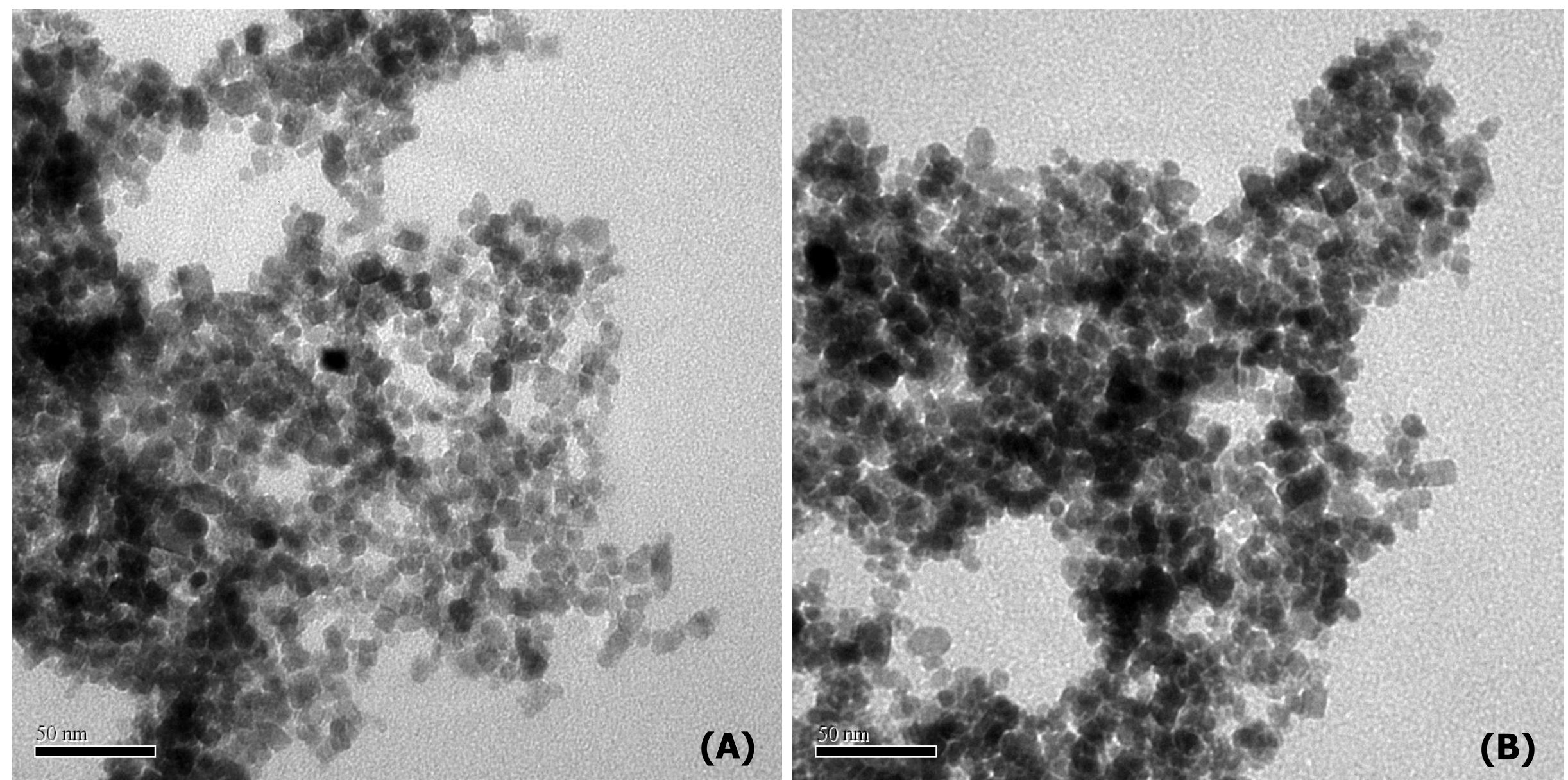

Figura 4.3. Microscopia eletrônica de transmissão da distribuição de nanopartículas magnéticas de $\mathrm{Fe}_{3} \mathrm{O}_{4}$. (A) Não modificada; (B) Superfície modificada com ácido oleico. 

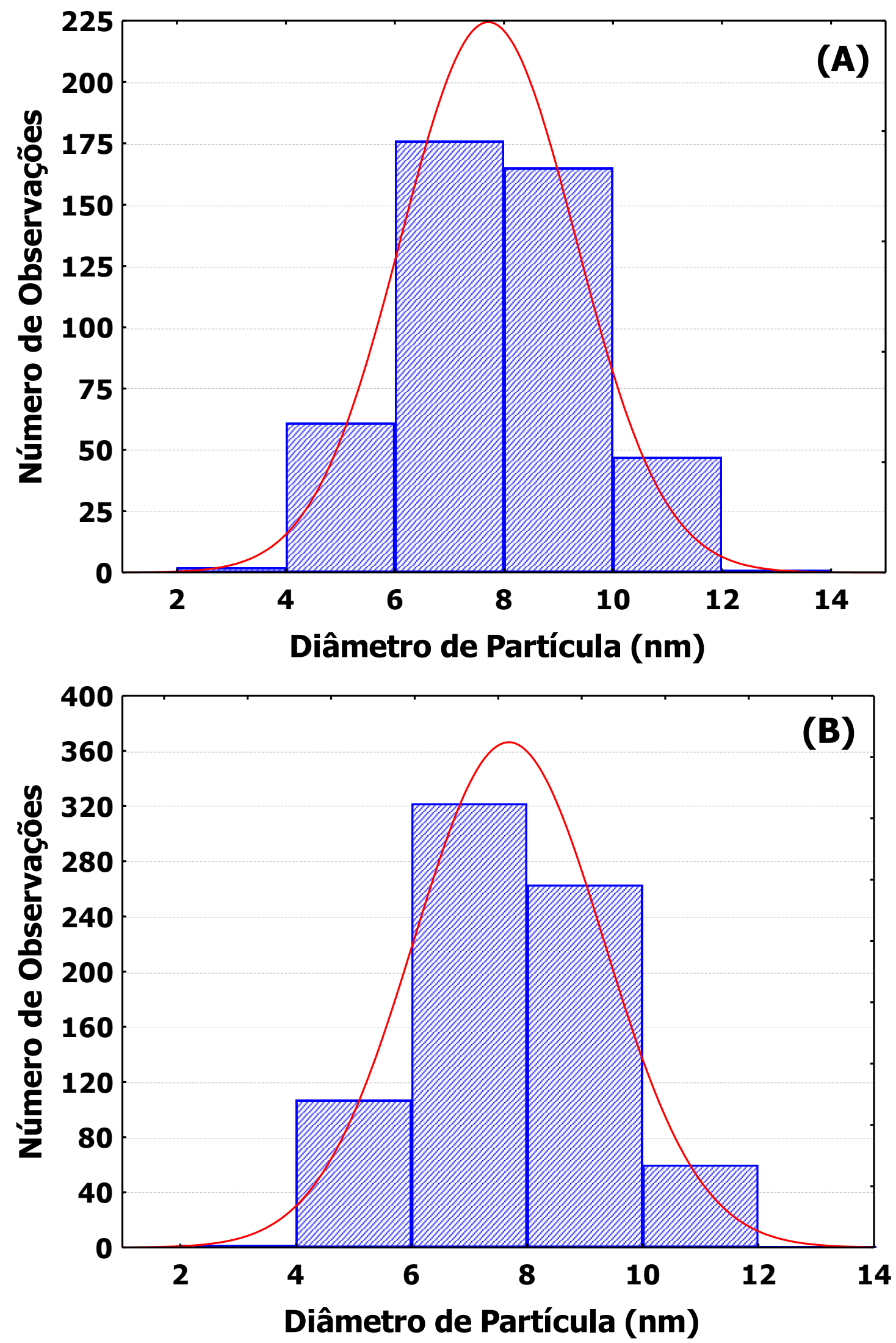

Figura 4.4. Distribuição de tamanho de partícula de nanopartículas magnéticas de $\mathrm{Fe}_{3} \mathrm{O}_{4}$. (A) Não modificada; (B) Superfície modificada com ácido oleico. 


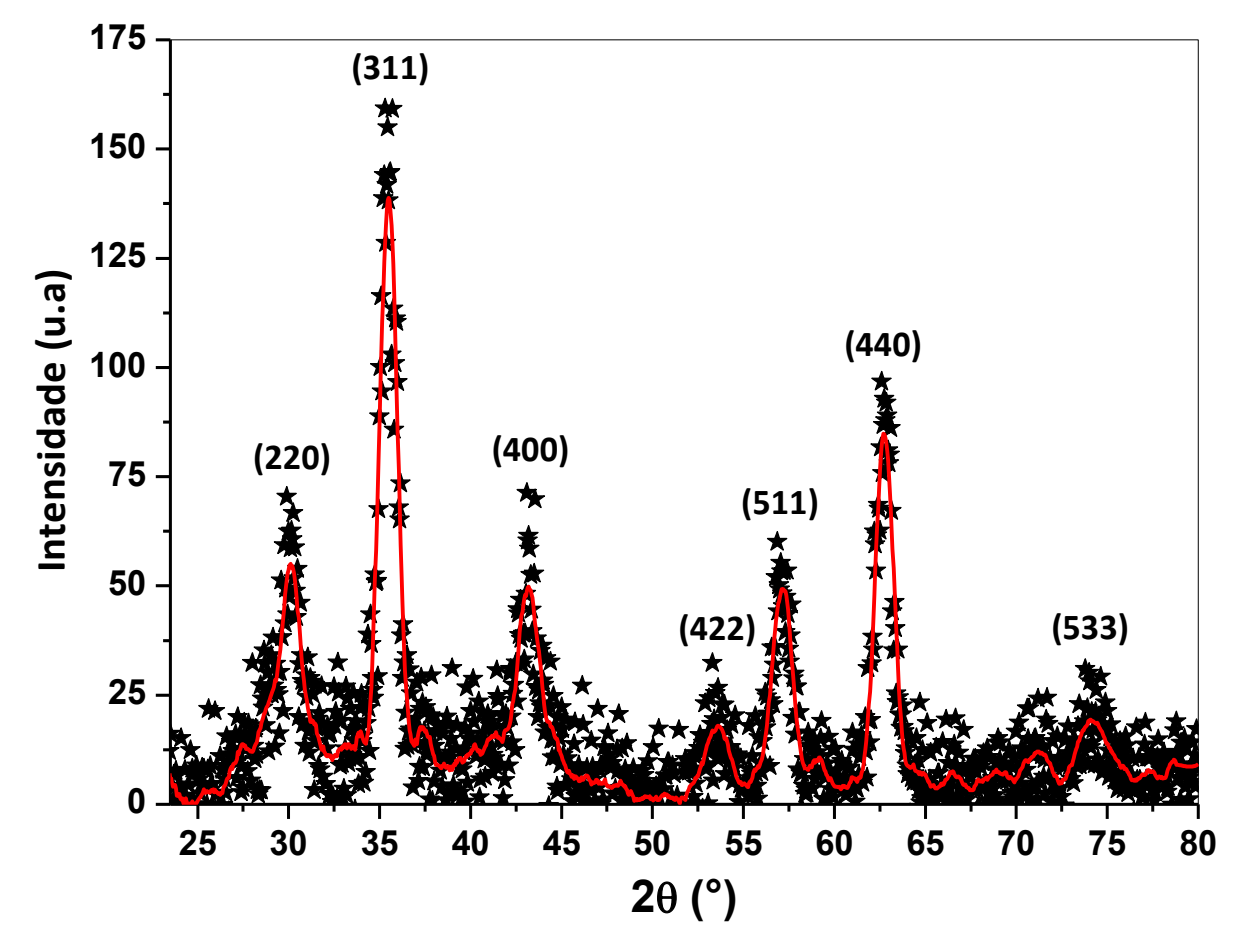

Figura 4.5. Difratograma das nanopartículas magnéticas de $\mathrm{Fe}_{3} \mathrm{O}_{4}$.

A Figura 4.6 ilustra o comportamento de perda de massa das NPMM modificadas com AO. O perfil de estabilidade térmica observado deve-se essencialmente a degradação térmica do $A O$ presente na superfície das nanopartículas de magnetita, o que equivale a um percentual de aproximadamente $15 \%$ em massa.

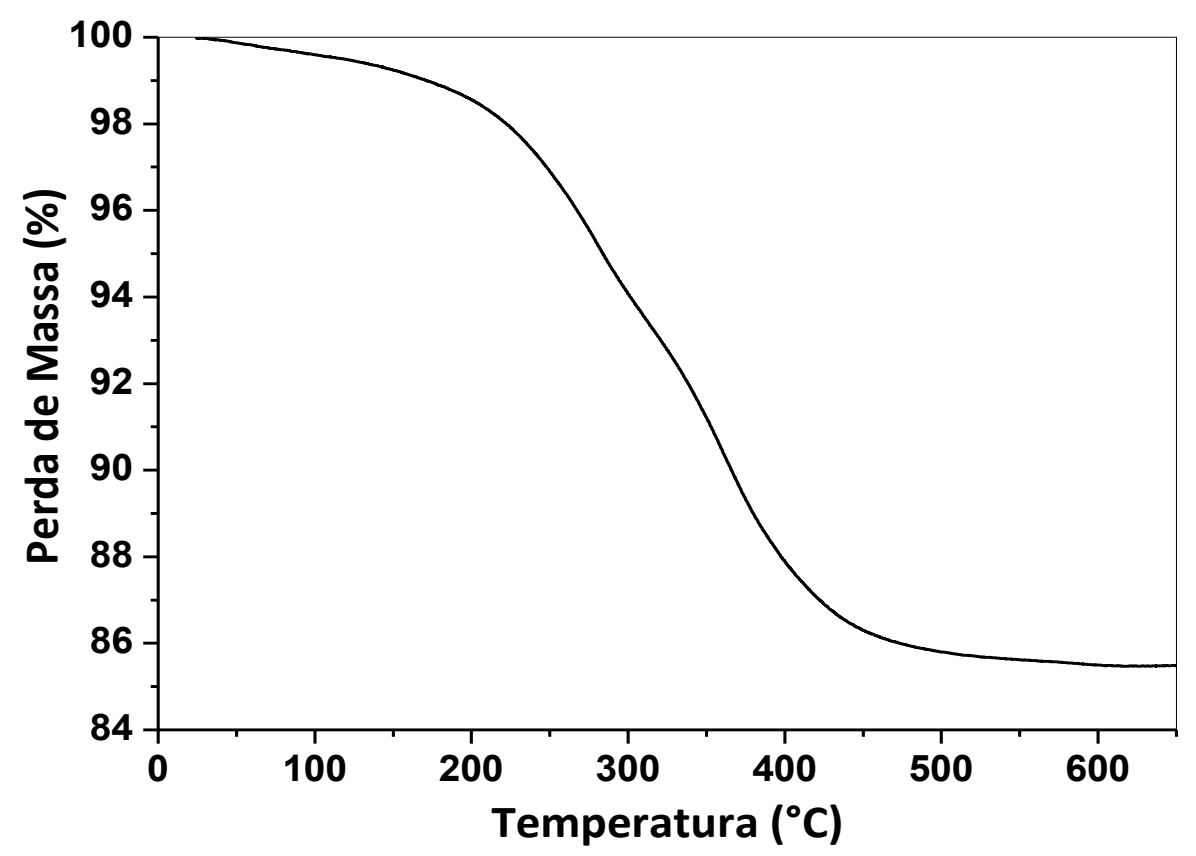

Figura 4.6. Perfil de perda de massa das nanopartículas magnéticas de $\mathrm{Fe}_{3} \mathrm{O}_{4}$ modificada com ácido oleico. 


\subsection{NANOCOMPÓSITOS POLIMÉRICOS OBTIDOS IN SITU VIA POLIMERIZAÇÃO EM SUSPENSÃO}

As reações do pivalato de vinila (PVi) em suspensão apresentam um comportamento cinético clássico de polimerização em adição de cadeia via radicais livres.

A Tabela 4.3 mostra as condições experimentais adotadas para obtenção de micropartículas de homopolímeros de poli(pivalato de vinila) - PPVi e nanocompósitos magnéticos caracterizados pela dispersão de nanopartículas magnéticas de magnetita - NPMM homogeneamente dispersas na matriz termoplástica de PPVi com morfologia também esférica em dimensão micrométrica.

Tabela 4.3. Condições experimentais utilizadas nas polimerizações. ${ }^{\ddagger}$

\begin{tabular}{|c|l|c|c|c|c|c|}
\hline Exp. & \multicolumn{1}{|c|}{ Código } & $\begin{array}{c}\text { Tempo } \\
(\mathbf{h})\end{array}$ & $\begin{array}{c}\mathbf{T} \\
\left({ }^{\circ} \mathbf{C}\right)\end{array}$ & $\begin{array}{c}\text { BPO } \\
(\mathbf{g})\end{array}$ & $\begin{array}{c}\text { PVA } \\
(\mathbf{g} / \mathbf{L})\end{array}$ & $\begin{array}{c}\text { Agitação } \\
(\mathbf{r p m})\end{array}$ \\
\hline 1 & $\mathrm{PVi}(\mathrm{a})$ & $4,(3 / 1)$ & $75 / 80$ & 0,10 & 1,2 & 450 \\
\hline 2 & $\mathrm{PVi}(\mathrm{b})$ & $4,(3 / 1)$ & $75 / 80$ & 0,10 & 0,5 & 450 \\
\hline 3 & $\mathrm{PVi}\left(\mathrm{b}_{2}\right)$ & $6,(4 / 2)$ & $75 / 85$ & 0,15 & 0,5 & 450 \\
\hline 4 & $\mathrm{PVi}\left(\mathrm{b}_{3}\right)$ & $6,(4 / 2)$ & $75 / 85$ & 0,20 & 0,4 & 450 \\
\hline 5 & $\mathrm{PVi}\left(\mathrm{b}_{4}\right)$ & $6,(4 / 2)$ & $75 / 85$ & 0,50 & 0,4 & 450 \\
\hline 6 & $\mathrm{PV}\left(\mathrm{b}_{5}\right)$ & $6,(4 / 2)$ & $75 / 80$ & 0,50 & 0,5 & 450 \\
\hline 7 & $\mathrm{PV}\left(\mathrm{b}_{6}\right)$ & $6,(4 / 2)$ & $75 / 80$ & 1,00 & 0,5 & 650 \\
\hline 8 & AOSUSP 2,5 & $4,(3 / 1)$ & $75 / 85$ & 0,15 & 0,5 & 450 \\
\hline 9 & AOSUSP 2,5b & $4,(3 / 1)$ & $75 / 85$ & 0,15 & 0,4 & 450 \\
\hline 10 & AOSUSP5a & $5,(3 / 2)$ & $75 / 85$ & 0,15 & 0,4 & 450 \\
\hline 11 & AOSUSP5b & $5,(3 / 2)$ & $75 / 85$ & 0,15 & 0,4 & 450 \\
\hline 12 & AOSUSP10a & $5,(3 / 2)$ & $75 / 85$ & 0,15 & 0,4 & 450 \\
\hline 13 & AOSUSP10b & $6,(4 / 2)$ & $75 / 85$ & 0,20 & 0,4 & 450 \\
\hline 14 & AOSUSP10c & $8,(6 / 2)$ & $75 / 85$ & 0,50 & 0,8 & 650 \\
\hline 15 & AOSUSP15a & $6,(4 / 2)$ & $75 / 80$ & 0,20 & 0,4 & 450 \\
\hline 16 & AOSUSP15b & $6,(4 / 2)$ & $75 / 80$ & 0,50 & 0,4 & 1000 \\
\hline 17 & AOSUSP15c & $6,(4 / 2)$ & $75 / 80$ & 2,00 & 0,5 & 650 \\
\hline 18 & AOSUSP20a & $6,(4 / 2)$ & $75 / 80$ & 2,00 & 0,5 & 650 \\
\hline
\end{tabular}

${ }^{\ddagger}$ As polimerizações foram conduzidas com uma fração mássica de fase orgânica de $30 \%$. Na coluna referente ao tempo de polimerização, o primeiro valor corresponde ao tempo total de reação e os valores em parênteses indicam o tempo no qual a temperatura do meio reacional foi mantida de acordo com os valores indicados na coluna de dados referente à temperatura de reação. 
Em processos poliméricos, o controle da distribuição de tamanhos depende de diversos efeitos como a quebra e a coalescência de gotas de monômero, que são resultantes, também, da velocidade de agitação do meio. Aumentos na velocidade causam uma maior quebra das gotas do monômero e redução no tamanho médio de partícula, velocidades menores provocam menos quebramentos e maiores tamanhos médios. ${ }^{127,151}$

A Figura 4.7 apresenta as distribuições de massa molar (DMM) de homopolímeros sintetizados com diferentes concentrações de iniciador peróxido de benzoíla (PBO), como apresentado na Tabela 4.3, com frações mássicas na faixa de $0,5 \%$ a 5,0 \% em relação a fase monomérica de $\mathrm{PVi}$.

Embora as DMMs apresentem comportamento unimodal, o efeito da concentração de PBO sobre a dispersão de massa molar (DISP) dos homopolímeros fica bastante claro, de forma que concentrações mais elevadas do iniciador organossolúvel conduz a DMMs largas e consequentemente a maiores valores de DISP, como ilustrado na Tabela 4.4.

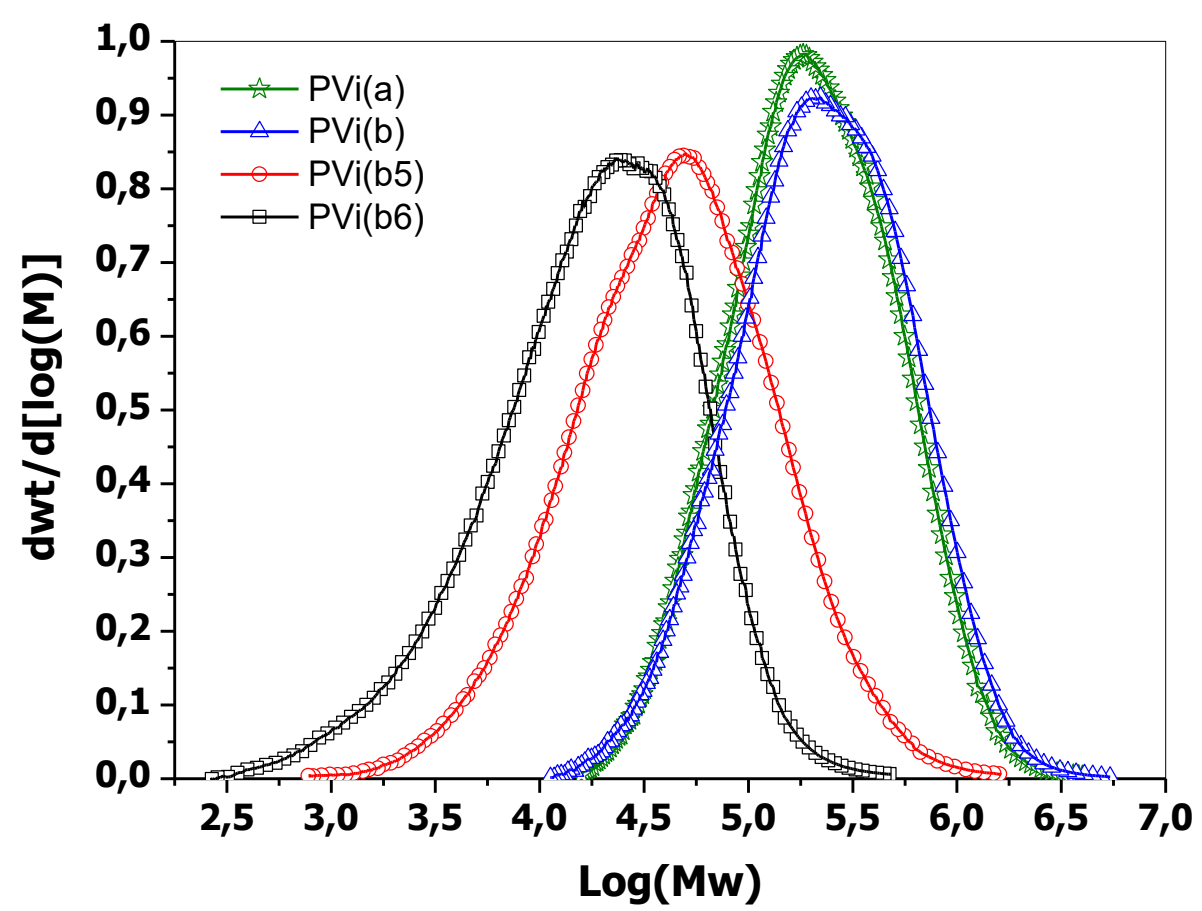

Figura 4.7. Distribuição de massa molar de homopolímeros de poli(pivalato de vinila).

Observa-se também na Figura 4.8 e Tabela 4.4 o efeito significativo da concentração de PBO sobre as massas molares médias em massa $\left(\mathrm{M}_{\mathrm{w}}\right)$ e em número $\left(\mathrm{M}_{n}\right)$. Valores pequenos de $\mathrm{M}_{\mathrm{w}}$ e $\mathrm{M}_{n}$ estão relacionados a uma menor 
concentração de cadeias poliméricas e a um número também reduzido de cadeias poliméricas com uma determinada concentração, respectivamente.

Tal comportamento reflete a capacidade dos radicais livres de iniciador de PBO em gerar mais cadeias poliméricas com tamanho menor a medida que sua concentração é aumentada no meio reacional.

Tabela 4.4. Massas molares médias de homopolímeros de PVi.

\begin{tabular}{|c|c|c|c|c|c|}
\hline Exp. & Código & BPO (g) & Mw (g/mol) & Mn (g/mol) & DISP \\
\hline 1 & $\mathrm{PVi}(\mathrm{a})$ & 0,10 & 304495 & 139096 & 2,19 \\
\hline 2 & $\mathrm{PVi}(\mathrm{b})$ & 0,10 & 346883 & 145165 & 2,39 \\
\hline 6 & $\mathrm{PVi}\left(\mathrm{b}_{5}\right)$ & 0,50 & 80508 & 22812 & 3,53 \\
\hline 7 & $\mathrm{PVi}\left(\mathrm{b}_{6}\right)$ & 1,00 & 30402 & 8350 & 3,64 \\
\hline
\end{tabular}

A Figura 4.8 apresenta a relação entre fração mássica de PBO e a DISP dos homopolímeros, que pode ser descrita por uma função do tipo sigmoide expressa pela Equação 3.2 .

$$
\mathrm{DISP}=\frac{\mathrm{a}}{1+\exp \left(-\mathrm{b} \cdot\left(\mathrm{x}_{\mathrm{PBO}}-\mathrm{c}\right)\right)}
$$

onde, XPBO corresponde a fração mássica de peroxido de benzoíla em relação a fase monomérica; $a, b$ e c são parâmetros ajustáveis $(a=3,64, b=7,29$ e c $=$ $\left.2,78 \times 10^{-2}\right)$.

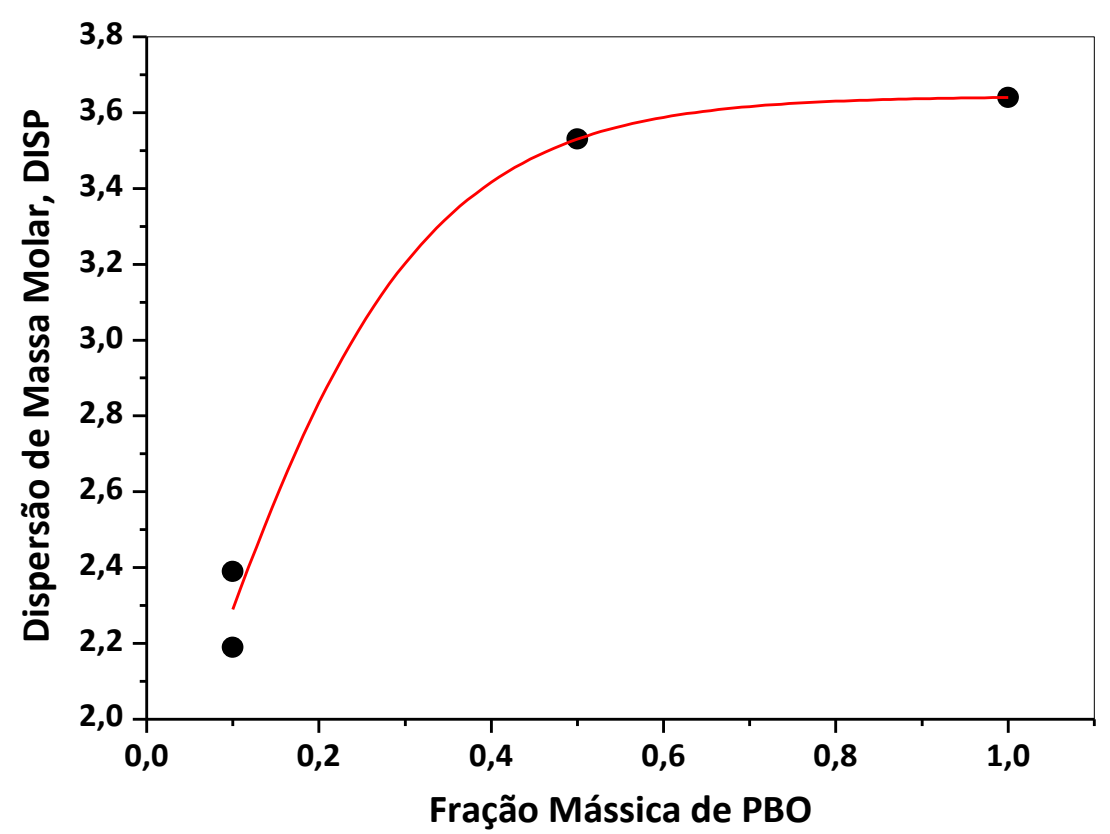

Figura 4.8. Efeito da concentração de PBO sobre a dispersão de massa molar dos homopolímeros. 
O efeito da concentração de iniciador também é observado quando a temperatura de transição vítrea $\left(T_{g}\right)$ dos homopolímeros de PVi são comparadas, como ilustrado na Tabela 4.5.

$A T_{g}$ de um material polimérico está diretamente relacionada a mobilidade das cadeias poliméricas amorfas presentes no mesmo, e em consequência disso, pode variar com o comprimento de cadeia dos polímeros. A partir dos dados mostrados na tabela 4.5 abaixo, podemos supor, também, que ocorreu uma competição do iniciador pelo monômero e pela nanopartícula, o que ajuda a entender a redução dos valores de $T_{g}$ nos experimentos 3 e 12 .

Desta forma, para um mesmo tipo de polímero sintetizado por um mesmo processo de polimerização é esperado que valores baixos de $T_{g}$ caracterizem baixas massas molares médias (obtidas graças a concentrações elevadas de PBO), que em última instância exibiriam maior mobilidade molecular. ${ }^{126,152}$

Tabela 4.5. Temperatura de Transição Vítrea de homopolímeros de PVi.

\begin{tabular}{|c|c|c|c|}
\hline Experimento & Código & BPO (g) & Tg $\left({ }^{\circ} \mathbf{C}\right)$ \\
\hline 3 & $\mathrm{PVi}\left(\mathrm{b}_{2}\right)$ & 0,15 & 81,2 \\
\hline 4 & $\mathrm{PVi}\left(\mathrm{b}_{3}\right)$ & 0,20 & 81,1 \\
\hline 5 & $\mathrm{PVi}\left(\mathrm{b}_{4}\right)$ & 0,50 & 61,2 \\
\hline 6 & $\mathrm{PVi}\left(\mathrm{b}_{5}\right)$ & 0,50 & 61,8 \\
\hline 7 & $\mathrm{PVi}\left(\mathrm{b}_{6}\right)$ & 1,00 & 60,2 \\
\hline 12 & $\mathrm{AOSUSP} 10 \mathrm{a}$ & 0,15 & 70,2 \\
\hline 16 & $\mathrm{AOSUSP} 15 \mathrm{~b}$ & 0,50 & 70,7 \\
\hline
\end{tabular}

A fração de nanopartículas magnéticas dispersas na matriz polimérica e a estabilidade do material frente à temperatura foram avaliadas por meio de análises termogravimétricas, como mostra a Figura 4.9.

A Figura 4.10 mostra, também, que os materiais poliméricos de natureza magnética analisados apresentam fração mássica de NPMM na faixa de $8 \%$ a $16 \%$. 


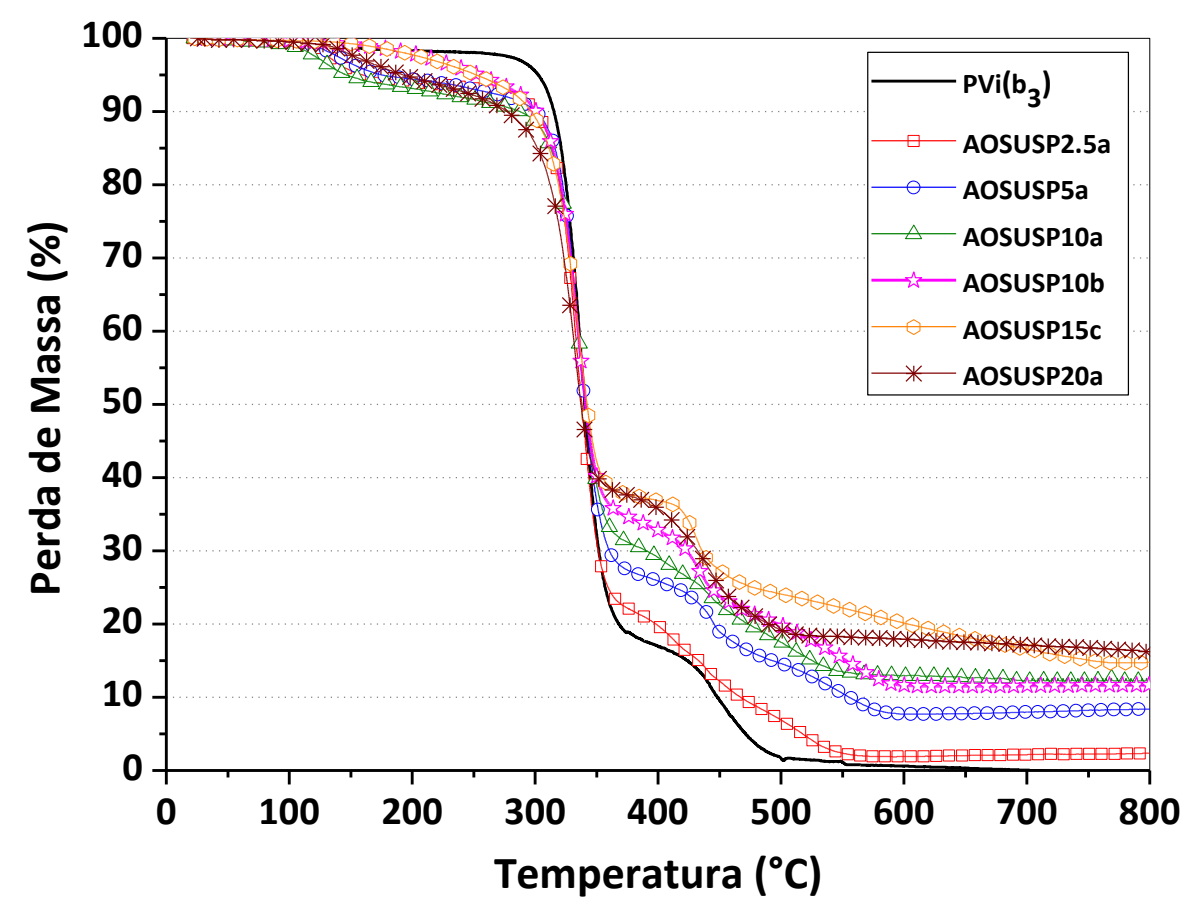

Figura 4.9. Estabilidade térmica dos materiais poliméricos. AOSUSP2,5a - INP $=2,15 \% \mathrm{p} / \mathrm{p} ;$ AOSUSP $5 \mathrm{a}-\mathfrak{I N N P}_{\mathrm{NP}}=7,97 \% \mathrm{p} / \mathrm{p} ;$ AOSUSP $10 \mathrm{~A}-\mathfrak{I}_{\mathrm{NP}}=11,79 \% \mathrm{pp}$ AOSUSP $10 b-\mathfrak{I N P}_{\mathrm{NP}}=11,55 \% \mathrm{pp}$ AOSUSP $15 \mathrm{c}-\mathfrak{I}_{\mathrm{NP}}=14,76 \% \mathrm{p} / \mathrm{p} ;$ AOSUSP20a $-\mathfrak{I}_{N P}=16,22 \% \mathrm{p} / \mathrm{p}$

Verifica-se que os materiais poliméricos sofrem degradação total numa faixa de temperatura entre 100 e $600{ }^{\circ} \mathrm{C}$, exibindo perdas de massa características:

i) A primeira perda de massa ocorre na faixa situada entre $100^{\circ} \mathrm{C} \mathrm{e}$ $200^{\circ} \mathrm{C}$ corresponde a aproximadamente $10 \% \mathrm{p} / \mathrm{p}$ de massa, atribuída à água livre;

ii) A segunda perda de massa, relacionada à decomposição de matéria orgânica, é observada na faixa situada entre $300^{\circ} \mathrm{C}$ e $450^{\circ} \mathrm{C}$, correspondendo a aproximadamente $70 \% \mathrm{p} / \mathrm{p}$;

iii) A terceira perda $450^{\circ} \mathrm{C}$ e $700^{\circ} \mathrm{C}$, diz respeito à ocorrência de transformações estruturais em outros óxidos de ferro. ${ }^{153}$

As curvas de decomposição indicam que o material apresenta boa estabilidade térmica e que há um padrão de decomposição associado à magnetita e os compostos de pivalato de vinila que a possuem em sua composição.

A Tabela 4.6 apresenta dados de tamanho de cristalito $\left(\chi_{\mathrm{NP}}\right)$ e fração mássica (JNP) de nanopartículas de magnetita dispersas na matriz termoplástica do PPVi. De a acordo com as condições experimentais avaliadas, materiais 
sintetizados apresentando $\Im_{N P}$ na faixa de $8 \%$ a $16 \%$ exibem tamanhos de cristalito similares (determinados com base nos dados apresentados na Figura 4.9) ao valor determinado para a magnetita pura, o que sugere que as propriedades magnéticas das NPMM precursoras são preservadas, e que as nanopartículas magnéticas foram apropriadamente dispersas na matriz termoplástica de PPVi.

Tabela 4.6. Fração mássica de NPMM e tamanho de cristalito.

\begin{tabular}{|c|l|c|c|c|}
\hline Experimento & \multicolumn{1}{|c|}{ Código } & BPO (g) & $\mathfrak{I}_{\mathbf{N P}}(\%)$ & $\chi_{\mathbf{N P}}(\mathbf{n m})$ \\
\hline 4 & $\mathrm{PVi}\left(\mathrm{b}_{3}\right)$ & 0,20 & 0,00 & 0,00 \\
\hline 10 & AOSUSP5a & 0,15 & $7,97 \pm 0,99$ & 7,42 \\
\hline 11 & AOSUSP5b & 0,15 & $8,15 \pm 0,67$ & 8,59 \\
\hline 12 & AOSUSP10a & 0,15 & $11,79 \pm 0,14$ & 8,28 \\
\hline 13 & AOSUSP10b & 0,20 & $11,55 \pm 0,98$ & 8,07 \\
\hline 16 & AOSUSP15b & 0,50 & $11,77 \pm 0,72$ & 8,17 \\
\hline 17 & AOSUSP15c & 2,00 & $14,76 \pm 2,17$ & 9,29 \\
\hline 18 & AOSUSP20a & 2,00 & $16,22 \pm 0,03$ & 8,59 \\
\hline
\end{tabular}

A Figura 4.10 mostra os difratogramas dos nanocompósitos magnetopoliméricos com diferentes concentrações de nanopartículas de $\mathrm{Fe}_{3} \mathrm{O}_{4}$ dispersas na matriz de poli(pivalato de vinila).

Os picos característicos às nanopartículas magnéticas são observados em $2 \theta=30,2 ; 35,6 ; 43,3 ; 53,4 ; 57,3 ; 62,8$ e $74,3^{\circ}$, correspondendo as reflexões (220), (311), (400), (422), (511), (440) e (533) da estrutura cristalina do tipo espinélio da magnetita. A Figura 3 mostra ainda dois picos de reflexão largos relativos ao poli(pivalato de vinila), localizados em $2 \theta=9,1^{\circ}$ e $17,8^{\circ}$. 


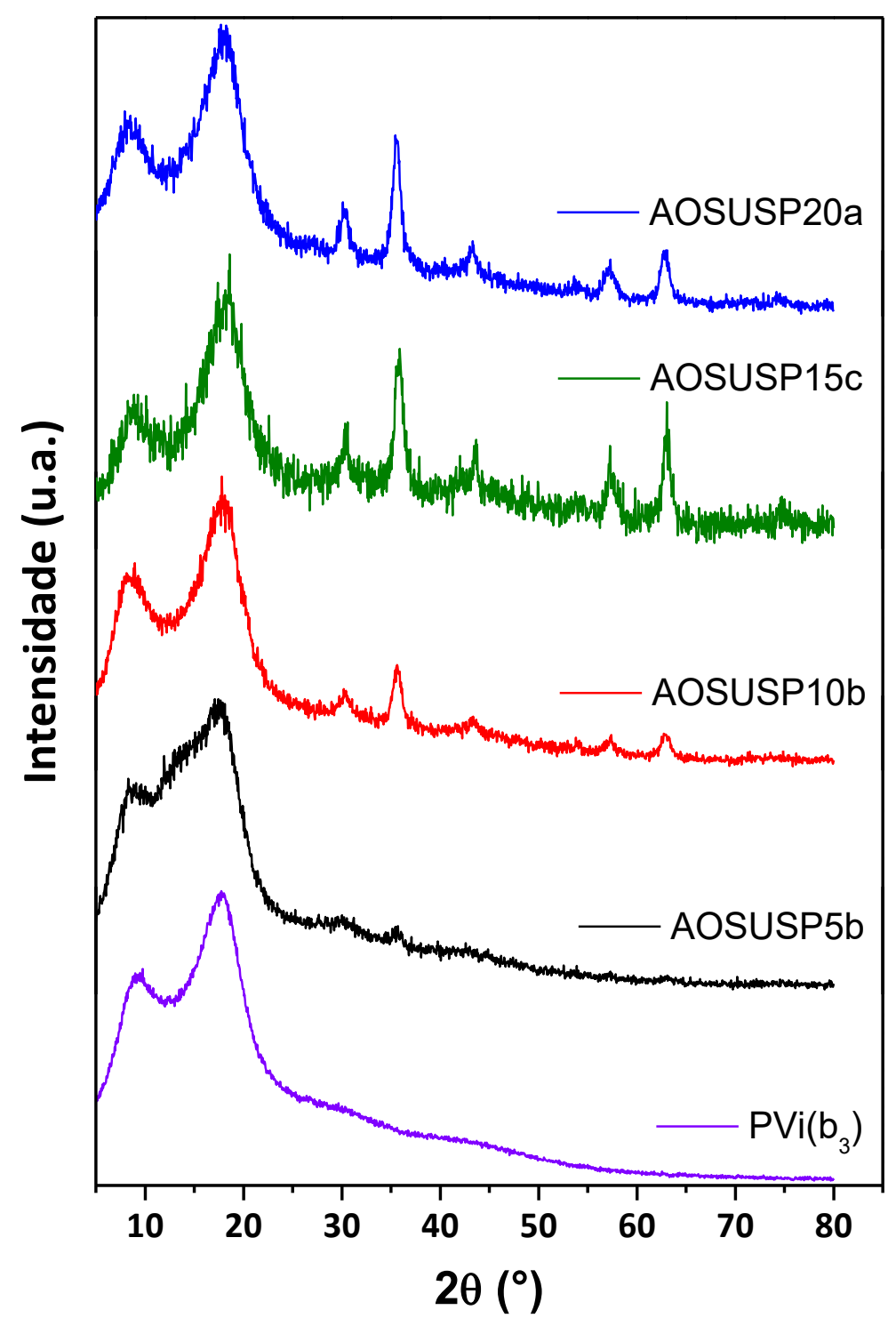

Figura 4.10. Difratograma dos nanocompósitos magnéticos. Concentração de nanopartículas de $\mathrm{Fe}_{3} \mathrm{O}_{4}$ igual a 8,5\% p/p para amostra AOSUSP5b, 11,6 \% p/p para AOSUSP10b, 14,8 \% p/p para AOSUSP $15 \mathrm{c}, 16,2 \%$ p/p para AOSUSP $20 a$.

Os valores de tamanho de cristalito - $\chi_{\mathrm{NP}}$ - determinados com base nos espectros de DRX, são importantes do ponto de vista da aplicação médica de embolização intravascular, dado que o caráter supermagnético, essencial para este procedimento médico, permanece presente nas micropartículas de poli(pivalato de vinila) / $\mathrm{Fe}_{3} \mathrm{O}_{4}$.

A Figura 4.11 mostra espectros de energia dispersiva de raios $X$ (EDX) dos nanocompósitos magnéticos, caracterizados por apresentar picos ka e k $\beta$ referentes ao ferro na faixa de $6,14 \mathrm{keV}$ a $7,27 \mathrm{keV}$. A fração de Fe nas amostras avaliadas foi determinada na faixa de $92 \%$ a $99 \%$. Análises de EDX também mostraram a presença de pequenas quantidades de $\mathrm{Al}, \mathrm{Mn}, \mathrm{Zn}, \mathrm{S}$ e $\mathrm{Si}$, que 
podem ser considerados como impurezas presentes nos reagentes empregados na síntese das nanopartículas.

Os resultados mostrados na Figura 4.11 são similares aqueles obtidos em outros trabalhos do nosso grupo de pesquisa, que dizem respeito a obtenção de micropartículas poliméricas a base de poliestireno / $\mathrm{Fe}_{3} \mathrm{O}_{4}$, poli(acetato de vinila) / $\mathrm{Fe}_{3} \mathrm{O}_{4}$ e poli(acetato de vinila) / poli(álcool vinílico) / $\mathrm{Fe}_{3} \mathrm{O}_{4}$ com morfologia do tipo casca-núcleo. ${ }^{42-44}$
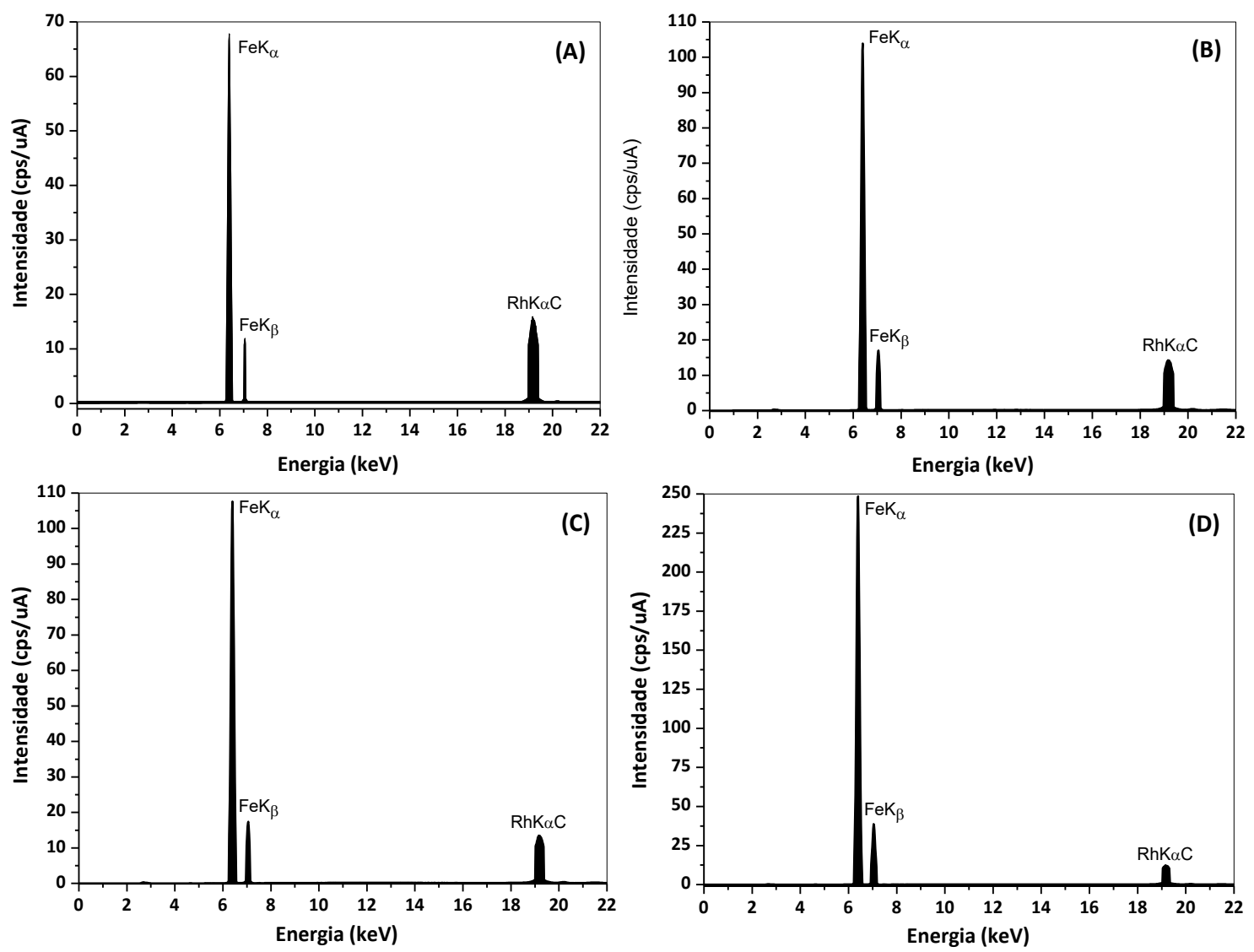

Figura 4.11. Espectros de energia dispersiva de raios $X$ dos nanocompósitos magnéticos. AOSUSP10a.
(A) AOSUSP2,5;
(B) AOSUSP5a;
(C) AOSUSP5b;

(D)

Morfologia uniforme é comumente considerada como uma característica essencial para um material polimérico ser utilizado com sucesso como agente embolizante em procedimentos de embolização intravascular (adotada para o tratamento de tumores, aneurismas e malformações arteriovenosas).

Espera-se que partículas poliméricas esféricas com superfície lisa apresentem uma grande capacidade de obstrução mecânica dos vasos sanguíneos, graças a fácil acomodação (empacotamento) o que favorece a interrupção do fornecimento de nutrientes à região tumoral, o que em última 
instância leva a diminuição de tamanho, permitindo a recuperação do tecido após intervalo de tempo menor.

As Figuras 4.12 e 4.13 apresentam a morfologia dos homopolímeros de $\mathrm{PVi}$ e nanocompósitos de $\mathrm{PPVi} / \mathrm{Fe}_{3} \mathrm{O}_{4}$, respectivamente. Como pode ser observado, as partículas poliméricas micrométricas, esféricas e com superfície regular são obtidas.
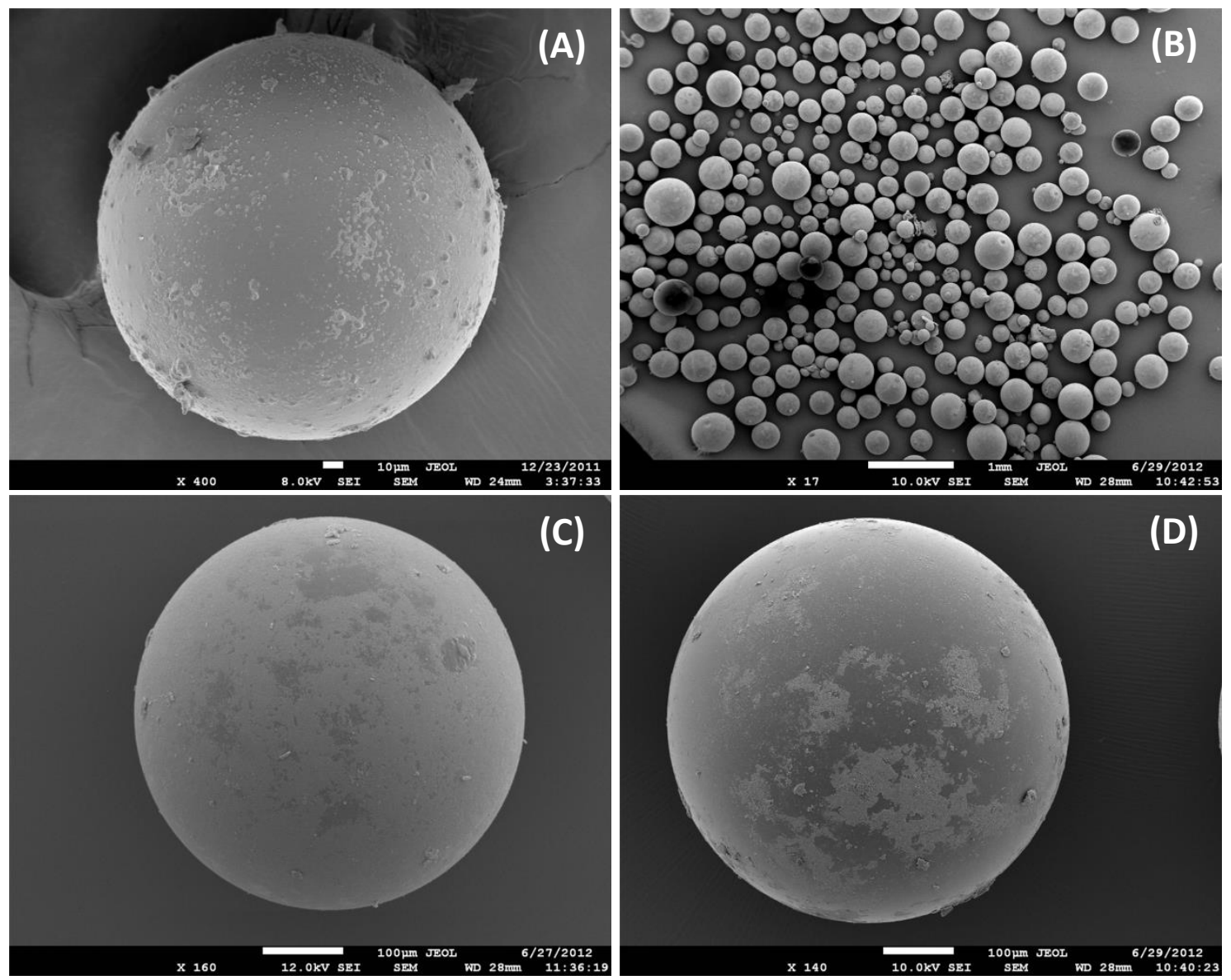

Figura 4.12. Microscopia eletrônica de varredura dos materiais poliméricos. (A) PVi(b 1$)$; (B) PVi(b $\left.b_{2}\right)$; (C) PVi(b3); (D) PVi(b4). 

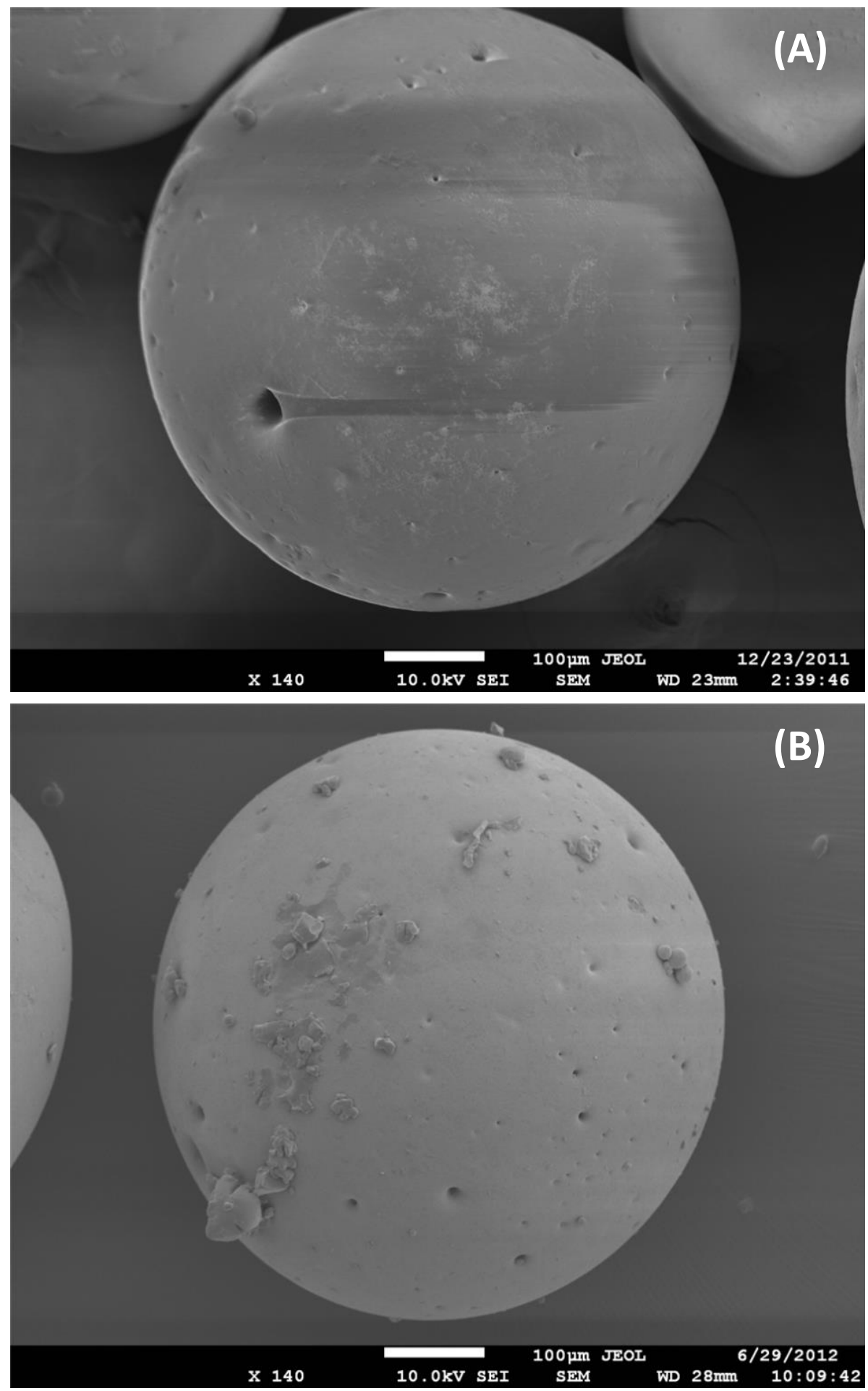

Figura 4.13. Microscopia eletrônica de varredura dos materiais poliméricos. (A) AOSUSP2,5; (B) AOSUSP2,5b.

As Figuras 4.14 a 4.16 apresentam a morfologia das partículas poliméricas com fração mássica de nanopartículas na faixa de $8 \%$ a $16 \%$ É interessante observar a formação de partículas poliméricas com morfologia irregular nestas condições experimentais. Estas formações morfológicas 
irregulares ocorrem como um efeito principal dos radicais de iniciador PBO, que atuam como um forte oxidante no meio de reação. ${ }^{126,154}$

Graças a esta característica marcante do PBO, é razoável acreditar que uma grande parte dos radicais de iniciador, gerados por decomposição térmica (cisão homolítica da molécula de PBO), atue significativamente na oxidação das nanopartículas de magnetita, transformando-as parcialmente em nanopartículas de maguemita. Como consequência imediata, a carência de radicais de iniciador no meio reacional conduz a uma diminuição significativa da conversão da reação.

Nestas situações, é comum a formação indesejável de partículas poliméricas achatadas, o que indica que a parcela de monômero não reagido presente na partícula de polímero impede que o ponto de identificação de partícula (PIP) seja alcançado (embora o PIP dependa das condições de reação, corresponde normalmente a conversões na faixa de $65 \%$ a 80\%), ${ }^{127,155,156}$ limite crítico a partir do qual a forma das partículas poliméricas não é alterada pela ação cisalhante do impedidor (responsável pela quebra das partículas) e/ou pela coalescência de partículas. ${ }^{157,} 158$

O problema de morfologia irregular das nanopartículas poliméricas pode ser resolvido pela adoção de concentrações de PBO elevadas, de forma a garantir que um excedente de radicais de iniciador no meio seja direcionada à polimerização eficaz das moléculas de monômero.

Como pode ser observado nas Figuras 4.14B, 4.15B e 4.16B, partículas poliméricas com morfologia regulares podem ser obtidas, quando concentrações de iniciador mais elevadas são utilizadas. 

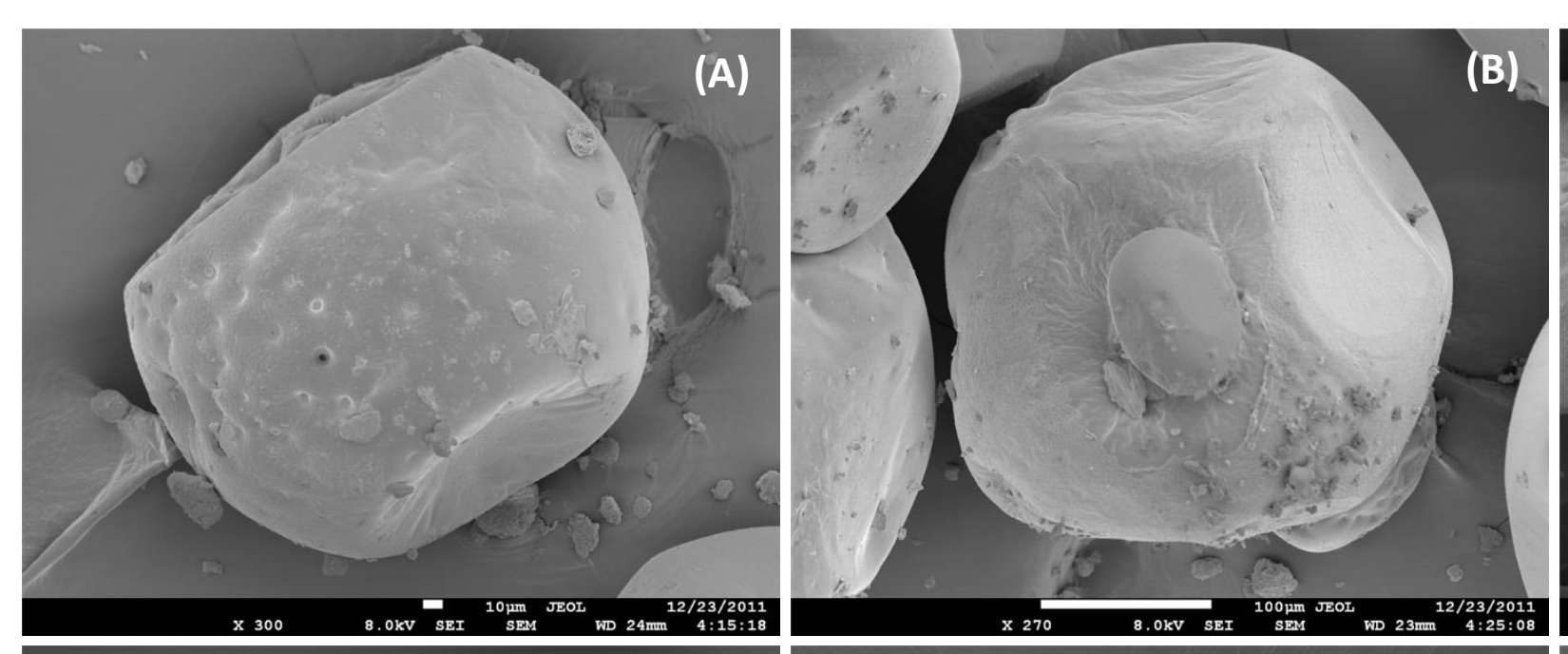

(D)
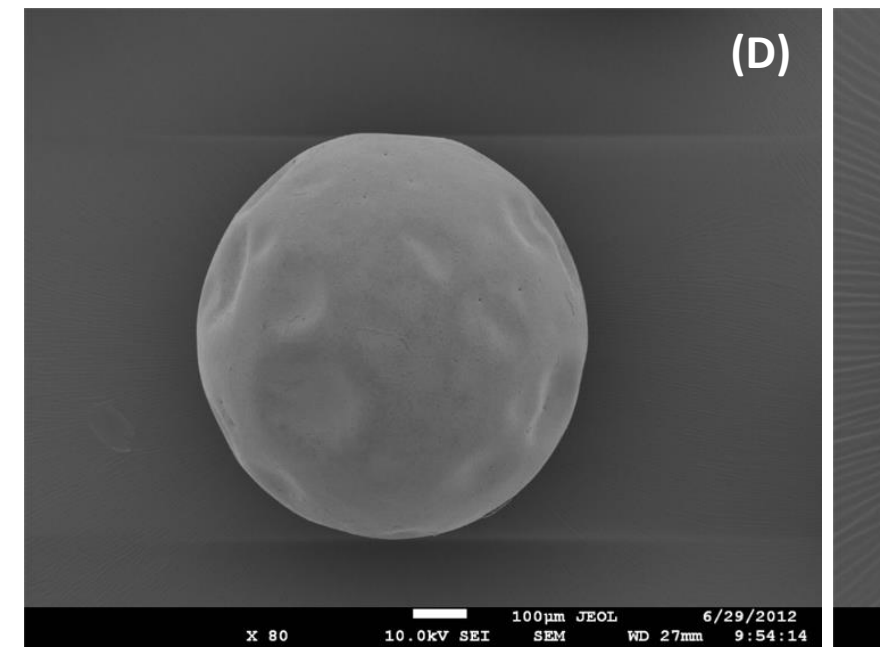

\begin{abstract}
$\times 270$
\end{abstract}
Figura 4.14. Microscopia eletrônica de varredura dos materiais poliméricos. (A-C) AOSUSP5a; (D-F) AOSUSP5b.

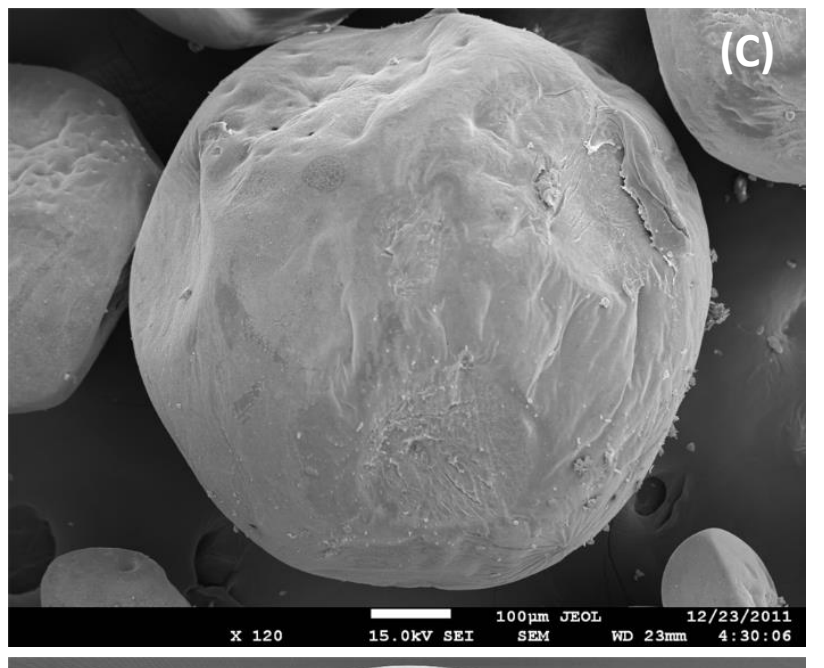

(F) 

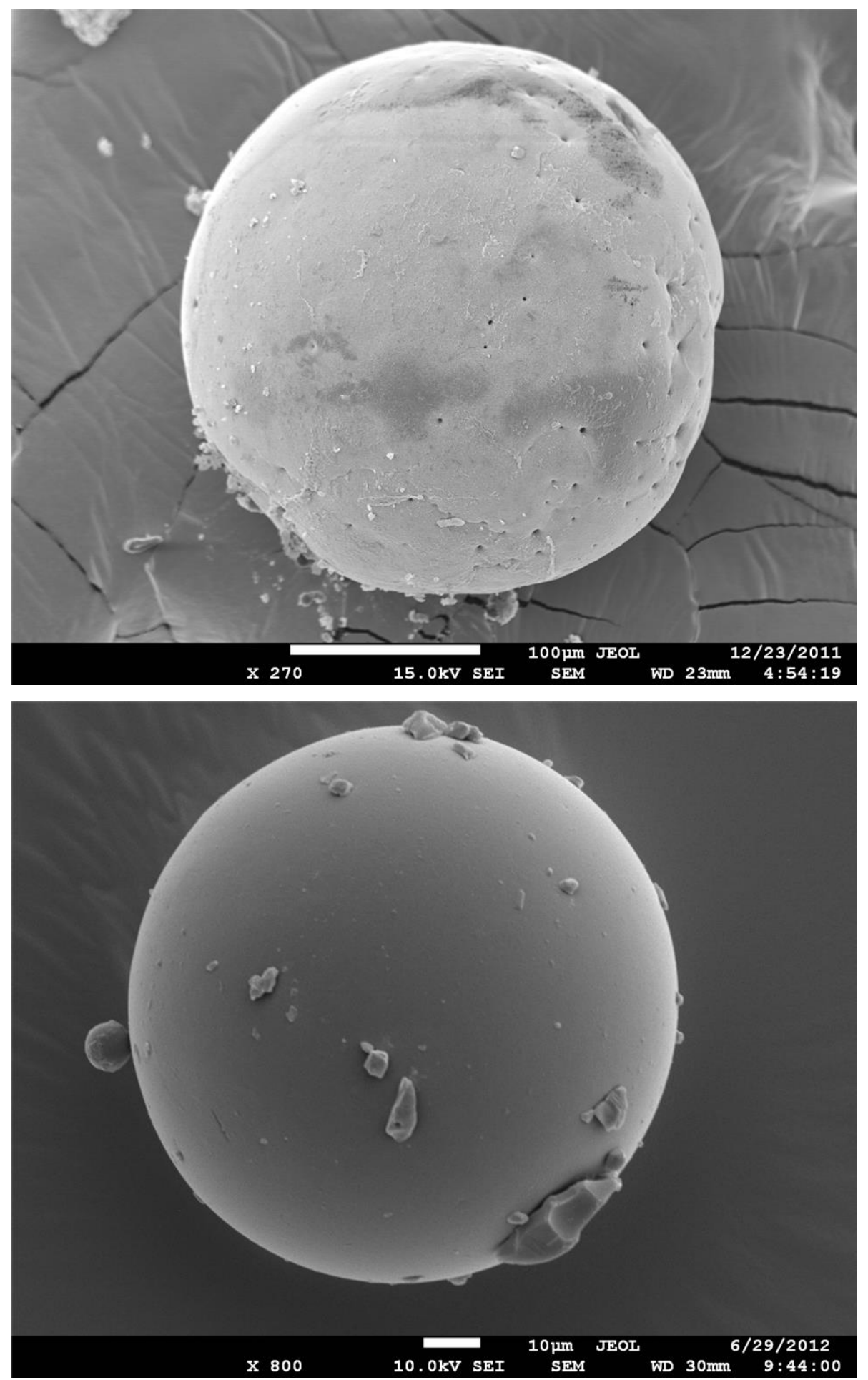

Figura 4.15. Microscopia eletrônica de varredura dos materiais poliméricos. (A) AOSUSP10a; (B) AOSUSP10b. 

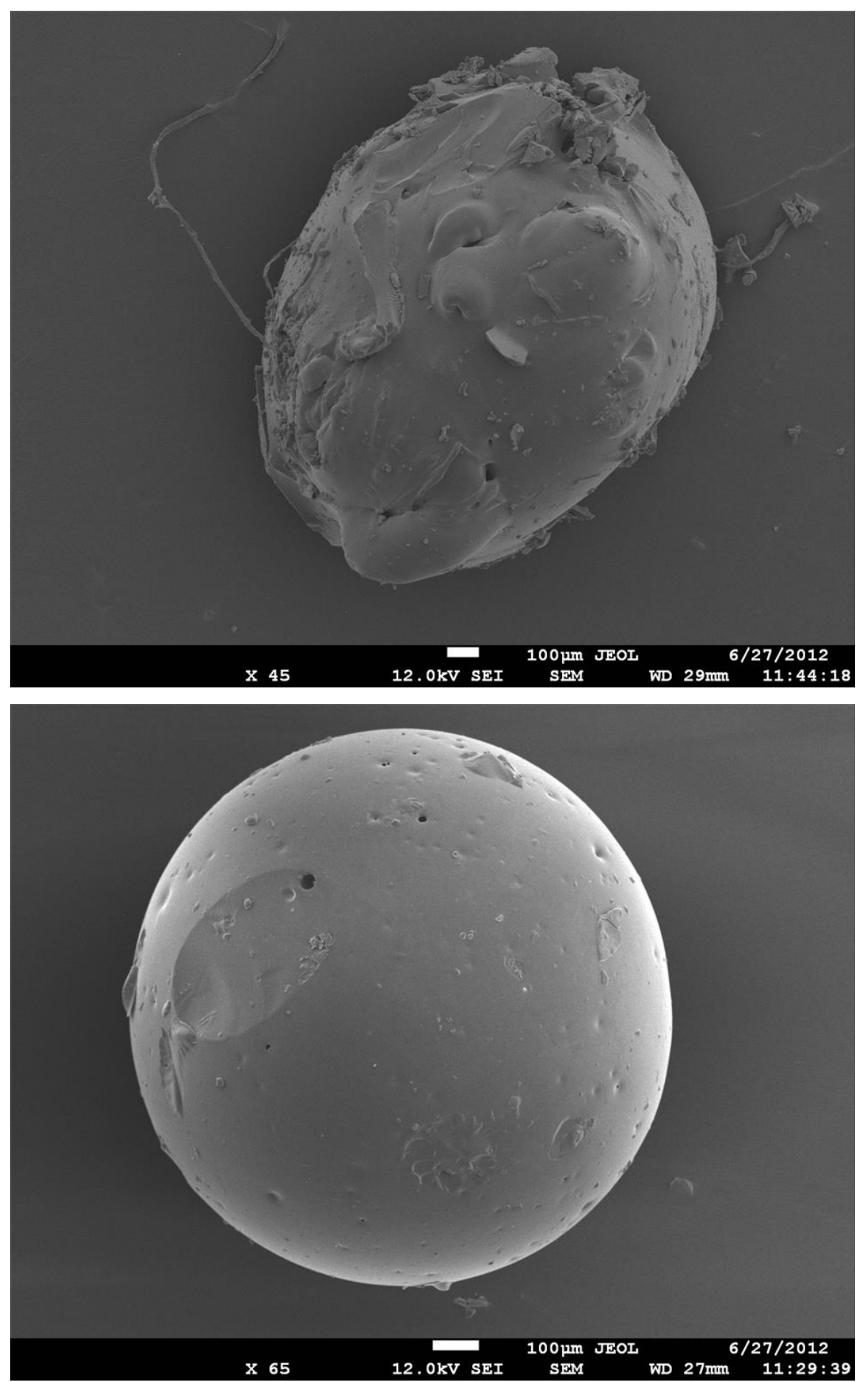

Figura 4.16. Microscopia eletrônica de varredura dos materiais poliméricos. (A) AOSUSP15a; (B) AOSUSP15c.

As Figuras 4.17 a 4.20 ilustram os perfis de magnetização da magnetita pura e de nanocompósitos de $\mathrm{PPVi} / \mathrm{Fe}_{3} \mathrm{O}_{4} \mathrm{com}$ teor de magnetita iguais a $8 \%$ $\mathrm{p} / \mathrm{p}$ e $16 \% \mathrm{p} / \mathrm{p}$. Observa-se que a resposta frente ao campo magnético é diretamente proporcional à fração de nanopartículas de $\mathrm{Fe}_{3} \mathrm{O}_{4}$ na amostra. 
Comparativamente, micropartículas contendo $16 \% \mathrm{p} / \mathrm{p}$ de $\mathrm{Fe}_{3} \mathrm{O}_{4}$ exibem uma força magnética cerca de cinco vezes maior a observada para a amostra com $8 \% \mathrm{p} / \mathrm{p}$ de $\mathrm{Fe}_{3} \mathrm{O}_{4}$ dispersos na matriz termoplástica de PPVi, como mostra a Figura 4.19.

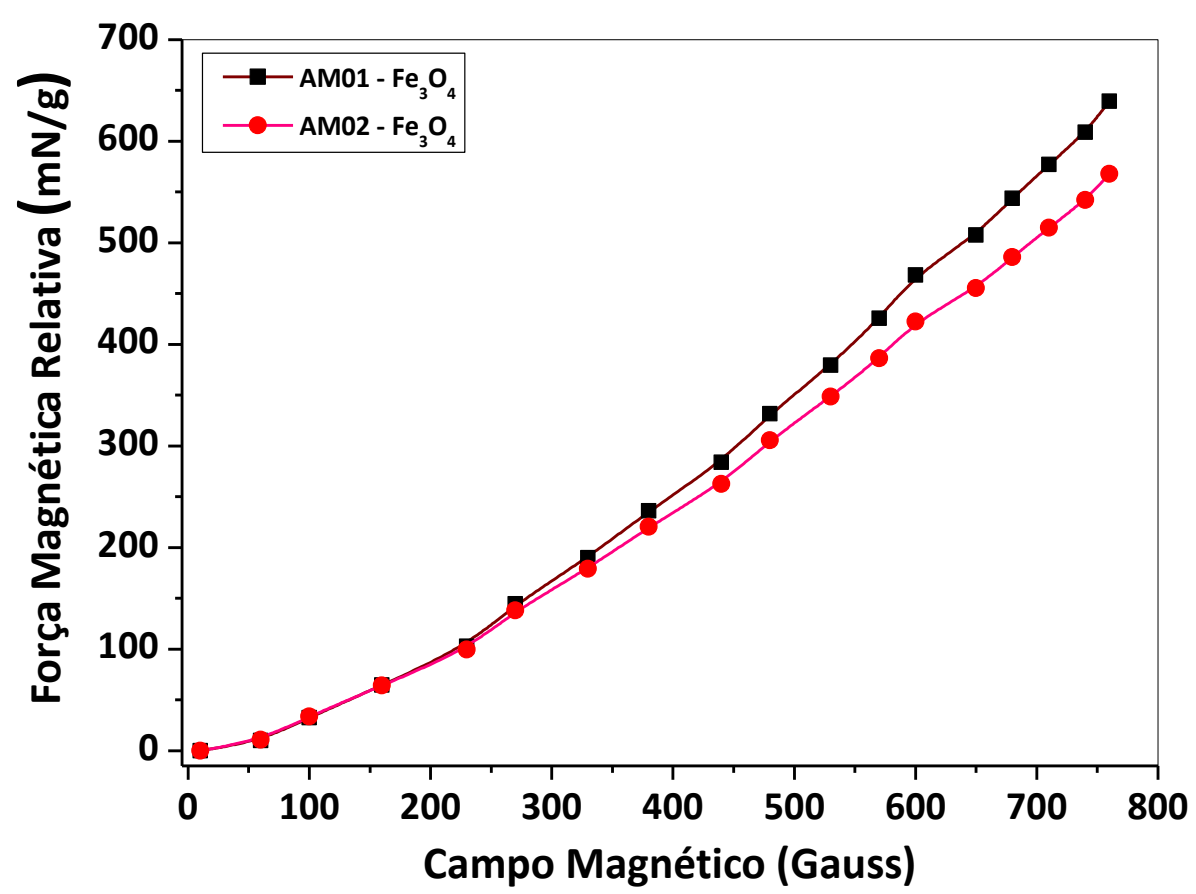

Figura 4.17. Força magnética relativa das nanopartículas magnéticas de $\mathrm{Fe}_{3} \mathrm{O}_{4}$.

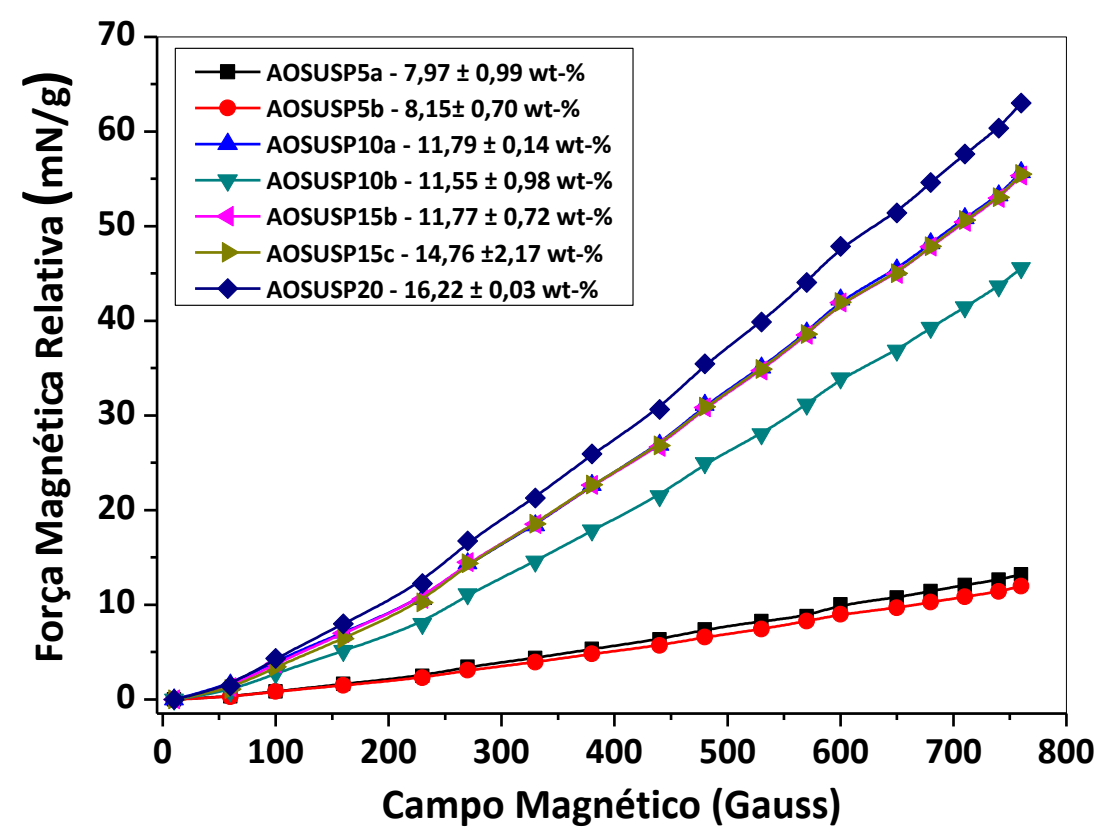

Figura 4.18. Comportamento magnético dos materiais poliméricos. 


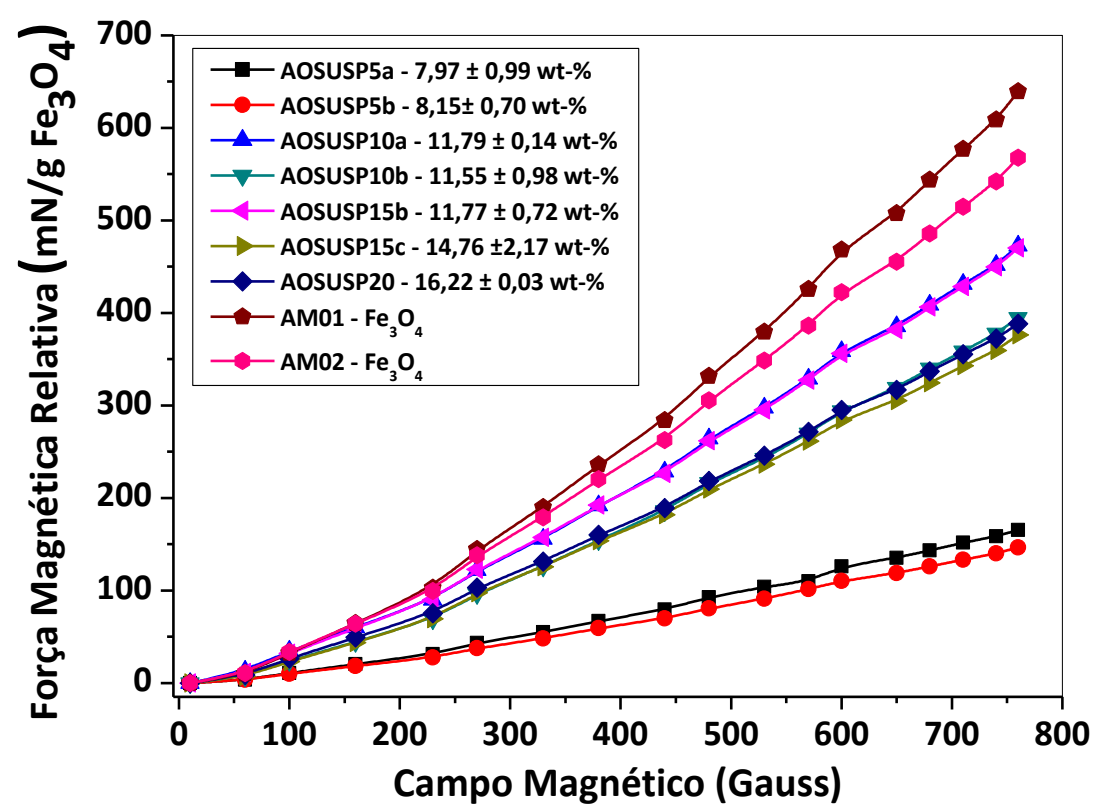

Figura 4.19. Força magnética relativa dos materiais poliméricos.

Comportamento similar é observado, quando a força magnética é corrigida pela quantidade de nanopartícula dispersa na matriz termoplástica de $\mathrm{PVi}$, com resposta magnética proporcional à fração de nanopartículas, como mostrado na Figura 4.19.

A Figura 4.19 também mostra o comportamento magnético dos materiais poliméricos. Observa-se, a partir das curvas, que a magnetização é proporcional ao teor de magnetita dispersa na matriz polimérica (Figura 4.19A). O mesmo é observável quando os valores de magnetização são representandos levando em conta a fração mássica (INP) de nanopartículas magnéticas, exibindo, assim, uma magnetização de saturação variando de 7 a $22 \mathrm{emu} / \mathrm{g}$ de magnetita, o que corresponde a uma fração mássica no intervalo $8<$ INP $<16$ (Figura 4.19B).

No caso das amostras em questão, a estimativa de magnetização de remanência e as forças coercitivas foram próximas a zero. Além disto, não foram observadas histereses, o que é um indicativo que os compostos sintetizados têm comportamento superparamagnético.

Estes materiais poliméricos são extremamente atrativos do posto de vista de aplicação em embolização intravascular, pois podem exibir ação dupla:

i) Embolização devida a obstrução mecânica apropriada dos vasos sanguíneos que irrigam a área lesionada, graças a forma esférica e 
morfologia controlada, o que favorece o empacotamento destas partículas;

ii) Comportamento superparamagnético, que consiste em característica fundamental para promover com sucesso o tratamento por hipertermia do tecido lesionado, em virtude da elevação controlada de temperatura, quando submetidos a um campo magnético externo.
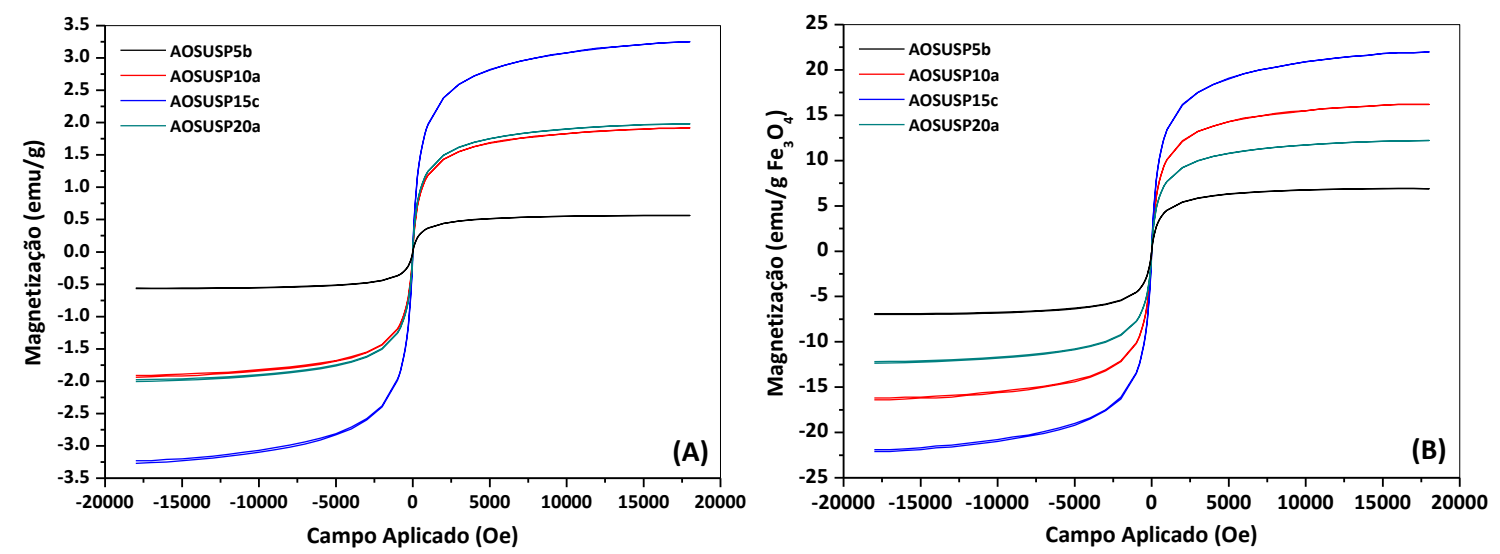

Figura 4.20. Curvas de magnetização dos nanocompósitos magnéticos. (A) comportamento magnético; $(\mathrm{B})$ comportamento magnético relativo.

A espectroscopia Raman auxilia na identificação do tipo de nanopartícula presente na amostra uma vez que traz alguns modos vibracionais que são inativos no infravermelho como previsto nas regras de seleção da teoria de grupos. ${ }^{103,159}$

A Figuras 4.21 mostra o espectro Raman dos materiais poliméricos com diferentes concentrações de NPMM adquiridos em modos de excitação em 633 $\mathrm{nm}$ (laser He-Ne) e 785 nm (diodo). As variações espectrais são observadas em diferentes comprimentos de onda como resposta as diferentes concentrações de nanopartículas de $\mathrm{Fe}_{3} \mathrm{O}_{4}$ dispersas na matriz de PPVi, cuja diminuição de intensidade dos picos é observada à medida que a fração de NPMM aumenta (ver Apêndice 3).

Observando o recorte da Figura 4.21, verifica-se uma faixa entre 667 e $708 \mathrm{~cm}^{-1}$ que traz informações a respeito do tipo de íons de ferro presentes na estrutura e, a partir da análise dos picos presentes, pode-se identificar as possíveis transformações em outros óxidos de ferro como a maguemita. 
O pico correspondente a $667 \mathrm{~cm}^{-1}$ pode ser associado ao fónon $A_{1 \mathrm{~g}}$ na teoria de grupos. No caso do ombro situado em $708 \mathrm{~cm}^{-1}$, o mesmo pode ser associado, pela teoria de grupos, ao fónon $A_{1}$ ativo, e que indica a presença de maguemita.

Esta observação auxilia na confirmação da ideia da interferência do iniciador da polimerização - peróxido de benzoíla - no sentido de provocar a transformação de parte da magnetita em maguemita.

Deste modo pode-se entender também a sobreposição das curvas na figura 4.21(A) para as amostras AOSUSP10a e AOSUSP20a a partir da tabela 4.6, uma vez que há um aumento na fração do iniciador na reação, e com isso, maior quantidade de maguemita pode ser formada e como a maguemita possui uma magnetização menor que a magnetita, há uma alteração no valor do sinal, tanto na magnetização quanto nos espectros de Raman mostrados na figura 4.21 a seguir .

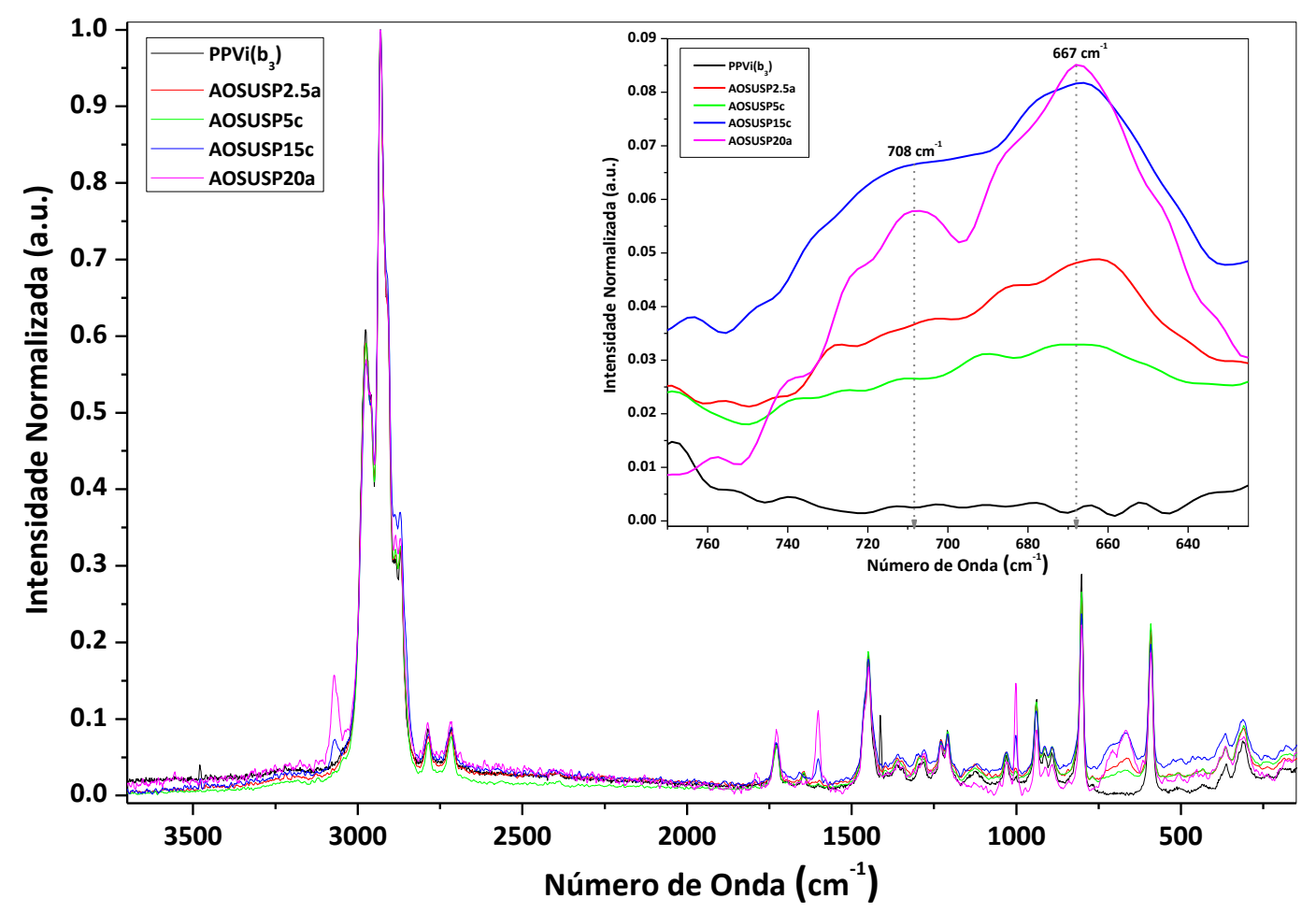

Figura 4.21. Espectro Raman dos Polímeros Sintetizados. (A)AOSUSP2,5a $\mathfrak{I N P}_{\mathrm{NP}}=2,15 \% \mathrm{p} / \mathrm{p}$; (B)AOSUSP $5 \mathrm{c}-\mathfrak{I N N P}_{\mathrm{N}}=7,97 \% \mathrm{p} / \mathrm{p} ;(\mathrm{C})$ AOSUSP $15 \mathrm{c}-\mathfrak{I N N P}_{\mathrm{N}}=$ $14,76 \% \mathrm{p} / \mathrm{p}$; (D) AOSUSP20a $-\Im_{\mathrm{NP}}=16,22 \% \mathrm{p} / \mathrm{p}$ 
Espectros de FTIR dos materiais poliméricos, mostrados na Figura 4.22, apresentam vibrações de estiramento $\mathrm{C}-\mathrm{H}\left(3015 \mathrm{~cm}^{-1}\right.$ vas $\mathrm{CH}_{3}, 2970 \mathrm{~cm}^{-1} v_{\text {as }} \mathrm{CH}_{2}$, $2946 \mathrm{~cm}^{-1} v_{\mathrm{s}} \mathrm{CH}_{3}$ e $2869 \mathrm{~cm}^{-1} v_{\mathrm{s}} \mathrm{CH}_{2}$ ), um pico por volta de $1737 \mathrm{~cm}^{-1}$ devido ao estiramento $\mathrm{C}=\mathrm{O}$ do grupo carbonila, modo vibracional de estiramento $\mathrm{CH}_{3}$ em $1435 \mathrm{~cm}^{-1}$, um pico de absorção em torno de $1216 \mathrm{~cm}^{-1}$ devido ao estiramento C-O do grupo carboxila. Observa-se também vibrações de estiramento dos grupos metila $\left(\mathrm{CH}_{3}\right)$ em $1147 \mathrm{~cm}^{-1}$ e do grupos metilenos $\left(\mathrm{CH}_{2}\right)$ em $1435 \mathrm{~cm}^{-1} .138$, $140,160,161$

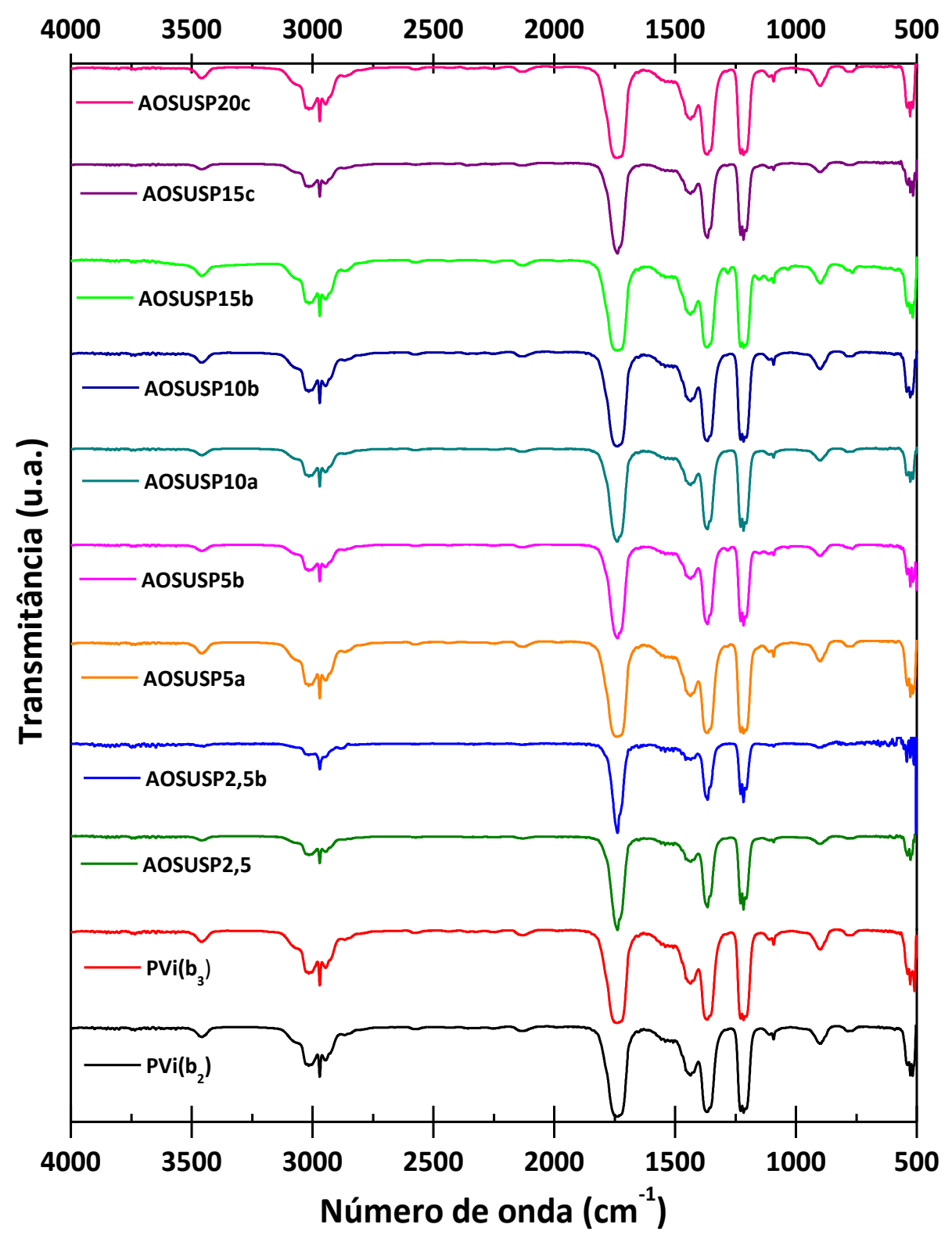

Figura 4.22. Espectroscopia FTIR dos materiais poliméricos. 


\section{CAPÍTULO 5 - CONCLUSÃO}

\subsection{CONSIDERAÇÕES FINAIS}

O desenvolvimento de materiais nanocompósitos poliméricos dotado de caráter magnético, apresentando morfologia controlada, visando aplicações biomédicas representa um grande desafio cientifico. Em particular para aplicações em emboloterapia, a síntese de micropartículas poliméricas com morfologia esférica é um requisito essencial para o êxito do procedimento cirúrgico.

Diferentes estudos experimentais foram realizados abordando os aspectos principais da síntese e caracterização de nanopartículas magnéticas de magnetita $\left(\mathrm{Fe}_{3} \mathrm{O}_{4}\right)$, homopolímeros de pivalato de vinila (PPVi) e nanocompósitos magnéticos a base de poli(pivalato de vinila) - PPVi e magnetita.

Nanopartículas de $\mathrm{Fe}_{3} \mathrm{O}_{4}$ sintetizadas com estrutura do tipo espinélio inversa e com propriedades superparamagnéticas, apresentando diâmetro médio de partícula em torno de $8 \mathrm{~nm}$ (determinado via análises de DRX e MET), após modificação química de suas superfícies com ácido oleico, foram homogeneamente dispersas em matrizes termoplásticas de PPVi. Análises termogravimétricas mostraram que os nanocompósitos magnéticos apresentam teor de $\mathrm{Fe}_{3} \mathrm{O}_{4}$ na faixa de 8 wt-\% a 16 wt- $\%$.

Partículas poliméricas magnéticas esféricas com morfologia controlada foram obtidas com sucesso, exibindo boa estabilidade térmica. No que tange a controle morfológico das micropartículas de PPVi, é necessário levar em consideração o efeito indesejável do iniciador radicalar BPO sobre a oxidação parcial das nanopartículas de $\mathrm{Fe}_{3} \mathrm{O}_{4}$, o que em última instância conduz a formação de PPVi com morfologia irregular, como consequência da carência de iniciador no meio de reação para promover a polimerização. A despeito deste aspecto negativo, micropartículas esféricas foram sintetizadas graças ao uso de excesso de iniciador.

Os tamanhos de cristalito determinados para os nanocompósitos magnéticos na faixa de 7,4 a 9,3 nm são bastantes similares ao valor determinado para a magnetita pura, o que sugere que as propriedades magnéticas das nanopartículas de $\mathrm{Fe}_{3} \mathrm{O}_{4}$ precursoras são preservadas, o que é 
um forte indicativo de que as nanopartículas magnéticas foram apropriadamente dispersas na matriz termoplástica de PPVi.

O comportamento magnético, avaliado através de medidas de magnetização, mostrou que os materiais magnetopoliméricos apresentam excelente resposta magnética proporcional a fração de $\mathrm{Fe}_{3} \mathrm{O}_{4}$ dispersa na matriz termoplástica de PPVi.

O resultados obtidos são bastantes promissores, já que do ponto de vista da aplicação médica de embolização intravascular, o caráter superparamagnético, essencial para este procedimento médico, permanece presente nas micropartículas de poli(pivalato de vinila) / $\mathrm{Fe}_{3} \mathrm{O}_{4}$.

No que tange a morfologia das micropartículas, o uso de agentes embolizantes com morfologia representa também uma característica essencial para o sucesso em procedimentos de embolização intravascular, pois a esfericidade e superfície lisa observadas nos materiais a base de PPVi e $\mathrm{Fe}_{3} \mathrm{O}_{4}$ podem ser responsáveis por uma maior capacidade de obstrução mecânica dos vasos sanguíneos, graças ao fácil empacotamento das micropartículas.

\subsection{PERSPECTIVAS DE TRABALHOS FUTUROS}

Embora nanocompósitos magnéticos com características magnéticas e morfológicas apropriadas para uso em procedimentos biomédicos tenham sido sintetizadas com sucesso, estudos adicionais devem ser realizados como uma tentativa de entender os efeitos principais da interação entre iniciador organossolúvel e as nanopartículas magnéticas de magnetita sobre o mecanismo cinético da polimerização.

Outro aspecto importante que deve ser levado em consideração diz respeito a incorporação de outras classes de nanopartículas magnéticas à matriz termoplástica de PPVi, como por exemplo, maguemita, e outras ferritas do tipo espinélio, $\xi \mathrm{Fe}_{2} \mathrm{O}_{4}$ (onde, $\xi=\mathrm{Ni}, \mathrm{Zn}$ ou $\mathrm{Co}$ ). $\mathrm{O}$ uso de novos tipos de ferritas de ferro ou mistas aumenta o leque de opções de aplicação desta nova classe de materiais magnetopoliméricos.

O teste in vitro destes novos materiais também corresponderia a uma etapa crucial para verificação da eficácia, no que tange a capacidade de obstrução mecânica dos vasos sanguíneos e de elevação controlada de 
temperatura pela ação de um campo magnético externo, promovendo assim, o efeito de hipertermia magnética. Outra possibilidade de aplicação para estes materiais seria a avaliação da possibilidade de uso como sensores para aplicação em diagnósticos médicos. 


\section{CAPÍTULO 6 - REFERÊNCIAS BIBLIOGRÁFICAS}

[1] LAURENT, S., FORGE, D., PORT, M., ROCH, A., ROBIC, C., ELST, L. V., MULLER, R.N. Magnetic Iron Oxide Nanoparticles: Synthesis, Stabilization, Vectorization, Physicochemical Characterizations, and Biological Applications. Chemical Reviews, v. 108, n. 6, p. 2064-2110, 2008.

[2] MAHMOUDI, M., SANT, S.; WANG, B., LAURENT, S., SEN, T. Superparamagnetic Iron Oxide Nanoparticles (Spions): Development, Surface Modification and Applications in Chemotherapy. Advanced Drug Delivery Reviews, v. 63 n. 1-2, p. 24-46, 2011.

[3] FIGUEROLA, A., DI CORATO, R., MANNA, L., PELLEGRINO, T. From Iron Oxide Nanoparticles Towards Advanced Iron-Based Inorganic Materials Designed for Biomedical Applications. Pharmacological Research, v. 62 n. 02, p. 126-143, 2010.

[4] KARAAGAC, O., KOCKAR, H. Effect of Synthesis Parameters on the Properties of Superparamagnetic Iron Oxide Nanoparticles. Journal of Superconductivity and Novel Magnetism, v. 25, n. 8, p. 2777-2781, 2012.

[5] MAHDAVIAN, A. R. \& MIRRAHIMI, M. A. Efficient Separation of Heavy Metal Cations by Anchoring Polyacrylic Acid on Superparamagnetic Magnetite Nanoparticles through Surface Modification. Chemical Engineering Journal, v. 159, n. 1-3, p. 264-271, 2010.

[6] SHEN, Y. F., TANG, J., NIE, Z. H., WANG, Y. D., REN, Y. \& ZUO, L. Preparation and Application of Magnetic $\mathrm{Fe}_{3} \mathrm{O}_{4}$ Nanoparticles for Wastewater Purification. Separation and Purification Technology, v. 68, n. 3, p. 312319, 2009.

[7] ZHANG, F., ZHU, Z., DONG, Z., CUI, Z., WANG, H., HU, W., ZHAO, P., WANG, P., WEI, S., LI, R. \& MA, J. Magnetically Recoverable Facile Nanomaterials: Synthesis, Characterization and Application in Remediation of Heavy Metals. Microchemical Journal, v. 98 n. 2, p. 328-333, 2011.

[8] GAMARRA, L. F., BRITO, G. E. S., PONTUSCHKA, W. M., AMARO, E., PARMA, A. H. C. \& GOYA, G. F. Biocompatible Superparamagnetic Iron Oxide Nanoparticles Used for Contrast Agents: A Structural and Magnetic Study. Journal of Magnetism and Magnetic Materials, v. 289, p. 439-441, 2005.

[9] KIM, B. H., LEE, N., KIM, H., AN, K., PARK, Y. I., CHOI, Y., SHIN, K., LEE, Y., KWON, S. G., NA, H. B., PARK, J., AHN, T., KIM, Y., MOON, W. K., CHOI, S. H. \& HYEON, T. Large-Scale Synthesis of Uniform and Extremely SmallSized Iron Oxide Nanoparticles for High-Resolution $\mathrm{T}_{1}$ Magnetic Resonance Imaging Contrast Agents. Journal of the American Chemical Society, v. 133, n. 32, p. 12624-12631, 2011.

[10] TOGASHI, T., NAKA, T., ASAHINA, S., SATO, K., TAKAMI, S. \& ADSCHIRI, T. Surfactant-Assisted One-Pot Synthesis of Superparamagnetic Magnetite Nanoparticle Clusters with Tunable Cluster Size and Magnetic Field Sensitivity. Dalton Transactions, v. 40, n. 5, p. 1073 -1078, 2011.

[11] WITTENBERG, N. J. \& HAYNES, C. L. Using Nanoparticles to Push the Limits of Detection. WIREs Nanomedicine and Nanobiotechnology, v. 1, n. 2, p. 237-254, 2009.

[12] HERGT, R. \& DUTZ, S. Magnetic Particle Hyperthermia-Biophysical Limitations of a Visionary Tumour Therapy. Journal of Magnetism and Magnetic Materials v. 311, n. 1, p. 187-192, 2007. 
[13] SHARMA, R. \& CHEN, C. J. Newer Nanoparticles in Hyperthermia Treatment and Thermometry. J Nanopart Res v. 11, n. 3, p. 671-689, 2009

[14] VILLANUEVA, A., DE LA PRESA, P., ALONSO, J. M., RUEDA, T., MARTÍNEZ, A., CRESPO, P., MORALES, M. P., GONZALEZ-FERNANDEZ, M. A., VALDÉS, J. \& RIVERO, G. Hyperthermia Hela Cell Treatment with Silica-Coated Manganese Oxide Nanoparticles. Journal of Physical Chemistry C, v. 114, n. 5, p. 1976-1981, 2010.

[15] ALLEN, T. M., CULLIS, P. R. Drug Delivery Systems: Entering the Mainstream. Science v. 303, n. 5665, p. 1818-1822, 2004.

[16] HU, A., YEE, G. T. \& LIN, W. Magnetically Recoverable Chiral Catalysts Immobilized on Magnetite Nanoparticles for Asymmetric Hydrogenation of Aromatic Ketones. Journal of the American Chemical Society, v. 127, n. 36, p. 12486-12487, 2005.

[17] SOUZA, W. F., PEREIRA, M. C. \& OLIVEIRA, L. C. A. Amphiphilic Catalysts Based on Onion-Like Carbon over Magnetic Iron Oxide for Petrochemical Industry Use. Fuel v. 96, p. 604-607, 2012.

[18] DHAKSHINAMOORTHY, A., NAVALON, S., ALVARO, M. \& GARCIA, H. Metal Nanoparticles as Heterogeneous Fenton Catalysts. ChemSusChem, v. 5, n. 1, p. 46-64, 2012.

[19] WANG, Y. \& DAVIS, B. H. Fischer-Tropsch Synthesis. Conversion of Alcohols over Iron Oxide and Iron Carbide Catalysts. Applied Catalysis A: General, v. 180, n. 1-2, p. 277-285, 1999.

[20] MOODLEY, P., SCHEIJEN, F. J. E., NIEMANTSVERDRIET, J. W. \& THÜNE, P. C. Iron Oxide Nanoparticles on Flat Oxidic Surfaces-Introducing a New Model Catalyst for Fischer-Tropsch Catalysis. Catalysis Today, v. 154, n. 1-2, p. 142-148, 2010.

[21] GOODE, J. A. \& MATSON, M. B. Embolisation of Cancer: What is the Evidence? Cancer Imaging, v. 4, n. 2, p. 133-141, 2004.

[22] LOOKSTEIN, R. A. \& GULLER, J. Embolization of Complex Vascular Lesions. The Mount Sinai Journal of Medicine, v. 71, n. 1, p. 17-28, 2004.

[23] TAM, K. Y., LEUNG, K. C. \& WANG, Y. J. Chemoembolization Agents for Cancer Treatment. European Journal of Pharmaceutical Sciences, v. 44, n. 1-2, p. 1, 2011.

[24] DERDEYN, C. P., GRAVES, V. B., SALAMAT, M. S. \& RAPPE, A. CollagenCoated Acrylic Microspheres for Embolotherapy: In Vivo and in Vitro Characteristics. American Journal of Neuroradiology, v. 18, p. 647-653, 1997.

[25] CHEN, X., LV, H., YE, M., WANG, S., NI, E., ZENG, F., CAO, C., LUO, F. \& YAN, J. Novel Superparamagnetic Iron Oxide Nanoparticles for Tumor Embolization Application: Preparation, Characterization and Double Targeting. International Journal of Pharmaceutics v. 426, p. 248- 255, 2012.

[26] BAER, D. R., BURROWS, P. E., EL-AZAB, A. A. . Enhancing Coating Functionality Using Nanoscience and Nanotechnology. Progress in Organic Coatings, v. 47 n. 3-4, p. 342-356, 2003.

[27] WOODING, A., KILNER, M., LAMBRICK, D.B. Studies of the Double Surfactant Layer Stabilization of Water-Based Magnetic Fluids. Journal of Colloid and Interface Science, v. 144, n. 1, p. 236-242, 1991. 
[28] MAJEWSKI, P., THIERRY, B. Functionalized Magnetite NanoparticlesSynthesis, Properties, and Bio-Applications. Critical Reviews in Solid State and Materials Sciences, v. 32, n. 3-4, p. 203-215, 2007.

[29] ABDALLA, M. A., JAAFAR, M. H., AL-OTHMAN, Z. A., ALFADUL, S. M. \& KHAN, M. A. New Route for Preparation and Characterization of Magnetite Nanoparticles. Arabian Journal of Chemistry v. 4, n. 2, p. 235-237, 2011.

[30] LASSALLE, V. L., ZYSLER, R. D. \& FERREIRA, M. L. Novel and Facile Synthesis of Magnetic Composites by a Modified Co-Precipitation Method. Materials Chemistry and Physics, v. 130, n. 1-2, p. 624-634, 2011.

[31] DAOU, T. J., POURROY, G., BÉGIN-COLIN, S., GRENÈCHE, J. M., ULHAQ-BOUILLET, C., LEGARE, P., BERNHARDT, P., LEUVREY, C. \& ROGEZ, G. Hydrothermal Synthesis of Monodisperse Magnetite Nanoparticles. Chemistry of Materials, v. 18, n. 18, p. 4399-4404, 2006

[32] YANG, X., JIANG, W., LIU, L., CHEN, B., WU, S., SUN, D. \& LI, F. One-Step Hydrothermal Synthesis of Highly Water-Soluble Secondary Structural $\mathrm{Fe}_{30}$ Nanoparticles. Journal of Magnetism and Magnetic Materials, v. 324, n. 14, p. 2249-2257, 2012.

[33] ABU-MUCH, R., GEDANKEN, A.;. Sonochemical Synthesis under a Magnetic Field: Structuring Magnetite Nanoparticles and the Destabilization of a Colloidal Magnetic Aqueous Solution under a Magnetic Field. Journal of Physical Chemistry C, v. 112, n. 1, p. 35-42, 2008.

[34] SHAFI, K. V. P. M., WIZEL, S., PROZOROV, T. \& GEDANKEN, A. The Use of Ultrasound Radiation for the Preparation of Magnetic Fluids. Thin Solid Films v. 318, n. 1-2, p. 38-41, 1998.

[35] LIVAGE, J., HENRY, M. \& SANCHE, C. Sol-Gel Chemistry of Transition Metal Oxides. Progress in Solid State Chemistry, v. 18, n. 4, p. 259-342, 1988.

[36] RAJA, K., VERMA, S., KARMAKAR, S., KAR, S., DAS, S. J. \& BARTWAL, K. S. Synthesis and Characterization of Magnetite Nanocrystals. Crystal Research and Technology, v. 46, n. 5, p. 497-500, 2011

[37] SALADO, J., INSAUSTI, M., DE MURO, I. G., LEZAMA, L. \& ROJO, T. Synthesis and Magnetic Properties of Monodisperse $\mathrm{Fe}_{3} \mathrm{O}_{4}$ Nanoparticles with Controlled Sizes. Journal of Non-Crystalline Solids, v. 354, n. 47-51, p. 5207-5209, 2008.

[38] CHENG, Z., CHU, X., ZHONG, H., YIN, J., ZHANG, Y. \& XU, J. Synthesis of $\mathrm{Fe}_{3} \mathrm{O}_{4}$ Nanoflowers by a Simple and Novel Solvothermal Process. Materials Letters, v. 76, p. 90-92, 2012.

[39] JEAN, M., NACHBAUR, V. \& LE BRETON, J. M. Synthesis and Characterization of Magnetite Powders Obtained by the Solvothermal Method: Influence of the $\mathrm{Fe}^{3+}$ Concentration. Journal of Alloys and Compounds, v. 513 p. 425-429, 2012.

[40] COSTO, R., BELLO, V., ROBIC, C., PORT, M., MARCO, J. F., MORALES, M. P. \& VEINTEMILLAS-VERDAGUER, S. Ultrasmall Iron Oxide Nanoparticles for Biomedical Applications: Improving the Colloidal and Magnetic Properties. Langmuir, v. 28, n. 1, p. 178-185, 2012.

[41] BANERJEE, S., JOHN, V. T., MCPHERSON, G. L., O'CONOR, C. J., BUISSON, Y. S. L., AKKARA, J. A. \& KAP, D. L. Polymer Microsphere and Polymer Ferrite Nanocomposite Preparation by Precipitation from Water-inOil Microemulsions. Colloid and Polymer Science, v. 275, n. 10, p. 930-937, 1997. 
[42] FERREIRA, G. R., SEGURA, T., JÚNIOR., F. G. S., UMPIERRE, A. P. \& MACHADO, F. Synthesis of Poly(Vinyl Acetate)-Based Magnetic Polymer Microparticles. European Polymer Journal, v. 48, n. 12, p. 2050-2069, 2012.

[43] FERREIRA, G. R., UMPIERRE, A. P. \& MACHADO, F. Synthesis of Tailored Core-Shell Magnetic Microparticles for Intravascular Embolization. In: (Ed.). Supplemental Proceedings: Materials Processing and Interfaces, Volume 1 (Ed Tms), : John Wiley \& Sons, Inc., 2012. p.345-352.

[44] NEVES, J. S., DE SOUZA JR., F. G., SUAREZ, P. A. Z., UMPIERRE, A. P. \& MACHADO, F. In Situ Production of Polystyrene Magnetic Nanocomposites through a Batch Suspension Polymerization Process. Macromolecular Materials and Engineering, v. 296, n. 12, p. 1107-1118, 2011.

[45] MA, Z., LIU, H. Synthesis and Surface Modification of Magnetic Particles for Application in Biotechnology and Biomedicine China Particuology, v. 05, n. 1-2, p. 1-10, 2007.

[46] MACKAY, M. E. E. A. General Strategies for Nanoparticle Dispersion. Science, v. 311, n. 5768, p. 1740-1743, 2006.

[47] COTTON, F. A., WILKINSON, G. \& GAUS, P. L. Basic Inorganic Chemistry. $3^{\text {rd }}$. Wiley, 1995.

[48] GUIMARÃES, A. P. Introdução Ao Nanomagnetismo. Centro Brasileiro de Pesquisas Físicas, 2006.

[49] HALLIDAY, D., WALKER, J. Fundamentos Da Física. 8ª Rio de Janeiro: LTC, 2009.

[50] SCHOLTEN, P. C. Which Si? Journal of Magnetism and Magnetic Materials, v. 1491995.

[51] SWARTZENDRUBER, L. J. Properties, Units and Constants in Magnetism. Journal of Magnetism and Magnetic Materials, v. 100 p. 573-575, 1991.

[52] BEVERIDGE, J. S., STEPHENS, J. R. \& WILLIAMS, M. E. The Use of Magnetic Nanoparticles in Analytical Chemistry. Annual Review of Analytical Chemistry, v. 4, p. 251-273, 2011.

[53] HUHEEY, J. E., KEITER, E. A. \& KEITER, R. L. Inorganic Chemistry Principles of Structure and Reactivity. $4^{\text {th }}$. Harper Collins College Publisher, 1993.

[54] AKBARZADEH, A., SAMIEI, M., DAVARAN, S. Magnetic Nanoparticles: Preparation, Physical Properties, and Applications in Biomedicine. Nanoscale Research Letters, v. 7, 2012.

[55] CULLIT, B. D. \& GRAHAM, C. D. Introduction to Magnetic Materials. $2^{\text {nd }}$. Hoboken, New Jersey: John Wiley \& Sons, Inc., 2009.

[56] CALLISTER, J. W. D. Fundamentals of Materials Science and Engineering. $5^{\text {th }}$. John Wiley \& Sons, Inc., 2001.

[57] CHAMBERS, C. \& HOLLIDAY, A. K. Modern Inorganic Chemistry - an Intermediate Text. The Butterworth Group, 1975.

[58] GETZLAFF, M. Fundamentals of Magnetism. Berlin Heidelberg: SpringerVerlag, 2008

[59] GUPTA, A. K., GUPTA, M. Synthesis and Surface Engineering of Iron Oxide Nanoparticles for Biomedical Applications. Biomaterials, v. 26 p. 3995-4021, 2005.

[60] LIU, B., XIE, W., WANG, D., HUANG, W., YU, M., YAO, A. Preparation and Characterization of Magnetic Luminescent Nanocomposite Particles. Materials Letters, v. 62 p. 3014-3017, 2008. 
[61] SATO, T., IIJIMA, T., SEKIN, M. , INAGAKI, N. . Magnetic Properties of Ultrafine Ferrite Particles. Journal of Magnetism and Magnetic Materials, v. 65, p. 252, 1987.

[62] THOSTENSON, E. T., LI, C., CHOU, T-S. Nanocomposites in Context. Composites Science and Technology, v. 65 p. 491-516, 2005.

[63] ROSEI, F. Nanostructured Surfaces: Challenges and Frontiers in Nanotechnology. Journal of Physics: Condensed Matter, v. 16, n. 17, p. S1373-S1436, 2004.

[64] CHRISSAFIS, K. \& BIKIARIS, D. Can Nanoparticles Really Enhance Thermal Stability of Polymers? Part I: An Overview on Thermal Decomposition of Addition Polymers. Thermochimica Acta, v. 523, n. 1-2, p. 1-24, 2011.

[65] LESLIE-PELECKY, D. L. \& RIEKE, R. D. Magnetic Properties of Nanostructured Materials. Chemistry of Materials, v. 8, n. 8, p. 1770-1783, 1996.

[66] AKBARZADEH, A., SAMIEI, M., DAVARAN, S. Magnetic Nanoparticles: Preparation, Physical Properties, and Applications in Biomedicine. Nanoscale Research Letters, v. 7, p. 144, 2012.

[67] RIBEIRO, G. A. P. As Propriedades Magnéticas Da Matéria: Um Primeiro Contato. Revista Brasileira de Ensino de Física, v. 22, n. 03, p. 299-305, 2000.

[68] CORNELL, R. M. \& SCHWERTMANN, U. The Iron Oxides: Structure, Properties, Reactions, Occurrences and Uses. $2^{\text {nd }}$. Weinheim: Wiley-VCH, 2003.

[69] QIU, X.-P. Synthesis and Characterization of Magnetic Nanoparticles. Chinese Journal of Chemistry, v. 18, n. 6, 2000.

[70] BELIKOV, V. G., KUREGYAN, A. G. \& ISMAILOVA, G. K. Standardization of Magnetite. Pharmaceutical Chemistry Journal, v. 36, n. 6, p. 333-336, 2002.

[71] BHARDE, A., RAUTARAY, D., BANSAL, V., AHMAD, A., SARKAR, I., YUSUF, S. M., SANYAL, M. \& SASTRY, M. Extracellular Biosynthesis of Magnetite Using Fungi. Small, v. 2, n. 1, p. 135-141, 2006.

[72] SWADDLE, T. W. Inorganic Chemistry - an Industrial and Environmental Perspective. Elsevier Science \& Technology Books, 1997.

[73] HOUSE, J. E. Inorganic Chemistry. Elsevier Inc., 2008.

[74] NETO, W. S., JENSEN, A. T., FERREIRA,G. R., VALADARES, L. F., GAMBETTA, R., GONÇALVES, S. B., MACHADO, F. A Survey on Synthesis Processes of Structured Materials for Biomedical Applications: Iron-Based Magnetic Nanoparticles, Polymeric Materials and Polymerization Processes. Current Pharmaceutical Design v. 21, p. 5336-5358, 2015.

[75] BELOV, K. P. Electronic Processes in Magnetite (or, "Enigmas of Magnetite"). Physics - Uspekhi, v. 36 n. 5, p. 380-391, 1993.

[76] GRIBANOV, N. M., BIBIK, E.E., BUZUNOV, O.V., NAUMOV, V.N. PhysicoChemical Regularities of Obtaining Highly Dispersed Magnetite by the Method of Chemical Condensation. Journal of Magnetism and Magnetic Materials, v. 85 , p. 7-10, 1990.

[77] SOARES, P. I. P., ALVES, A. M.R., PEREIRA, L. C.J., COUTINHO, J. T., FERREIRA, I. M.M., NOVO, C.M.M., BORGES, J.P.M.R. . Effects of Surfactants on the Magnetic Properties of Iron Oxide Colloids. Journal of Colloid and Interface Science, v. 419 p. 46-51, 2014. 
[78] LOURENCO, C., TEIXEIRA, M., SIMÕES, S., GASPAR, R. Steric Stabilization of Nanoparticles: Size and Surface Properties. International Journal of Pharmaceutics, v. 138 p. 1-12, 1996.

[79] LESNIKOVICH, A. E., SHUNKEVICH,T. M., NAUMENKO, V. N., VOROBYOVA, S. A., BAYKOV, M. W. Dispersity of Magnetite in Magnetic Liquids and the Interaction with a Surfactant. Journal of Magnetism and Magnetic Materials, v. 85, p. 14-16, 1990.

[80] KHAlafalla, S. E., REIMERS, G. W. Ppreparation of Dilution-Stable Aqueous Magnetic Fluids. IEEE Transctions on Magnetics, v. 16, n. 2, p. 178-183, 1980.

[81] ALIAKBARI A., S. M., MIRZAEE, S., HODA, H. Influence of Different Synthesis Conditions on Properties of Oleic Acid-Coated-Fe304 Nanoparticles. Materials Science-Poland, v. 33, n. 1, p. 100-106, 2015.

[82] REZAYAN, A. H., MOUSAVI, M., KHEIRJOU, S., AMOABEDINY, G., ARDESTANI, M. S., MOHAMMADNEJAD, J. Monodisperse Magnetite( $\left.\mathrm{Fe}_{3} \mathrm{O}_{4}\right)$ Nanoparticles Modified with Water Soluble Polymers for the Diagnosis of Breast Cancer by Mri Method. Journal of Magnetism and Magnetic Materials, v. 420, p. 210-217, 2016.

[83] MUTHUKUMARAN, T., PHILIP, J. Effect of Phosphate and Oleic Acid Capping on Structure, Magnetic Properties and Thermal Stability of Iron Oxide Nanoparticles Journal of Alloys and Compounds, v. 689, p. 959-968, 2016.

[84] SCHWERTMANN, U. \& CORNELL, R. M. Iron Oxides in the Laboratory: Preparation and Characterization. $2^{\text {nd }}$. Weinheim, Germany: WILEY-VCH Verlag $\mathrm{GmbH}, 2000.210$.

[85] GNANAPRAKASH, G., PHILIP, J., JAYAKUMAR, T. \& RAJ, B. Effect of Digestion Time and Alkali Addition Rate on Physical Properties of Magnetite Nanoparticles. The Journal of Physical Chemistry B, v. 111, n. 28, p. 79787986, 2007.

[86] PETCHAROEN, K. \& SIRIVAT, A. Synthesis and Characterization of Magnetite Nanoparticles Via the Chemical Co-Precipitation Method. Materials Science and Engineering B., v. 177, n. 5, p. 421-427, 2012

[87] GNANAPRAKASH, G., MAHADEVAN, S., JAYAKUMAR, T., KALYANASUNDARAM, P., PHILIP, J., RAJ, B. Effect of Initial Ph and Temperature of Iron Salt Solutions on Formation of Magnetite Nanoparticles. Materials Chemistry and Physics, v. 103 p. 168-175, 2007.

[88] FORGE, D., ROCH,A., LAURENT, S., TELLEZ, H., GOSSUIN, Y., RENAUX, F., ELST, L. V., MULLER, R. N. . Optimization of the Synthesis of Superparamagnetic Contrast Agents by the Design of Experiments Method. The journal of physical chemistry. C, v. 112, n. 49, p. 19178-19185, 2008. [89] ROTH, H.-C., SCHWAMINGER, S. P., SCHINDLER, M., WAGNER, F. E. , BERENSMEIER, S. Influencing Factors in the Co-Precipitation Process of Superparamagnetic Iron Oxide Nano Particles: A Model Based Study. Journal of Magnetism and Magnetic Materials, v. 377, p. 81-89, 2015.

[90] ABU-MUCH, R. \& GEDANKEN, A. Sonochemical Synthesis under a Magnetic Field: Structuring Magnetite Nanoparticles and the Destabilization of a Colloidal Magnetic Aqueous Solution under a Magnetic Field. Journal of Physical Chemistry C, v. 112, n. 1, p. 35-42, 2008.

[91] PADILHA, A. F. Materiais De Engenharia - Microestrutura E Propriedades. Hemus S.A., 2000 
[92] ZARBIN, A. J. G. Quimica De (Nano)Materiais. Química Nova, v. 30, n. 6, p. 1469-1479, 2007.

[93] LIU, Y. D., HONG, C. H., CHOI, H. J. Polymeric Colloidal Magnetic Composite Microspheres and Their Magneto-Responsive Characteristics. Macromolecular Research, v. 20, n. 12, p. 1211-1218, 2012.

[94] BRAGA, T. P., VASCONCELOS, I. F., SASAKI, J. M., FABRIS, J. D., DE OLIVEIRA D.Q.L. \& VALENTINI, A. Magnetic Composites Based on Hybrid Spheres of Aluminum Oxide and Superparamagnetic Nanoparticles of Iron Oxides. Journal of Magnetism and Magnetic Materials, v. 322 p. 633-637, 2010.

[95] GRANCE, E. G. O., DE SOUZA JR., F. G., VARELA, A., PEREIRA, E. D., OLIVEIRA, G. E. \& RODRIGUES, C. H. M. New Petroleum Absorbers Based on Lignin-Cnsl-Formol Magnetic Nanocomposites. Journal of Applied Polymer Science, v. 126, n. S1, p. E305-E312, 2012.

[96] FURUSAWA, K., NAGASHIMA, K., ANZAI, C. Synthetic Process to Control the Total Size and Component Distribution of Multilayer Magnetic Composite Particles. Colloid and Polymer Science, v. 272, p. 1104-1110, 1994.

[97] SAUZEDDE, F., ELAISSARI, A., PICHOT, C. Hydrophilic Magnetic Polymer Latexes. 1. Adsorption of Magnetic Iron Oxide Nanoparticles onto Various Cationic Latexes. Colloid Polym Sci, v. 277, p. 846-855, 1999.

[98] SAUZEDDE, F., ELAÏSSARI, A. \& PICHOT , C. Hydrophilic Magnetic Polymer Latexes. 2. Encapsulation of Adsorbed Iron Oxide Nanoparticles. Colloid and Polymer Science, v. 277, n. 11, p. 1041-1050, 1999.

[99] NAKAMOTO, K. Infrared and Raman Spectra of Inorganic and Coordination Compounds - Part B: Applications in Coordination, Organometallic and Bioinorganic Chemistry. $6^{\text {th }}$. Hoboken, New Jersey: John Wiley \& Sons, Inc., , 2009. 416.

[100] RAMAN, A., KUBAN, B., RAZVAN, A. The Application of Infrared Spectroscopy to the Study of Atmospheric Rust Systems-- I. Standard Spectra and Illustrative Applications to Identify Rust Phases in Natural Atmospheric Corrosion Products. Corrosion Science v. 32, n. 12, p. 1295-1306, 1991.

[101] SLAVOV, L., ABRASHEV, M.V., MERODIISKA, T., GELEV , CH., VANDENBERGHE, R.E., MARKOVA-DENEVA, I., NEDKOV, I. Raman Spectroscopy Investigation of Magnetite Nanoparticles in Ferrofluids. Journal of Magnetism and Magnetic Materials, v. 322, p. 1904-1911, 2010.

[102] ZHANG, L., HE, R. \& GU, H.-C. Oleic Acid Coating on the Monodisperse Magnetite Nanoparticles. Applied Surface Science, v. 253, n. 5, p. 26112617, 2006.

[103] DAS, S. \& HENDRY, M. J. Application of Raman Spectroscopy to Identify Iron Minerals Commonly Found in Mine Wastes. Chemical Geology, v. 290, n. 3-4, p. 101-108, 2011.

[104] DAS, R. S., AGRAWAL, Y.K. Raman Spectroscopy: Recent Advancements, Techniques and Applications. Vibrational Spectroscopy, v. 57 p. 163- 176, 2011.

[105] Infrared and Raman Spectroscopy - Methods and Applications. VCH Verlagsgesellschaft mbH, 1995. 808.

[106] EFREMOV, E. V., ARIESE, F., GOOIJER, C. Achievements in Resonance Raman Spectroscopy Review of a Technique with a Distinct Analytical Chemistry Potential. Analytica Chimica Acta, v. 606, p. 119-134, 2008. 
[107] MORTIMER, R. G. Physical Chemistry. 3rd. Elsevier Academic Press, 2008.

[108] GASPAROV, L. V., TANNER, D. B., ROMERO, D. B., BERGER, H., MARGARITONDO,G. , FORRO, L. Infrared and Raman Studies of the Verwey Transition in Magnetite. Physical Review B, v. 62, n. 12 p. 79397944, 2000.

[109] CHAMRITSKI, I., BURNS, G. Infrared- and Raman-Active Phonons of Magnetite, Maghemite, and Hematite: A Computer Simulation and Spectroscopic Study. The Journal of Physical Chemistry B, v. 109, p. 49654968, 2005.

[110] SHEBANOVA, O. N., LAZOR, P. Raman Spectroscopic Study of Magnetite (Fefe204): A New Assignment for the Vibrational Spectrum. Journal of Solid State Chemistry, v. 174 p. 424-430, 2003.

[111] RAMAN, R. K. S., GLEESON, B., YOUNG, D. J. Laser Raman Spectroscopy: A Technique for Rapid Characterisation of Oxide Scale Layers. Materials Science and Technology, v. 14 p. 373-376, 1998

[112] COLDWELL, D. M., STOKES, K. R. \& YAKES, F. Embolotherapy: Agents, Clinical Applications, and Techniques. Radiographics, v. 14, n. 3, p. 623643, 1994.

[113] SCHWANER, S. L., HAUG, S. B. \& MATSUMOTO, A. H. Overview of Embolotherapy: Agents, Indications, Applications, and Nursing Management.

Perioperative Nursing Clinics, v. 5, n. 2, p. 137-176, 2010.

[114] OSUGA, K., MIKAMI, K., HIGASHIHARA, H., MAEDA, N., TSUBOYAMA, T., KUWABARA, M., ONISHI, H., HORI, M., KIM, T., TOMODA, K., MURAKAMI, T. \& NAKAMURA, $H$. Principles and Techniques of Transcatheter Embolotherapy for Peripheral Vascular Lesions. Radiation Medicine, v. 24, n. 4, p. 309-314, 2006.

[115] JORDAN, O., DOELKER, E. \& RUFENACHT, D. A. Biomaterials Used in Injectable Implants (Liquid Embolics) for Percutaneous Filling of Vascular Spaces. CardioVascular and Interventional Radiology, v. 28, n. 5, p. 561569, 2005.

[116] ALVES, M.-H., JENSEN, B. E. B., SMITH, A. A. A. \& ZELIKIN, A. N. Poly(Vinyl Alcohol) Physical Hydrogels: New Vista on a Long Serving Biomaterial. Macromolecular Bioscience, v. 11, p. 1293-1313, 2011.

[117] DERDEYN, C. P., MORAN, C. J., CROSS, D. T., DIETRICH, H. H. \& DACEY, R. G. J. Polyvinyl Alcohol Particle Size and Suspension Characteristics. American Journal of Neuroradiology, v. 16, p. 1335-1343, 1995.

[118] GOLZARIAN, J., LANG, E., HOVSEPIAN, D., KRONCKE, T., LAMPMANN, L., LOHLE, P., PELAGE, J., SHLANSKY-GOLDBERG, R., VALENTI, D., VORWERK, D. \& SPIES, J. Higher Rate of Partial Devascularization and Clinical Failure after Uterine Artery Embolization for Fibroids with Spherical Polyvinyl Alcohol. CardioVascular and Intervenlional Radiology, v. 29, n. 1, p. 1-3, 2006.

[119] SARALIDZE, K., VAN HOOY-CORSTJENSA, C. S. J., KOOLE, L. H. \& KNETSCH, M. L. W. New Acrylic Microspheres for Arterial Embolization: Combining Radiopacity for Precise Localization with Immobilized Thrombin to Trigger Local Blood Coagulation. Biomaterials, v. 28 p. 2457-2464, 2007.

[120] SARALIDZE, K., KOOLE, L. H. \& KNETSCH, M. L. W. Polymeric Microspheres for Medical Applications. Materials, v. 3, p. 3537-3564, 2010. 
[121] ALOMARI, A. \& DUBOIS, J. Interventional Management of Vascular Malformations. Techniques in Vascular and Interventional Radiology, $v$. 14, n. 1, p. 22-23, 2011

[122] PARK, H. S., DO, Y. S., PARK, K. B., KIM, D.-I., KIM, Y. W., KIM, M. J., SHIN, B. S. \& CHOO, I. W. Ethanol Embolotherapy of Hand Arteriovenous Malformations. Journal of Vascular Surgery, v. 53, n. 3, p. 725-731, 2011.

[123] BUCKMILLER, L. M., RICHTER, G. T. \& SUEN, J. Y. Diagnosis and Management of Hemangiomas and Vascular Malformations of the Head and Neck. Oral Diseases, v. 16, p. 405-418, 2010.

[124] LEGIEHN, G. M. \& HERAN, M. K. S. Classification, Diagnosis, and Interventional Radiologic Management of Vascular Malformations. Orthopedic Clinic of North America, v. 37 p. 435-474, 2006.

[125] DICKSON, D. P. E., WALTON, S. A., MANN, S.,WONG, K. . Properties of Magnetoferritin: A Novel Biomagnetic Nanoparticle NanoStructured Materials, v. 9, p. 595-598, 1997.

[126] ODIAN, G. Principles of Polimerization. $4^{\text {th }}$ Hoboken, New Jersey: John Wiley \& Sons, INC., 2004. 839.

[127] MACHADO, F., LIMA, E. L. \& PINTO, J. C. Uma Revisão Sobre Os Processos De Polimerização Em Suspensão. Polímeros, v. 17, n. 2, p. 166179, 2007.

[128] LYOO, W. S., PARK, C. S., CHOI, K. H., KWAK, J. W., YOON, W. S. \& $\mathrm{NOH}, \mathrm{S}$. K. Effect of Suspension Polymerization Conditions of Vinyl Pivalate on the Size and Its Distribution of Poly(Vinyl Pivalate) Microspheres. Polymer-Plastics Technology and Engineering, v. 44, n. 3, p. 475-487, 2005.

[129] BROOKS, B. W. Suspension Polymerization Processes Chemical Engineering \& Technology, v. 33, n. 11, p. 1737-1744, 2010.

[130] PHILIPPOVA, O., BARABANOVA, A., MOLCHANOV, V. \& KHOKHLOV, A. Magnetic Polymer Beads: Recent Trends and Developments in Synthetic Design and Applications. European Polymer Journal, v. 47, n. 4, p. 542-559, 2011.

[131] WANG, C., ZHANG, C., LI, Y., CHEN, Y. \& TONG, Z. Facile Fabrication of Nanocomposite Microspheres with Polymer Cores and Magnetic Shells by Pickering Suspension Polymerization. Reactive \& Functional Polymers, v. 69, n. 10, p. 750-754, 2009.

[132] BLANCO-ANDUJAR, C., TUNG, L. D. \& THANH, N. T. K. Synthesis of Nanoparticles for Biomedical Applications. Annual Reports Section "A" (Inorganic Chemistry) v. 106, p. 553-568, 2010.

[133] PERACCHIA, M. T., VAUTHIER, C., PASSIRANI, C., COUVREUR, P., LABARRE, D. Complement Consumption by Poly(Ethylene Glycol) in Different Conformations Chemically Coupled to Poly(Isobutyl 2cianoacrylate) Nanoparticles. Life Sciences, v. 61, n. 1, p. 749-761, 1997.

[134] PU, H.-T., JIANG, F.-J. \& YANG, Z.-L. Preparation and Properties of Soft Magnetic Particles Based on $\mathrm{Fe}_{3} \mathrm{O}_{4}$ and Hollow Polystyrene Microsphere Composite. Materials Chemistry and Physics, v. 100, n. 1, p. 10-14, 2006. [135] PICH, A., BHATTACHARYA, S., GHOSH, A. \& ADLER, H. J. P. Composite Magnetic Particles: 2. Encapsulation of Iron Oxide by Surfactant-Free Emulsion Polymerization. Polymer, v. 46, n. 13, p. 4596-4603, 2005.

[136] HUANG, J., PEN, H., XU, Z. \& YI, C. Magnetic Fes04/Poly(Styrene-CoAcrylamide) Composite Nanoparticles Prepared by Microwave-Assisted 
Emulsion Polymerization. Reactive and Functional Polymers, v. 68, n. 1, p. 332-339, 2008.

[137] PATTERSON, A. L. The Scherrer Formula for X-Ray Particle Size Determination. Physical Review, v. 56, n. 10, p. 978-982, 1939.

[138] PAVIA, D. L., LAMPMAN, G. M., KRIZ, G. S. \& VYVYAN, J. A. Introduction to Spectroscopy. 4. Brooks Cole, 2008.

[139] FIELD, L. D., STERNHELL, S. \& KALMAN, J. R. Organic Structures from Spectra $4^{\text {th }}$. John Wiley and Sons, 2008.

[140] SILVESTEIN, R. M., WEBSTER, F. X., KIEMLE, D. J. Spectrometric Identification of Organic Compounds. $7^{\text {th }}$. United States: John Wiley \& Sons, 2005.

[141] LAN, Q., LIU, C., YANG, F., LIU, S., XU, J. \& SUN, D. Synthesis of Bilayer Oleic Acid-Coated $\mathrm{Fe}_{3} \mathrm{O}_{4}$ Nanoparticles and Their Application in PhResponsive Pickering Emulsions. Journal of Colloid and Interface Science, v. 310, n. 1, p. 260-269, 2007.

[142] LEE, D. H. \& CONDRATE, R. A. Ftir Spectral Characterization of Thin Film Coatings of Oleic Acid on Glasses: I. Coatings on Glasses from Ethyl Alcohol. Journal of Materials Science, v. 34, n. 1, p. 139-146, 1999.

[143] MAITY, D. \& AGRAWAL, D. C. Synthesis of Iron Oxide Nanoparticles under Oxidizing Environment and Their Stabilization in Aqueous and Non-Aqueous Media. Journal of Magnetism and Magnetic Materials, v. 308, n. 1, p. 46$55,2007$.

[144] LEE, S. Y. \& HARRIS, M. T. Surface Modification of Magnetic Nanoparticles Capped by Oleic Acids:Characterization and Colloidal Stability in Polar Solvents. Journal of Colloid and Interface Science, v. 293, n. 2, p. 401408, 2006.

[145] RAMOS-GONZALEZ, R., GARCIA-CERDA, L. A. \& QUEVEDO-LOPEZ, M. A. Study of the Surface Modification with Oleic Acid of Nanosized $\mathrm{Hfo}_{2}$ Synthesized by the Polymerized Complex Derived Sol-Gel Method. Applied Surface Science, v. 258, n. 16, p. 6034-6039, 2012.

[146] WU, N., FU, L., SU, M., ASLAM, M., WONG, K. C. \& DRAVID, V. P. Interaction of Fatty Acid Monolayers with Cobalt Nanoparticles. Nano Letters, v. 4, n. 2, p. 383-386, 2004.

[147] LI, D., JIANG, D., CHEN, M., XIE, J., WU, Y., DANG, S. \& ZHANG, J. An Easy Fabrication of Monodisperse Oleic Acid-Coated $\mathrm{Fe}_{3} \mathrm{O}_{4}$ Nanoparticles. Materials Letters, v. 64, n. 22, p. 2462-2246, 2010.

[148] WANG, Y. M., CAO, X., LIU, G. H., HONG, R. Y., CHEN, Y. M., CHEN, X. F., LI, H. Z., XUE, B. \& WEI, D. G. Synthesis of $\mathrm{Fe}_{3} \mathrm{O}_{4}$ Magnetic Fluid Used for Magnetic Resonance Imaging and Hyperthermia. Journal of Magnetism and Magnetic Materials, v. 323, n. 23, p. 2953-2959, 2011.

[149] LIU, J. Scanning Transmission Electron Microscopy and Its Application to the Study of Nanoparticles and Nanoparticle Systems. Journal of Electron Microscopy, v. 54 n. 3, p. 251-278, 2005.

[150] SCHÜTH, F., LU, A. \& SALABAS, E. L. Magnetic Nanoparticles: Synthesis, Protection, Functionalization, and Application. Angewandte Chemie, International Edition, v. 46, n. 8, p. 1222-1244, 2007.

[151] KICHATOV, B. V., KORSHUNOV, A.M., SSOROVA, P. V. . Particle Size Distribution of the Product of Suspension Polymerization. Theoretical Foundations of Chemical Engineering, v. 37, p. 306-307, 2003. 
[152] CLAUDY, P., LÉTOFFÉ, J. M., CAMBERLAIN, Y. \& PASCAULT, J. P. Glass Transition of Polystyrene Versus Molecular Weight. Polymer Bulletin, v. 9, n. 4-5, p. 208-215, 1983.

[153] SCHWERTMANN, U. \& CORNELL, R. M. Iron Oxides in the Laboratory

- Preparation and Characterization. New York: VCH, 1991.

[154] SAI RAM, M. \& PALANIAPPAN, S. Benzoyl Peroxide Oxidation Route to Polyaniline Salt and Its Use as Catalyst in the Esterification Reaction. Journal of Molecular Catalysis A: Chemical, v. 201, n. 1, p. 289-296, 2003.

[155] CAMPELO, N. M., MACHADO, F.M. Reciclagem De Poli(EstirenoDivinilbenzeno) Via Processo De Polimerização Em Massa-Suspensão. Polímeros: Ciência e Tecnologia, v. 23, n. 2, p. 212-222, 2013.

[156] CAMPELO, N. M., UMPIERRE, A. P. \& MACHADO, F. Recycling of Styrene-Divinylbenzene Copolymer through Sequential Mass-Suspension Polymerization Process. In: (Ed.). Epd Congress 2012: John Wiley \& Sons, Inc., 2012. p.395-400.

[157] TSOURIS, C., TAVLARIDES, L. L. Breakage and Coalescence Models for Drops in Turbulent Dispersions. AIChE Journal, v. 40, n. 3, p. 395-405, 1994. [158] WRIGHT, H. \& RAMKRISHNA, D. Factors Affecting Coalescence Frequency of Droplets in a Liquid-Liquid Dispersion. AIChE Journal, v. 40, n. 5, p. 767-776, 1994.

[159] CHAMRITSKI, I. \& BURNS, G. Infrared- and Raman-Active Phonons of Magnetite, Maghemite, and Hematite: A Computer Simulation and Spectroscopic Study. Journal of Physical Chemistry B, v. 109, n. 11, p. 4965-4968, 2005.

[160] BUCKLES, J. M., GARAY, J. C., KAUFMAN, D. J., LAYSON, A. R. \& COLUMBIA, M. R. Specular-Reflectance Ir Spectroscopy of Polymethylmethacrylate Thin Films: An Experiment for the Undergraduate Instrumental Analysis Course. Chem Educ, v. 3, n. 3, p. 1-11, 1998.

[161] RAMESH, S., LEEN, K. H., KUMUTHA, K. \& AROF, A. K. Ftir Studies of Pvc/Pmma Blend Based Polymer Electrolytes. Spectrochimica Acta Part A: Molecular and Biomolecular Spectroscopy, v. 66, n. 4-5, p. 1237-1242, 2007. 
APÊNDICE 1 - Microscopia Eletrônica de Transmissão das Nanopartículas Magnéticas de $\mathrm{Fe}_{3} \mathrm{O}_{4}$
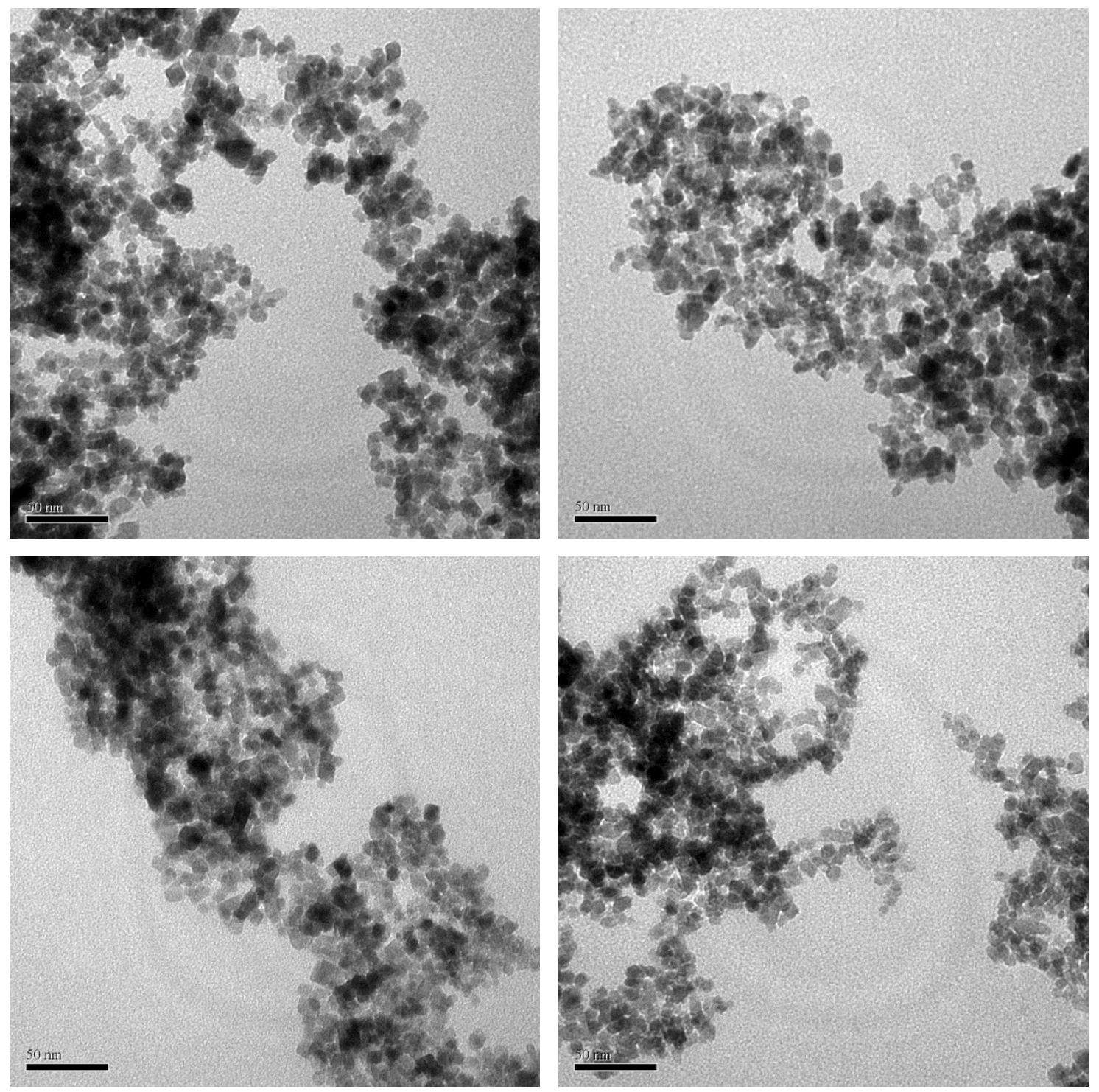
APÊNDICE 2 - Microscopia Eletrônica de Transmissão das Nanopartículas Magnéticas de $\mathrm{Fe}_{3} \mathrm{O}_{4} \mathrm{com}$ Superfície Modificada com Ácido Oleico
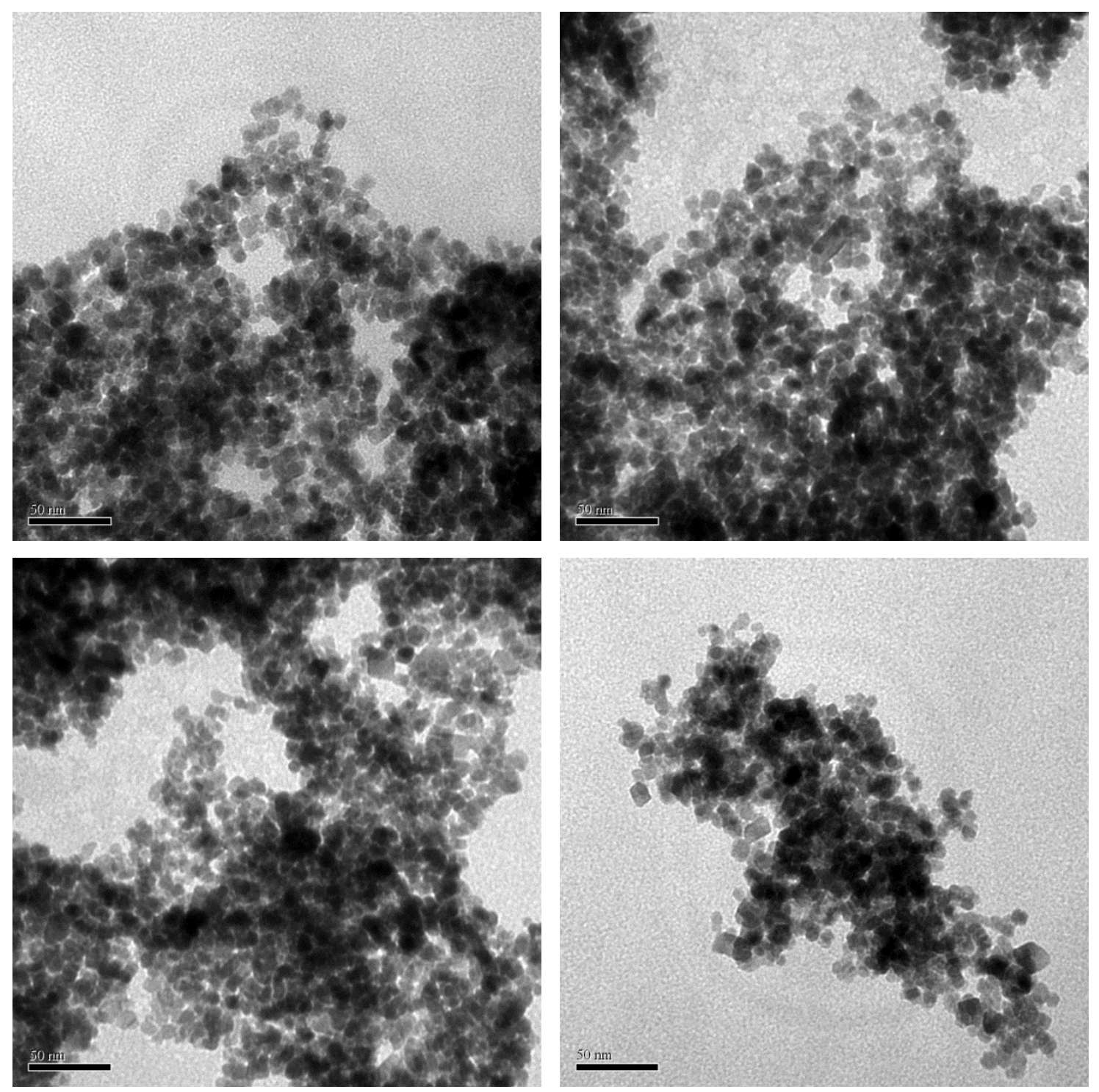


\section{APÊNDICE 3 - Espectros Raman dos Materiais Poliméricos com Diferentes Concentrações de Nanopartículas Magnéticas de $\mathrm{Fe}_{3} \mathrm{O}_{4}$}
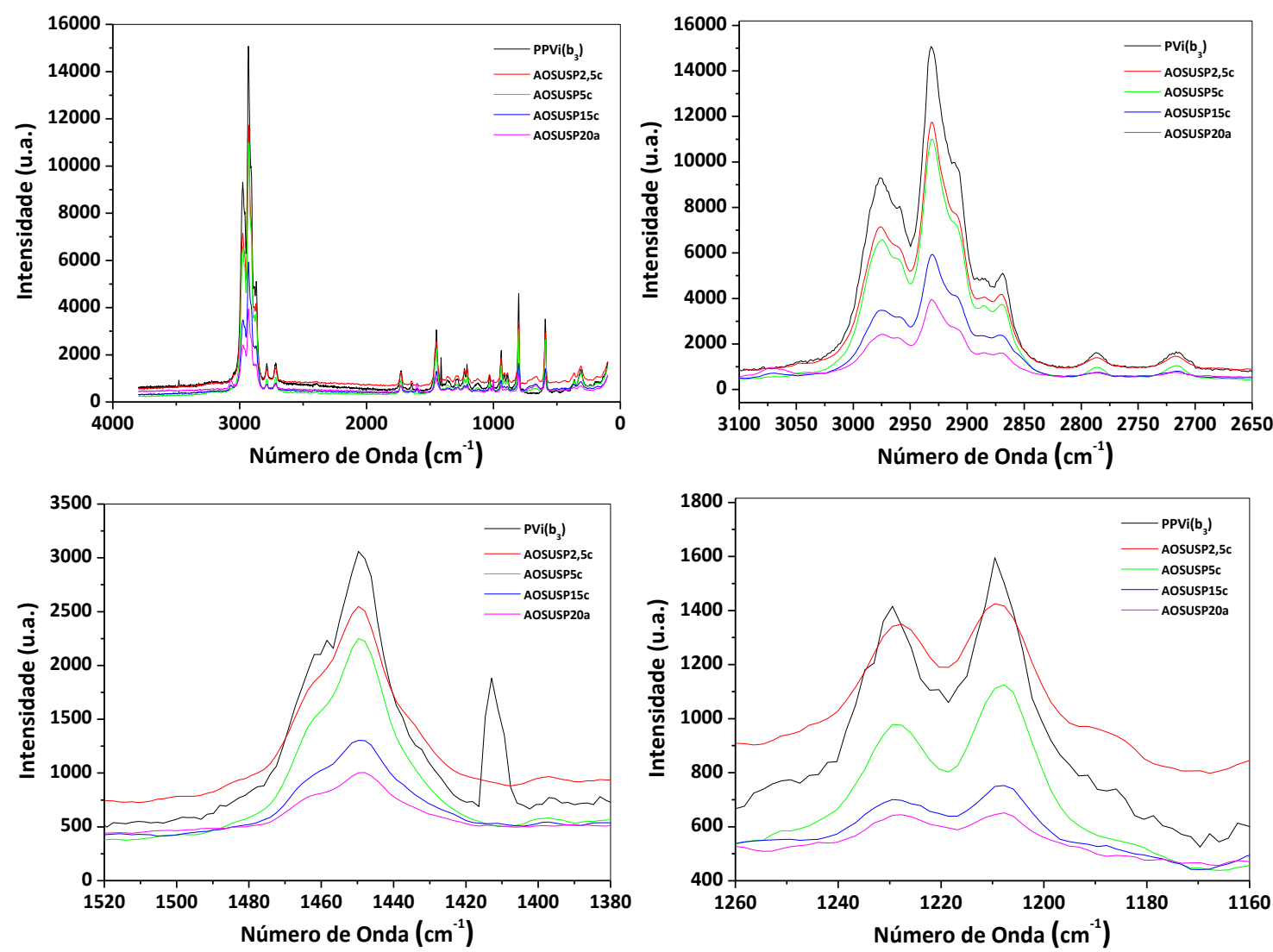

Figura A3.1. Espectroscopia Raman dos nanocompósitos poliméricos. Espectros coletados com modo de excitação em 633 nm (laser He-Ne). 

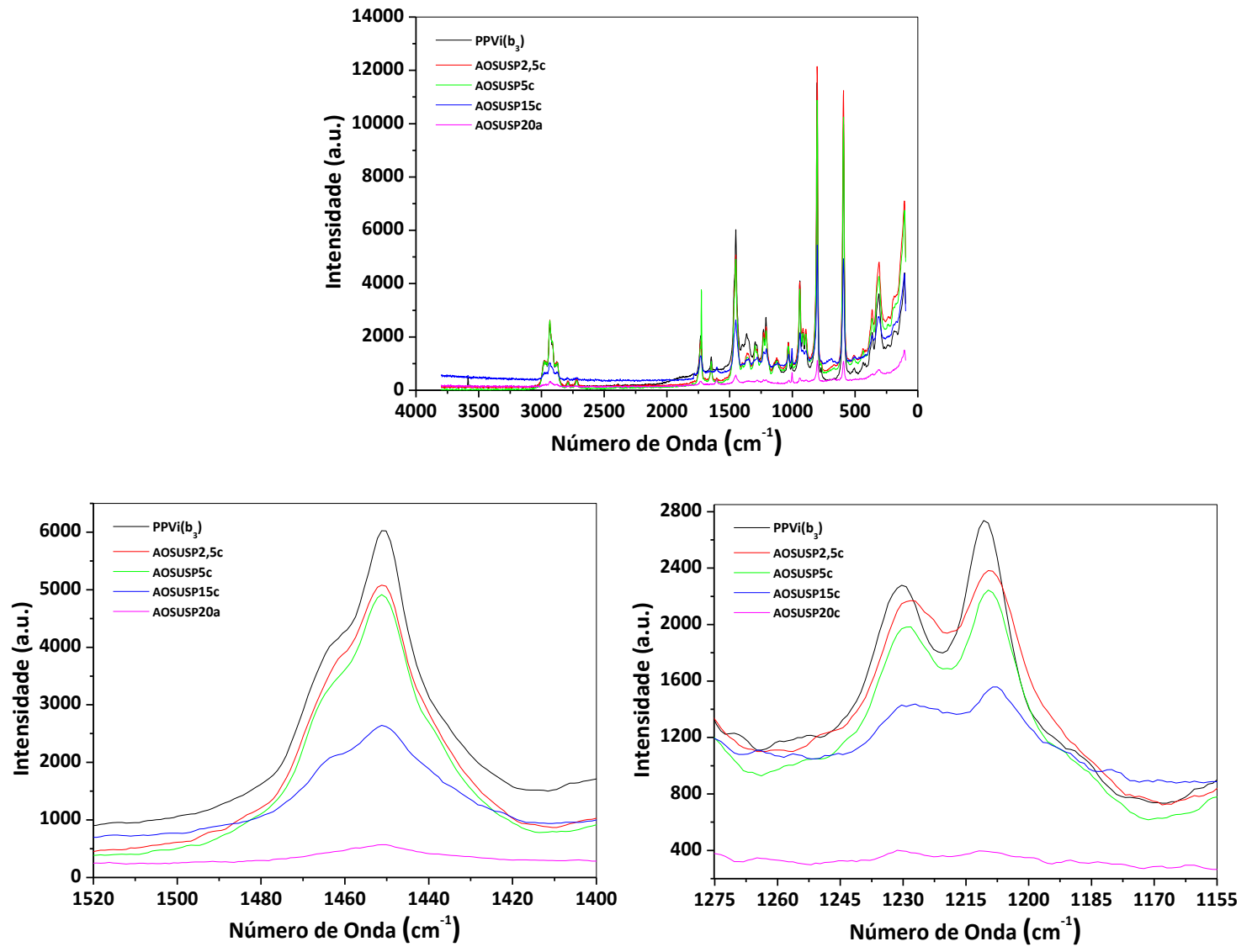

Figura A3.2. Espectroscopia Raman dos nanocompósitos poliméricos. Espectros coletados com modo de excitação em $785 \mathrm{~nm}$ (diodo). 